University of Redlands

\title{
Monitoring Community Health Using a Web-Based GIS Application
}

A Major Individual Project submitted in partial satisfaction of the requirements

for the degree of Master of Science in Geographic Information Systems

by

Haimwant Persaud

Ruijin Ma, Ph.D., Committee Chair

Douglas Flewelling, Ph.D.

July 2013 
Monitoring Community Health Using a Web-Based GIS Application

Copyright (C) 2013

by

Haimwant Persaud 
The report of Haimwant Persaud is approved.
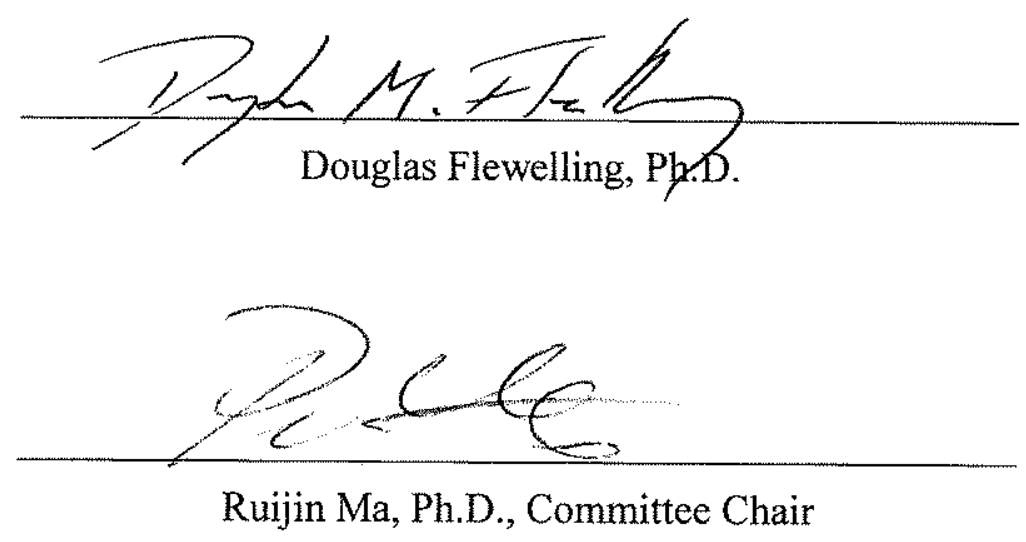

July 2013 



\section{Acknowledgements}

First of all, I thank the Almighty God for giving me strength and grace to complete this MSc. degree in GIS at the University of Redlands. Thanks to Mr. Jack Dangermond, the President of Esri for the scholarship and the MS GIS program, of the University of Redlands for the additional funding they provided for the completion of my studies. I could not have accomplished this without your kindness.

I would like to thank my advisor Dr. Ruijin Ma for his guidance through the project. Without him, the project could not have been completed successfully. Thanks to the Faculty members, Doug, Mark, Fang, Russell, and the adjunct Faculty members for their guidance and support throughout the program. Thanks to Ruben Ortiz, Assistant Systems Manager, for troubleshooting and technical assistance. Special Thanks to Debra Riley, Program Coordinator, MS GIS Program, University of Redlands for all of her assistance, sweets, cookies, and most of all her advices.

Very special gratitude to my lovely wife Mandy for having the understanding, patience, and giving me support while I pursue my studies here in Redlands, California, also special thanks to my caring parents, brothers, and sister for their continuous encouragement, prayers, and best wishes to whom I'm grateful and appreciative.

I have to thank Raymol Rappai, Software Engineer and Flex developer at the Redlands Institute, for her help in brainstorming ideas for my project. She was very helpful to me in understanding the Flex API and the Flex framework.

Last but not least, I thank all the Cohort 21, 22, and 23 students in the MS GIS program, University of Redlands for their assistance in one way or the other. 



\author{
Abstract \\ Monitoring Community Health Using \\ a Web-Based GIS Application \\ by \\ Haimwant Persaud
}

Monitoring and assessing health problem trends require health specialists to access high quality information in order to identify and prioritize problems, develop and evaluate policies and actions, organize the delivery of clinical health services, guide research and development, and contribute to the development of standards and guidelines. This enables public health planning, management, and monitoring. HARC is a non-profit organization in the Coachella Valley, collecting a wealth of data and information; but it lacked an effective or efficient approach to communicate the information with its clients. Their data were contained in a 700-page report on health indicators and disparities in Coachella Valley. Presenting data in a user-friendly format through the developed application made it easier for people to locate data for specific populations and to produce clear and easy-to-understand maps. HARC will also be able to increase awareness of the health problems faced by communities in Coachella Valley. HARC and its clients will use the application to view, query, print, and share information on health indicators, behavior, and disparities in the Coachella Valley. 



\section{Table of Contents}

Chapter 1 - Introduction ................................................................................................ 1

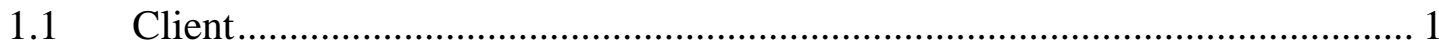

$1.2 \quad$ Problem Statement ................................................................................ 1

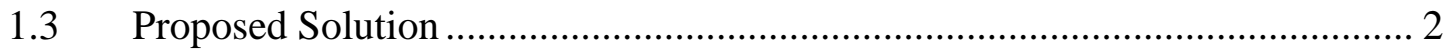

1.3.1 Goals and Objectives ............................................................................. 2

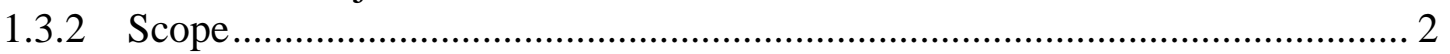

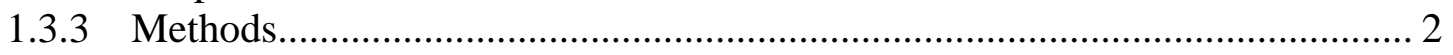

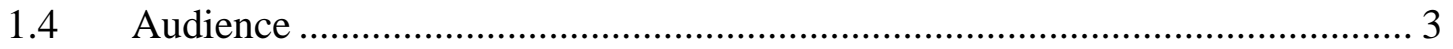

1.5 Overview of the Rest of this Report ........................................................... 3

Chapter 2 - Background and Literature Review ............................................................. 5

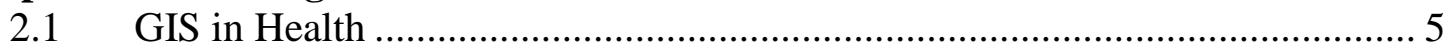

2.2 The Internet and Web GIS Development..................................................... 7

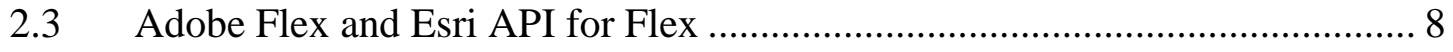

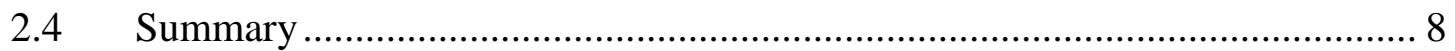

Chapter 3 - Systems Analysis and Design..................................................................... 11

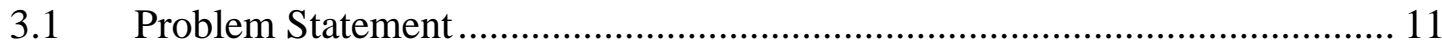

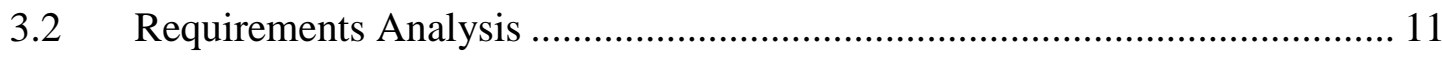

3.2.1 Functional Requirements ................................................................... 12

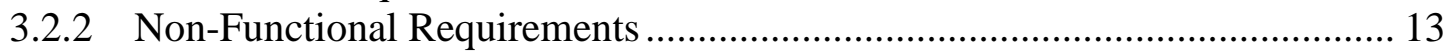

3.3 System Design ..................................................................................... 13

3.3.1 Application Interface Design ..................................................................... 14

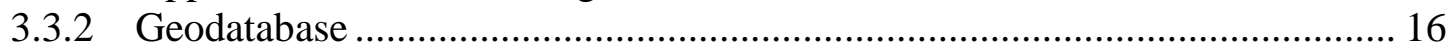

3.3.3 Map Services .................................................................................. 16

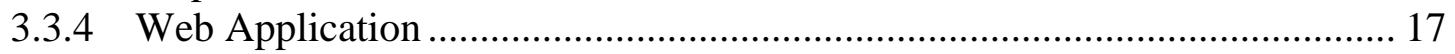

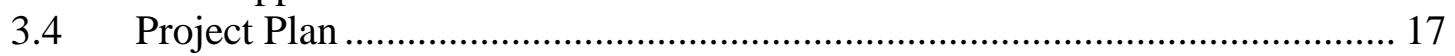

3.4.1 Project Requirement Analysis................................................................ 17

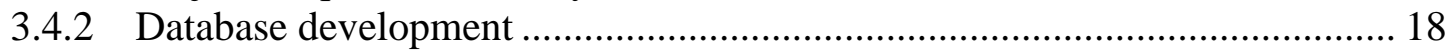

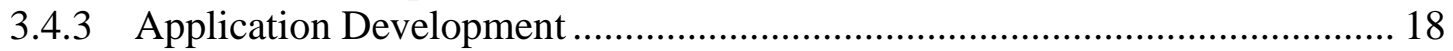

3.4.4 Documentation and Delivery …………………….................................. 19

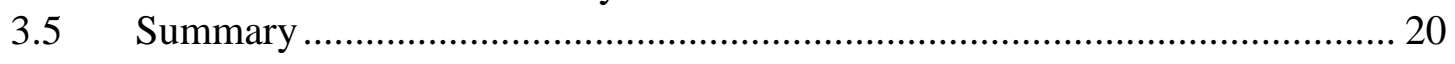

Chapter 4 - Database Design............................................................................... 21

$4.1 \quad$ Conceptual Data Model ........................................................................... 21

4.2 Logical Data Model ………………………................................... 22

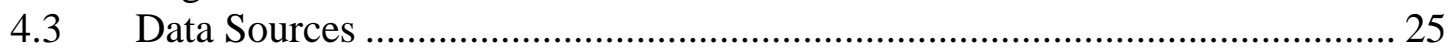

4.4 Data Scrubbing and Loading …………………….................................. 25

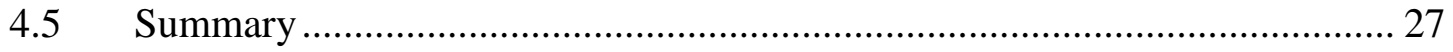

Chapter 5 - Implementation............................................................................................. 29

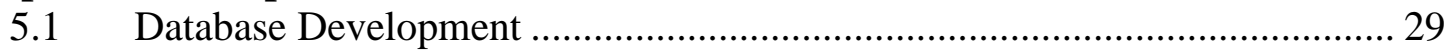

5.1.1 Data Loading and Geocoding ……………………................................... 30

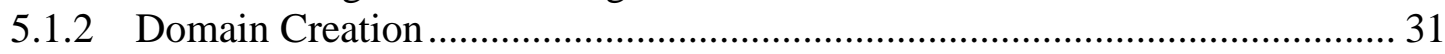

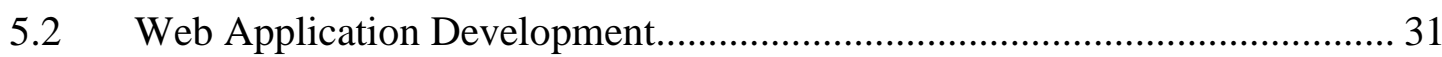

5.2.1 Preparation of Map Documents ................................................................ 32 
5.2.2 GIS Server Connection and Data Registration ....................................... 34

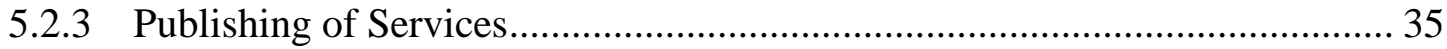

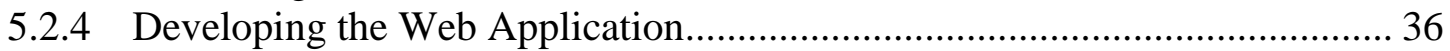

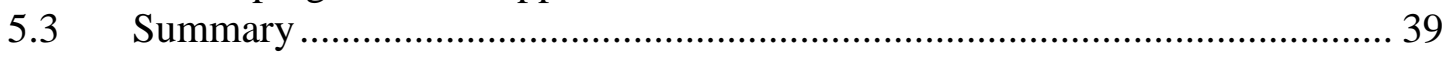

Chapter 6 - Use Case ................................................................................... 41

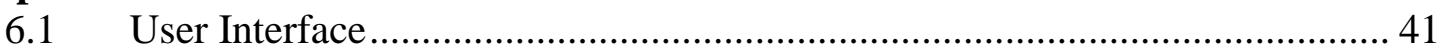

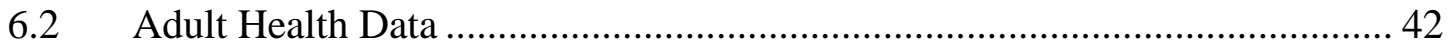

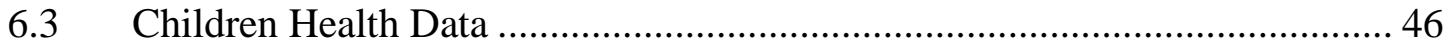

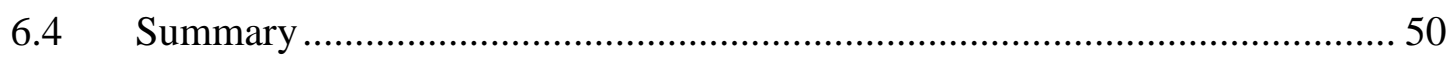

Chapter 7 - Conclusions and Future Work ...................................................................... 51

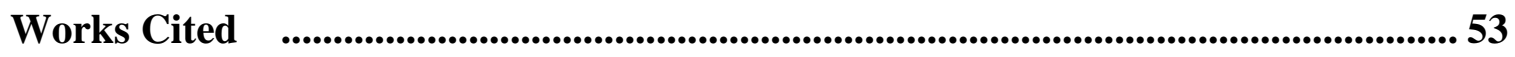

Appendix A. Recoded Datasets........................................................................................... 55

Appendix B. Sample ActionScript Classes ............................................................. 63

Appendix C. Sample XML Scripts ...................................................................................... 65

Appendix D. Sample MXML Scripts ..............................................................69

Appendix E. Sample Charts Scripts ................................................................ 71

Appendix F. Web-Service Reconfiguration ..................................................... 73 


\section{Table of Figures}

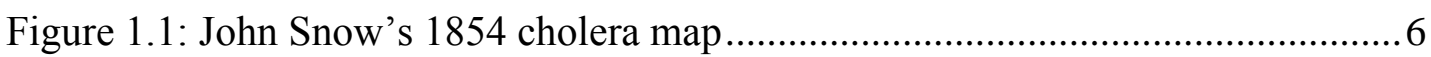

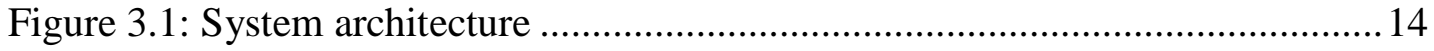

Figure 3.2: Application graphic interface layout .................................................... 15

Figure 3.3: Additional graphic user interface ………………………………......... 16

Figure 3.4: Requirements analysis workflow ………………................................ 17

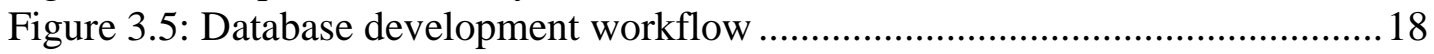

Figure 3.6: Application development workflow .................................................... 19

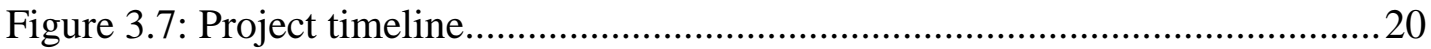

Figure 4.1: Conceptual data model ..................................................................22

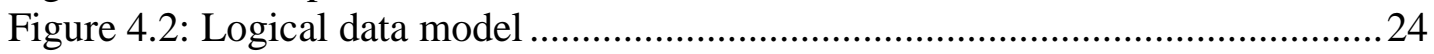

Figure 5.1: Geodatabase schema.....................................................................2

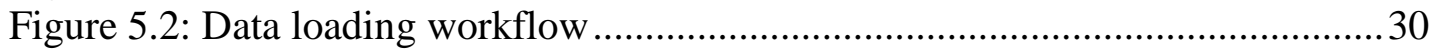

Figure 5.3: Geocoding workflow ......................................................................... 31

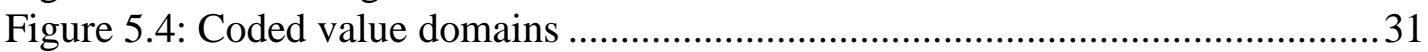

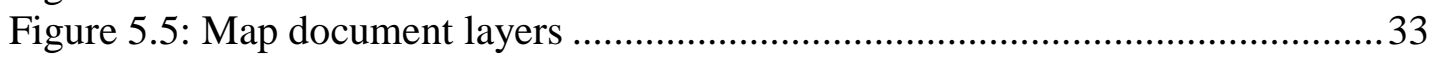

Figure 5.6: Map document with layers ………………………………………......... 34

Figure 5.7: ArcGIS server connection workflow..................................................... 35

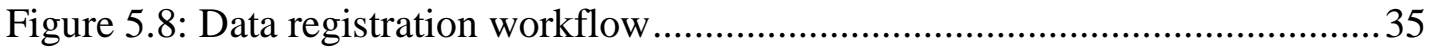

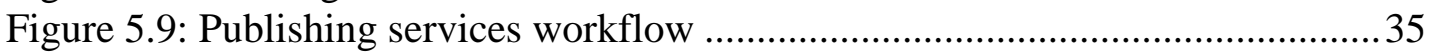

Figure 5.10: ArcGIS REST services directory …………….....................................36

Figure 5.11: Application start-up interface ………………........................................ 37

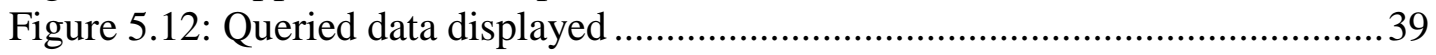

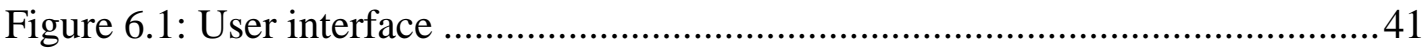

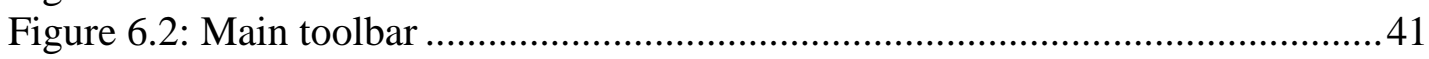

Figure 6.3: Basemap toolbar ...........................................................................4

Figure 6.4: Bottom toolbar............................................................................42

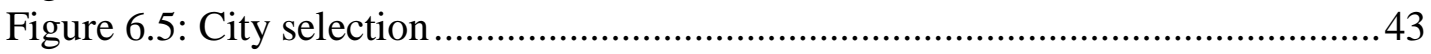

Figure 6.6: Health coverage results displayed ......................................................... 44

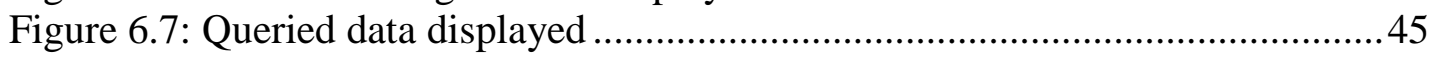

Figure 6.8: Printing and exporting maps generated ................................................4

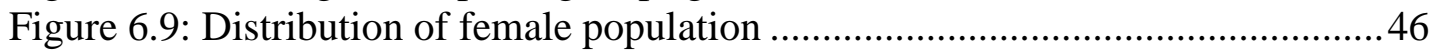

Figure 6.10: Children health data tab................................................................4

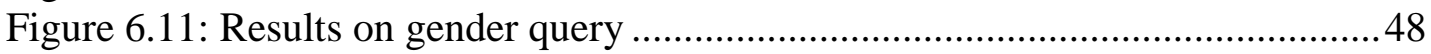

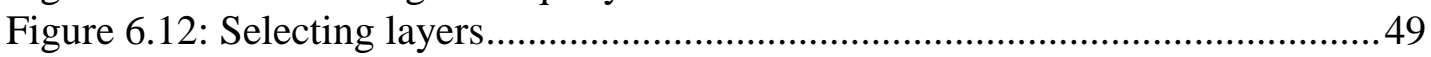

Figure 6.13: Selection of facility .........................................................................5 



\section{List of Tables}

Table 3.1: Overview of functional and non-functional requirements ...................... 12

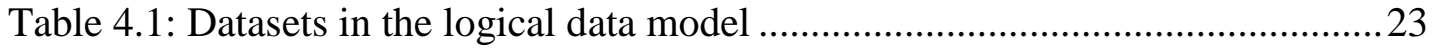

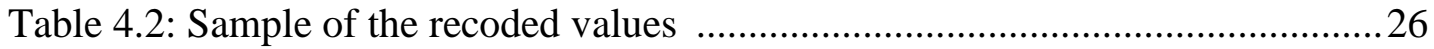

Table 4.3: Sample of the recoded column aliases....................................................26

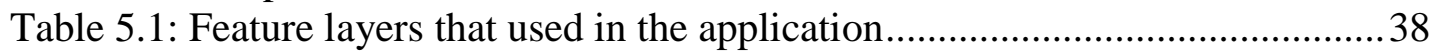

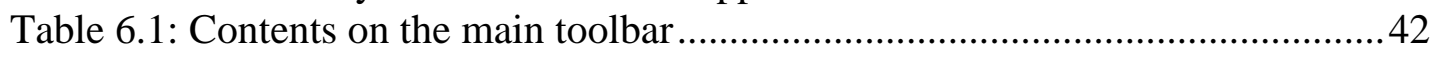





\section{List of Acronyms and Definitions}

$\begin{array}{ll}\text { API } & \text { Application Programming Interface } \\ \text { CDC } & \text { Center for Disease Control and Prevention } \\ \text { GIS } & \text { Geographic Information System } \\ \text { GUI } & \text { Graphical User Interface } \\ \text { HTTP } & \text { HyperText Transfer Protocol } \\ \text { HARC } & \text { Health Assessment Resource Center } \\ \text { HTML } & \text { HyperText Markup Language } \\ \text { IDE } & \text { Integrated Development Environment } \\ \text { IIS } & \text { Internet Information Services } \\ \text { KML } & \text { Keyhole Markup Language } \\ \text { PAHO } & \text { Pan-American Health Organization } \\ \text { REST } & \text { Representational State Transfer } \\ \text { RIA } & \text { Rich Internet Application } \\ \text { RIF } & \text { Rapid Inquiry Facility } \\ \text { SWC } & \text { Shockwave Flash Component } \\ \text { SDK } & \text { Software Development Kit } \\ \text { UML } & \text { Unified Modeling Language } \\ \text { URL } & \text { Universal Resource Locator } \\ \text { WWW } & \text { World Wide Web } \\ \text { WHO } & \text { World Health Organization } \\ \text { XML } & \text { Extensible Markup Language }\end{array}$





\section{Chapter 1 - Introduction}

Monitoring and assessing health problem trends require health specialists to access high quality information in order to identify and prioritize problems, develop and evaluate policies and actions, organize the delivery of clinical health services, guide research and development, and contribute to the development of standards and guidelines. This enables public health planning, management, and monitoring (Bedard et al., 2003). With introduction and popularization of the Internet in the 1990s, access to information has become simpler and far-reaching (Longley, Goodchild, Maguire, \& Rhind, 2011).

The Health Assessment Resource Center (HARC) is a non-profit, community based organization that conducts need assessment, program evaluation, and community health survey using both quantitative and qualitative methods. HARC collects a lot of health data and distributes the data through publish hard copy books to a wide spectrum of clients.

This chapter provides an introduction of the project. The first section introduces the project client; the problem definition is addressed in the second section; the third section describes the goals, objectives, and methods used to implement the project; the fourth section addresses the report audience; and the final section provides an outline of the remainder of the report.

\subsection{Client}

The client for this project was Dr. Jenna LeComte-Hinely, Director of Research and Evaluation at HARC. HARC was founded by a collaboration of community agencies and individuals in response to the scarcity of objective, timely, and comprehensive health data for Coachella Valley. The client was interested in developing a web mapping application, with which users can perform queries, create maps, and print maps of health indicators, behaviors, and disparities in Coachella Valley in an effort to provide solutions to community health problems. Dr. LeComte-Hinely provided data in forms of Microsoft Excel and SPSS spreadsheets, with guidelines for the representation of each indicator in the application.

\subsection{Problem Statement}

Although HARC collected a wealth of data and information, it lacked an effective or efficient approach to communicate the information with its clients. The data were contained in a 700-page report on health indicators, behaviors, and disparities in Coachella Valley. HARC needed an application that would enable data visualization in a user-friendly format, making it easier for people to produce clear and easy-to-understand maps with just a few clicks. HARC would then be able to increase awareness of the health problems faced by communities in Coachella Valley and will encourage funding and services towards the community. 


\subsection{Proposed Solution}

The proposed solution for the client was to develop a Web GIS application that HARC and its clients could use to view, query, print, and share information on health indicators, behaviors, and disparities in the Coachella Valley. The project scope was determined to help define a successful project. The elements and techniques used to achieve the goals and objectives are described in the following sections.

\subsubsection{Goals and Objectives}

The goal of this project was to help HARC communicate the information it collected effectively and efficiently to its clients. The main objective was to create an-easy-to use GIS web-based application to simplify the visualization and dissemination of health indicators, behaviors, and disparities in Coachella Valley.

There were three objectives identified for this project to achieve the stated goal:

- Geo-locate data about the health indicators, behaviors, and disparities by cities.

- Create a geodatabase to house the datasets for the project.

- Using the data presented by the client, develop an interactive Web GIS application for the visualizing of health indicators, behaviors, and disparities in the Coachella Valley.

\subsubsection{Scope}

The scope included transforming the 2007-2010 health data in forms of Microsoft Excel and SPSS spreadsheets to GIS format and geo-locating incidents at the city level.

Datasets containing the locations of farmer markets, public schools, health facilities, city parks, community centers, emergency food distribution centers, grocery stores, shelters, libraries, and youth programs were also collected. These were combined with the dataset of the 10 cities of the Coachella Valley and loaded into a File geodatabase. This paved the way for the development of the web application with a user friendly interface using Adobe Flash Builder and ArcGIS API for Flex. In this way, HARC and their data users could view and query different health indicators, behaviors, and disparities in Coachella Valley in the form of graphs, maps, and charts. This would allow the users to conduct analyses such as identifying the most affected city by a particular health indicator, behavior, or disparity.

\subsubsection{Methods}

Different techniques and methods were used in each stage of the project's development life cycle. In the system analysis and design phase, similar projects were studied and multiple meetings were held with the client to define the functional and non-functional requirements.

The conceptual and logical data models were then designed to identify the data needed to build the database schema. A File geodatabase was created with coded value domains and the data were imported. 
A web-based application was developed using Adobe Flash builder Flex SDK 4.6 and ArcGIS API for Flex version 3.0. The required map services were published to ArcGIS 10.1 for Server using ArcGIS Desktop 10.1.

\subsection{Audience}

The intended audience for this report includes the managers and employees of HARC, public health management officials, community health workers, and donors of HARC's health programs. It also includes individuals who have an intermediate knowledge of GIS and a basic understanding of programming.

\subsection{Overview of the Rest of this Report}

This report is comprised of seven chapters, which describe how the project was implemented and executed. Chapter Two presents the literature review of previous work related to the use of GIS for public health and web application for mapping. Chapter Three describes the system analysis and design of the project. Chapter Four covers the data scrubbing and loading, database design, and database conceptual and logical models. Chapter Five outlines the steps taken to implement and complete the project. Chapter Six provides a use case scenario of the developed application. Chapter Seven provides a summary, conclusions and ideas for possible future work. 


\section{Chapter 2 - Background and Literature Review}

The Internet and Geographic Information Systems (GIS) web mapping applications have become an important and effective method of presenting vital information to the public. This chapter presents previous work done in the application of GIS in community health monitoring. The chapter is arranged into four sections. Section 2.1 reviews the work done in GIS and health; Section 2.2 discusses the evolution of the Internet, Web GIS and their current use; Section 2.3 presents an overview of Adobe Flex and Esri's API for Flex; and Section 2.4 summarizes the chapter.

\subsection{GIS in Health}

Linkages between pieces of information and their geographic distribution create a visual picture that aids public health practitioners in understanding and suggesting solutions to public health problems (Riner, Cunningham, \& Johnson, 2004). The rationale of using GIS in the public health framework follows two distinct purposes. First, a GIS is used at the individual or aggregate level to identify the etiology of a disease, specifically to understand the association of a disease with environmental variables. Second, by utilizing the epidemiologic methods, a GIS can identify a particular disease based on its geographic distribution and determines where control and prevention should be focused (Glass et al., 1995).

John Snow's study of the 1854 outbreak of cholera in London serves as a good example of how GIS can provide insights into disease etiology and assist in the control efforts (Figure 1.1). Although his map did not determine the cause of the 1854 cholera epidemic, it served as a useful tool to summarize his findings and convince his contemporaries of his conclusion. With the ability to display the cholera cases along the streets, Snow was able to associate the incidents to the well locations in a way that made sense. By combining spatial clusters of events and the distance decay effects, he then calculated the deaths as a percentage of the population and the projected deaths if action was not taken to correct the situation (Koch, 2005). 


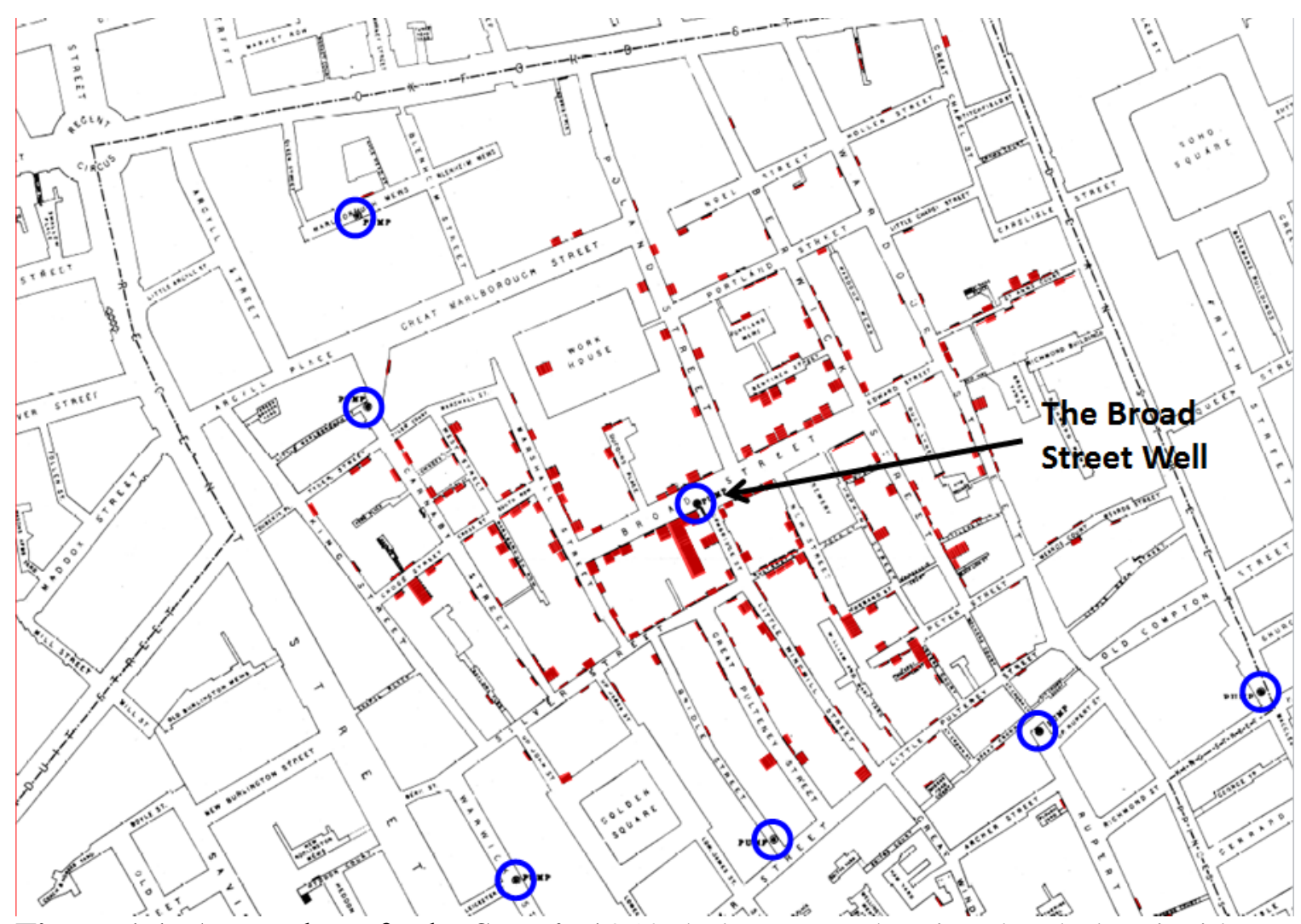

Figure 1.1: A snapshot of John Snow's 1854 cholera map, showing the cholera incidents and highlighting the famous Broad Street Well (Gleick, 2013).

Advances in GIS technology have made mapping and analyzing data much more effective with the combination of statistical methodologies and accurate geographically referenced databases, presenting new opportunities to study the environmental, socialeconomical, infrastructural, and behavioral factors contributing to public health problems (Mayunga, 2002). Glass et al. (1995) demonstrated the use of a GIS in the assessment of environmental risk factors for Lyme disease. The study focused on characterising samples in relation to each other, then provided an approach to study the disease distribution and the associated environmental causes. In Tanzania, a GIS was used for the creation of a Demographic Surveillance System (DSS) to analyze the mortality among children under five years due to malaria. The DSS provided health authorities with the information which enabled effective intervention (Kamara, 2008). Similarly in the United Kingdom, Beale et al. (2007) utilized a GIS to develop and link a Rapid Inquiry Facility (RIF) with an environmental health database, creating an effective tool that enabled researchers and public health professionals to easily and rapidly determine environmental health hazards and diseases.

The future trends in health policy, research, planning, and management point to GIS being an important role in the automation and integration of data on patients, facilities, programs, and events that include incidents of disease, medical diagnostics, and treatments at an optimal level of details (Kurland \& Gorr, 2012). 


\subsection{The Internet and Web GIS Development}

The Internet and information technology revolution continues to expand the volume and accessibility of data. Since its popularization, the Internet is a worldwide telecommunication network where the demand and transfer of data necessitate the integration of technologies (Peng \& Tsou, 2003). Before the 1990s, the use of such technologies was very limited by an average person due to its cost and complexity. The Internet in particular was mainly used by research professionals and government agencies and its services consisted mainly of e-mail, Usenet news, file transfer, and remote access to computers (Fu \& Sun, 2011).

Fu and Sun (2011) defined Web GIS as a distributive information system that possesses an advantage over the traditional GIS with its far reaching capabilities across the Internet without the need for locally installed software. The development and expansion of Web GIS providing a visual interaction with data allowed users to produce and publish maps via the Internet and to access them from many location. This combination of easy access and visual representation of data addressed some of the difficulties geoscientists faced in the past (Alesheikh, Helali, \& Behroz, 2002). Additional functionalities of a Web GIS include query attributes, data collection, data dissemination, and geospatial analysis such as measuring distance, finding locations, proximity analysis, and route optimization. It also reduces the costs of training, licenses, and the required criteria of a user's machine (Fu \& Sun, 2011).

Web GIS is based on a HyperText Transfer Protocol (HTTP) request sent to a web server via a browser. The web server processes this request and returns a HyperText Markup Language (HTML) response or binary images such as JavaScript Object Notation (JSON) or an Extensible Markup Language (XML) (Fu \& Sun, 2011). GIS applications over the Internet were faced with performance issues. As Alesheikh et al. (2002) explained, these issues are mainly due to the exchange of large quantities of data between clients and servers. This problem can be solved by using appropriate Web GIS architecture. The architectural choice depends on the application requirements and the available resources. The first architecture is called "Thin Client/ Thick Server." In this design the processing is completed on the server side and the results are displayed on the client side. However, it involves a longer response time. The second architecture is "Thick Client/ Thin Server." In this architecture, processing is done on the client side, hence extending its functionality while the server sends the required data. Network speed significantly influences this architecture, since a large amount of data needs to be transferred in this type of architecture. Also, this architecture requires a powerful client machine to handle all processes. "Medium Client and Server" is the third type of system architecture, where the processing is done on both sides. This architecture becomes favorable when the processing loads are balanced between the client side and server side. The final architecture is known as "Distributive." This framework supports the concurrent use of many applications and servers, and uses a scalable distributive GIS model to improve the traditional client/server GIS model.

Web GIS applications have become essential for the planning, management, and monitoring of health situations for many international organizations. The Health Mapper is a surveillance and mapping application developed by the World Health Organization (WHO) to provide public health officials with information in the form of charts, tables, 
and maps of health variables at national and global levels (WHO, 2013). Similar systems exist in organizations such as the Center for Disease Control and Prevention (CDC) and the Pan-American Health Organization (PAHO). Epi INFO is a system developed by the CDC to provide health workers with a rapid assessment tool for disease outbreaks in order to develop small to mid-size disease surveillance system (CDC, 2013). PAHO developed a system called Geographic Information System in Epidemiology and Public Health (SIG-EPI) using GIS as a tool to strengthen health worker's capability for epidemiological analysis and to facilitate the dissemination of data relating to epidemiology and public health in the Americas (PAHO, 2013).

Another example of Web GIS is the Advanced Emergency Geographic Information System (AEGIS) used by the Loma Linda University Medical Center (LLUMC) to share real-time information to relevant Emergency Medical Services (EMS). AEGIS monitors and maps the locations and statuses of emergency resources such as hospitals, ambulances, and rescue helicopters by incorporating information from different sources. Such an infrastructure has assisted emergency personnel to get patients to hospitals that specialize in their needs in a timely manner (Esri, 2007).

\subsection{Adobe Flex and Esri API for Flex}

The profound technology of Web GIS today is due to great advancements in web service technology. These technologies facilitated the dramatic evolution in Web GIS products such as servers, browsers, and web portals that correspond to different roles in Web GIS architectures (Fu \& Sun, 2011). Rich Internet Applications (RIA) are the next step in this ongoing evolution, providing an efficient and high performance way to execute code, content, and communication (Labriola, Tapper, \& Boles, 2012). Adobe Flex is a developer friendly RIA tool whose application, when compiled, runs inside web browsers with an Adobe Flash Player plug-in installed. Applications developed in Adobe Flex are capable of dynamic updates and background data loading, and provide a rich set of controls and data visualization components leveraging the use of MXML, an XML-base language and ActionScript (Fu \& Sun, 2011).

Esri's web mapping APIs such as ArcGIS API for JavaScript, Flex, and Silverlight provide a straightforward environment for the developing RIAs. The ArcGIS API for Flex is built on the Adobe Flex framework, allowing the use of Flex components such as data grids, trees, panels, and charts. It enables the displaying of interactive maps, execution of models, address location, editing, and the combination of data from multiple sources (Esri, 2013).

\subsection{Summary}

The goal of this project was to create an easy-to-use Web GIS application to facilitate the dissemination and visualization of health indicators, behaviors, and disparities in Coachella Valley. Section 2.1 of this chapter explained the use of GIS in studying the environmental, socio-economical, infrastructural, and behavioral factors contributing to environmental health problems. Section 2.2 discussed the evolution of the Internet and Web GIS development, including their advantages, capabilities, and the types of architectures it could support, along with examples of applications in facilitating better 
decision making. Finally, Section 2.3 talked about the capabilities of the Adobe Flex framework and Esri API for Flex in the development of Web GIS applications. 


\section{Chapter 3 - Systems Analysis and Design}

Understanding the design and specification of the application makes the difference between a successful and an unsuccessful project. To provide the best solution to the client's problem, survey methods such as questionnaires and interviews were applied to gain an understanding of the organization's mission, user requirements, data, and current processes being applied. The project began with a general design methodology, recognizing the users, application technology, and the selected data sources. As the project progressed, detailed designs were created for individual components of the application.

This chapter consists of five sections. Section 3.1 restates the problem to be addressed. Section 3.2 describes the functional and non-functional requirements of the project; Section 3.3 discusses the system design; and Section 3.4 explains the overall project plan; and Section 3.5 summarizes of this chapter.

\subsection{Problem Statement}

Although HARC collected a wealth of data and information, it lacked an effective or efficient approach to communicate the information with its clients. The data were contained in a 700-page report on health indicators, behaviors, and disparities in Coachella Valley. HARC needed an application that would enable data visualization in a user-friendly format, making it easier for people to produce clear and easy-to-understand maps with just a few clicks. HARC would then be able to increase awareness of the health problems faced by communities in Coachella Valley. These maps would encourage funding and services towards the community.

\subsection{Requirements Analysis}

The project requirements were classified into two categories: functional and nonfunctional. Functional requirements of the application include the functions that satisfy users' needs, and are part of the system that users interact with directly. These were derived after several meetings with the client and the end users in an effort to understand the specific needs to be addressed in the final product.

The non-functional requirements were those that the users do not interact with directly but ensured the system perform successfully. These requirements can be viewed as technical, operational, and transitional. The technical requirements describe both the technology the client needed to maintain the system and the technology end users needed to use the application. The operational requirements included the periodic maintenance requirements that the client is responsible for to keep the system up and running. Finally, the transitional requirements were those needed for handing the system over to the client and end-users, such as training and usage documentation. The functional and nonfunctional requirements are listed in Table 3.1. 
Table 3.1: Overview of functional and non-functional requirements

\begin{tabular}{|c|c|c|}
\hline Category & Requirement & Description \\
\hline \multirow{7}{*}{ Functional } & Manage Data & $\begin{array}{l}\text { A geodatabase to facilitate the storing, updating, } \\
\text { and retrieval of spatial and non-spatial data for the } \\
\text { project. }\end{array}$ \\
\hline & Data Publishing & $\begin{array}{l}\text { Use mapping services to communicate data stored } \\
\text { on the GIS server to users via the map display } \\
\text { within the web-based application. }\end{array}$ \\
\hline & $\begin{array}{l}\text { Display health } \\
\text { parameters } \\
\text { graphically }\end{array}$ & $\begin{array}{l}\text { Charts and maps to communicate health data } \\
\text { graphically to users. }\end{array}$ \\
\hline & $\begin{array}{l}\text { Communicate } \\
\text { information on } \\
\text { health facilities and } \\
\text { programs }\end{array}$ & $\begin{array}{l}\text { Include layers such as, City boundaries, location } \\
\text { of public schools, healthcare facilities, Emergency } \\
\text { food distribution centers, city parks, community } \\
\text { centers, farmer's market, Grocery stores, shelters, } \\
\text { libraries and youth programs. }\end{array}$ \\
\hline & $\begin{array}{l}\text { Reference to } \\
\text { HARC }\end{array}$ & $\begin{array}{l}\text { Link the mapping application to the harcdata.org } \\
\text { website. }\end{array}$ \\
\hline & Report generation & $\begin{array}{l}\text { Generate reports for each layer showing the Name, } \\
\text { Location and in case of cities, the population, } \\
\text { median age and the median household income. }\end{array}$ \\
\hline & Interactive graphics & $\begin{array}{l}\text { Customize and print maps from drawn graphics in } \\
\text { pdf, jpeg, emf and png formats or send maps to a } \\
\text { designated printer for a hard copy. }\end{array}$ \\
\hline \multirow{7}{*}{$\begin{array}{l}\text { Non- } \\
\text { Functional }\end{array}$} & \multirow{5}{*}{ Technical } & $\begin{array}{l}\text { Browser Adobe Flash Player plugin version11 or } \\
\text { higher. }\end{array}$ \\
\hline & & Esri's ArcGIS server 10.1 \\
\hline & & Esri's ArcGIS API for Flex 3.0 \\
\hline & & Internet Information Services (IIS) Web Server. \\
\hline & & Domain Name. \\
\hline & Operational & Maintenance of the application. \\
\hline & Transitional & Training and user documentation. \\
\hline
\end{tabular}

\subsubsection{Functional Requirements}

There were several functional requirements of the application as outlined in Table 3.1. Essentially the system was required to store the datasets for easy manipulation and retrieval for sharing health information. The datasets included the adult and child health indicators and the locations of the different health programs, resources, and facilities in the Coachella Valley. These datasets were accessed via the published web services that 
were hosted on a GIS server and available to the public via a web application, enabling the display of queried data by city in the form of graphs, maps, and charts. The datasets were divided into adult and child categories for easy manipulation and also included tool tips to give users a good understanding of each tool's functionality and the data being queried. In addition users would be able to navigate around the application interface and have the capability to add graphical features such as points, lines, and polygons showing locations of interest.

The system has incorporated print and screen capture functionality which allows users to create and print graphically designed maps in different formats. It could also communicate city information such as name, location, population, median age, and median income. For users who would be interested in using HARC data, the application also included a link to the HARC data website.

\subsubsection{Non-Functional Requirements}

The technical requirements are the backbone of the non-functional requirements, focused on the technology required to build the system. Web services were created from a geodatabase and published using ArcGIS Desktop 10.1 to ArcGIS 10.1 for Server. They were made available to the users through the web application.

The application comprises a Graphical User Interface (GUI) and navigation components. It is hosted using Internet Information Services (IIS) web server and requires a Universal Resource Locator (URL) for access. It could be accessed via a browser with Adobe Flash Player plugin version 11 or higher. The web application was developed using Adobe Flash Builder 4.6 and Flex SDK, incorporating Esri's Application Programming Interface (API) for Flex 3.0.

The operational requirements of the application include the processes to keep the application up and running. The client is responsible for the cost of operating and maintaining the application. The transitional requirement involved creating detailed user documentation of the application and training the organization's staff in the use of the application.

\subsection{System Design}

The system design was dependent on the results of the requirements analysis. This analysis provided the design and implementation of the geodatabase, development and customization of the web based GIS application, and the creation of a web mapping service accessed through a GIS server.

Figure 3.1 shows the system architecture which consists of two tiers; the web server tier which comprises of an ArcGIS 10.1 for Server and the IIS web server connected to the system geodatabase, and the client tier by which the client can access the application using a web browser with Flash Player version 11 or higher. 


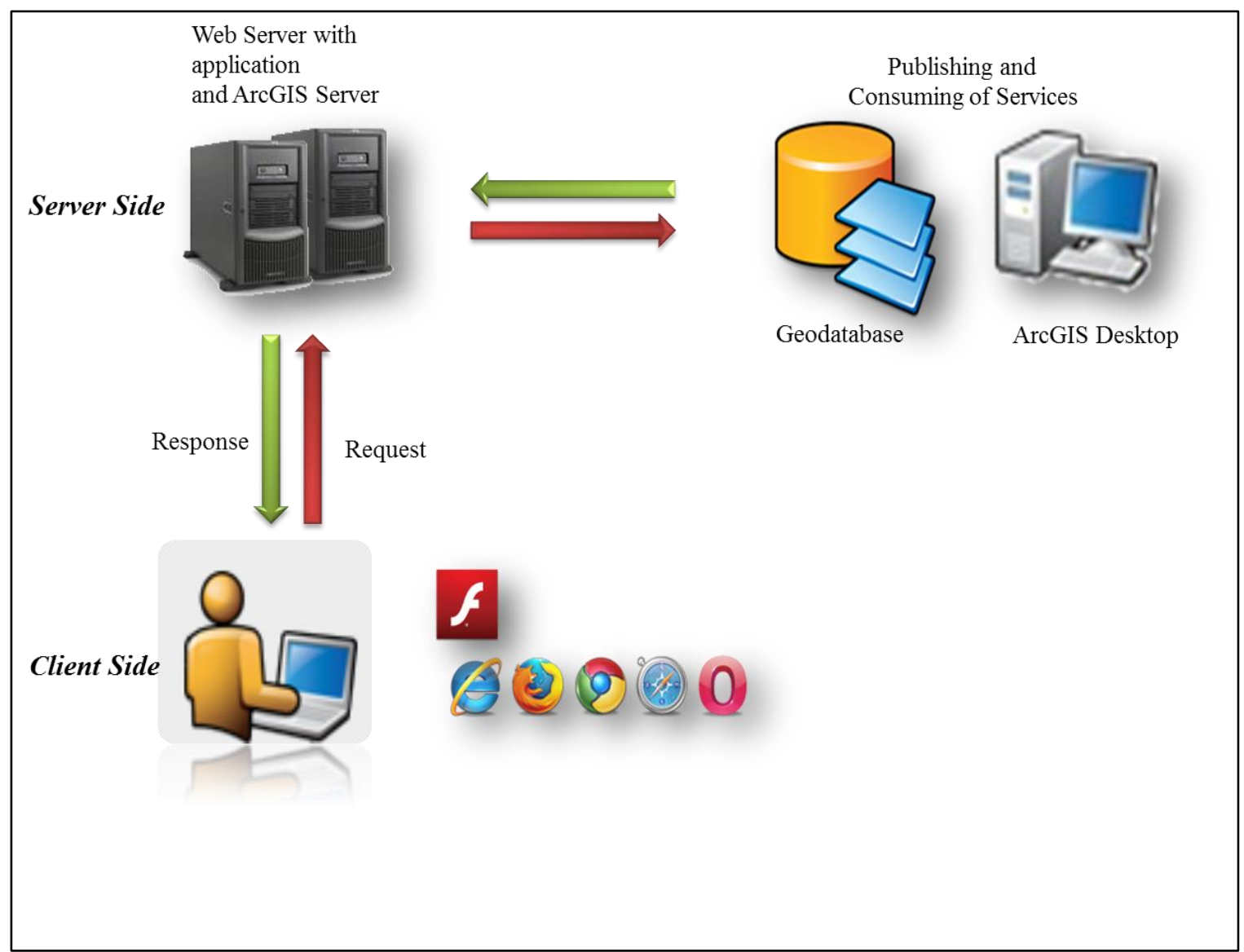

Figure 3.1: System architecture

\subsubsection{Application Interface Design}

The application interface design required several components which were laid out during the design phase and refined during the implementation phase. The layout of the application included two views, the start-up view and the operational view.

Figure 3.2 shows the application start-up, which includes the main toolbar that comprises of the navigation tools, draw tools, city selection menu and legend, print, and health dataset components. The main application interface includes the base map selection menu, the public health layer menu, the legend menu, and the navigation menu. The bottom control bar includes the scale bar, toggle layer visibility, and map coordinates. 


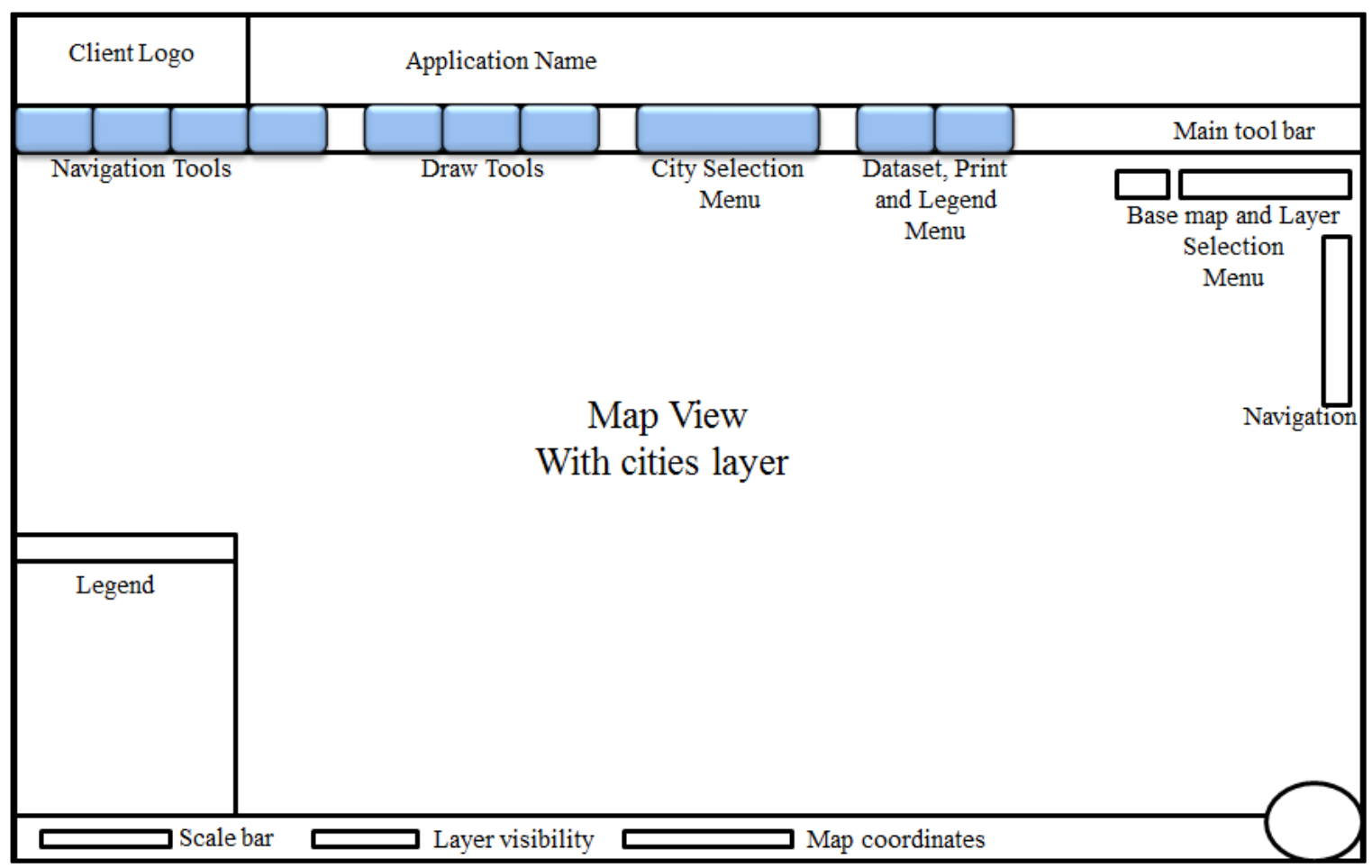

Figure 3.2: Application graphic interface layout

The system layout with all the components loaded is shown in Figure 3.3. In addition to the start-up components, health dataset components are shown along with a chart window, a print window, and the selected facilities layer widow. 


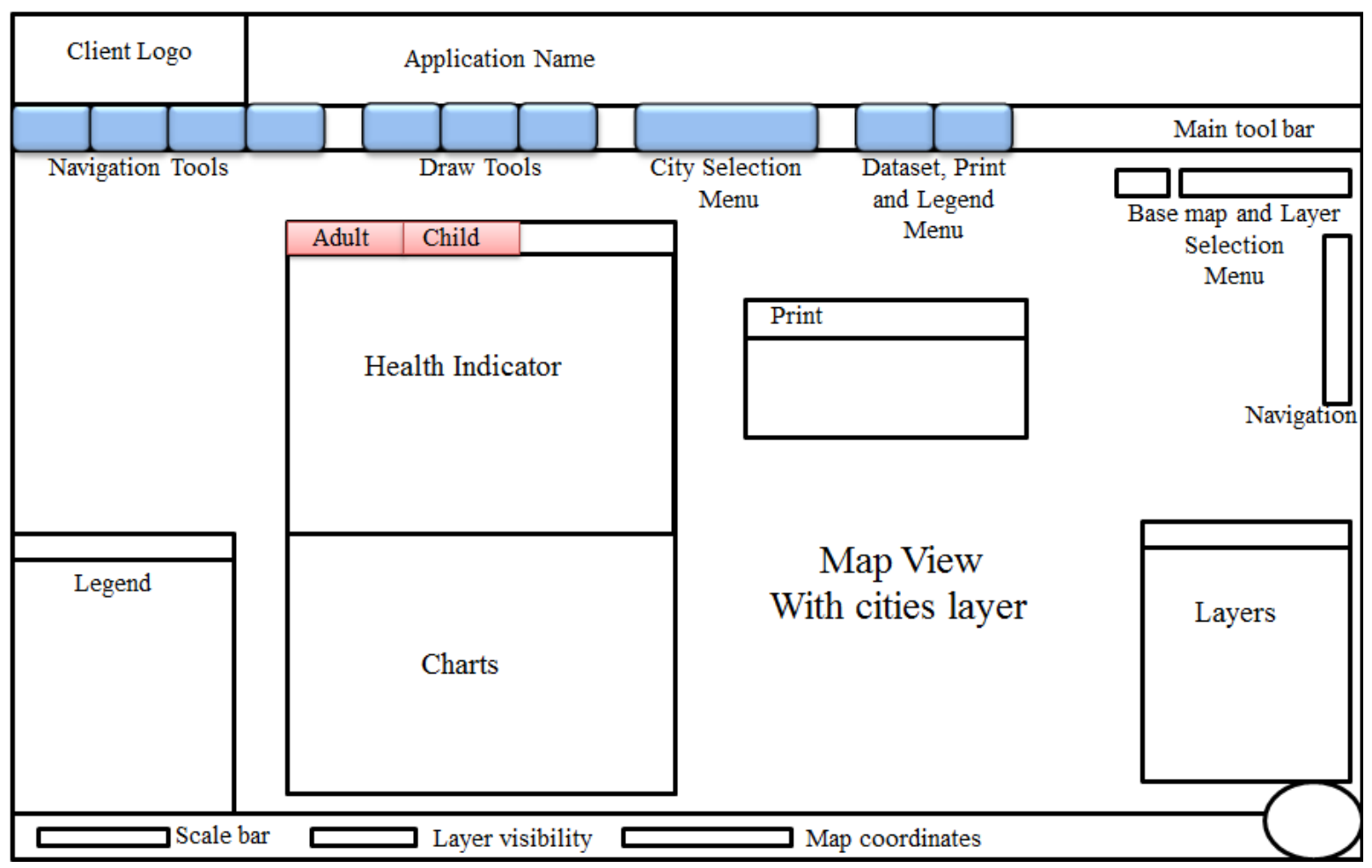

Figure 3.3: Additional graphic user interface

\subsubsection{Geodatabase}

The geodatabase is a data storage and management framework within ArcGIS that enables the robustness and extendibility of data. Within the ArcGIS suite of software, there are three types of geodatabases: File, Personal, and Enterprise. Considering the requirements of the project, the File geodatabase was selected to store the collected datasets for easy manipulation in ArcGIS Desktop 10.1 and later to create and publish the services to ArcGIS 10.1 for Server. The File geodatabase has larger size capacity as compared to the Personal geodatabase, therefore enabling the clients to update and expand the tables within the database in the future. Since the application users are not required to update or edit the feature classes, the enterprise system was not necessary.

\subsubsection{Map Services}

Map services are the means by which maps are used over the Internet using ArcGIS. The services were published to ArcGIS 10.1 for Server through ArcGIS Desktop 10.1; they are then consumed by a web application on a user's side. The server supports different types of operations including map, query, feature, network, geodata, geoprocessing, image, locator, and print services. The application design included a File geodatabase to manage the data from which map documents (.mxd) were created and published to the server using the Representational State Transfer (REST) service. 


\subsubsection{Web Application}

The ArcGIS API for Flex 3.0, along with Adobe Flash Builder SDK 4.6, were used to develop a rich Internet application. This application consumed the services published to the ArcGIS 10.1 for Server and the base maps service provided by ArcGIS Online.

A prerequisite for applications developed using the Flex SDK is that its users are required to have the Adobe Flash Player plugin version 11 or higher installed in their web browsers. With the application deployed, users would be able to view different thematic layers, to generate queries on health data by the different cities and to generate maps, in a rich internet application environment.

\subsection{Project Plan}

The project plan included five major tasks that were accomplished using the waterfall approach:

- Project requirement analysis

- Database development

- Application development

- Documentation

- Delivery

\subsubsection{Project Requirement Analysis}

A series of interviews and phone conversations were held with the staff and users of HARC data to determine the client's needs and requirements. The system requirements and scope of the project were addressed to establish a detailed description of the deliverables. Datasets were collected from HARC and the Riverside County GIS office. They were then reviewed and a selection of the datasets and related fields were included into the database. Figure 3.4 illustrates the project requirement analysis workflow.

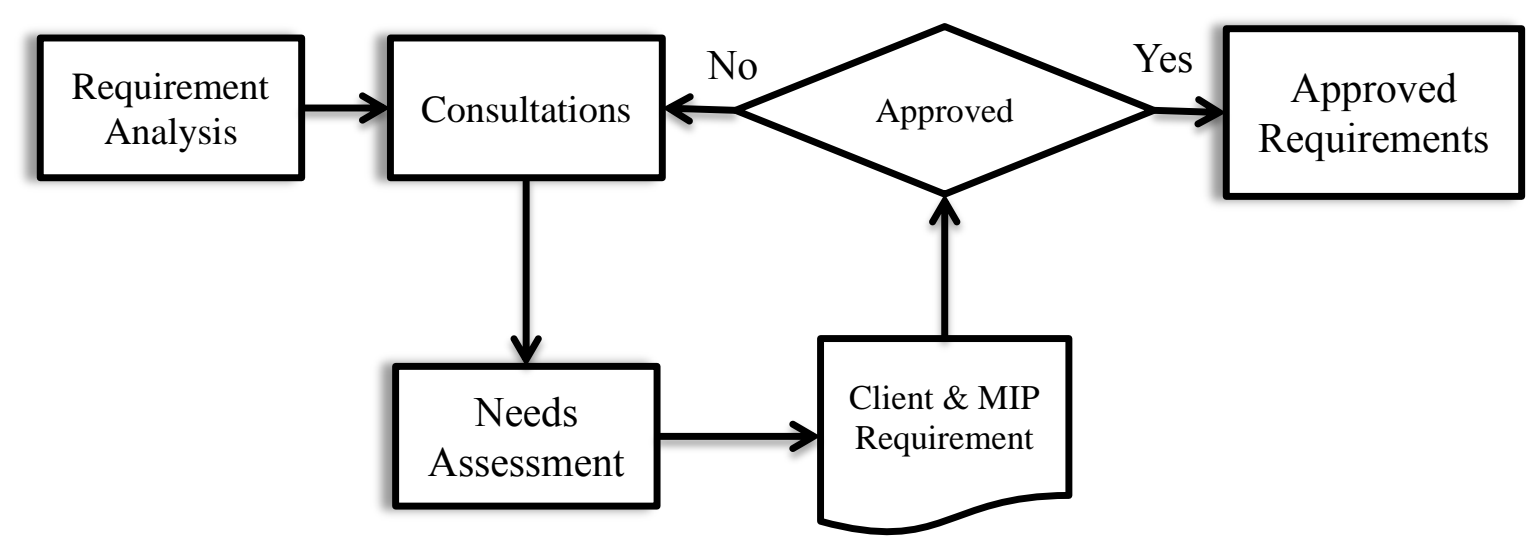

Figure 3.4: Requirements analysis workflow

Importantly, when performing this task the responses from the client were very punctual; this was significant because it kept the project on track. 


\subsubsection{Database development}

The second phase of the project was the database development as illustrated in Figure 3.5. A conceptual data model was created to identify and understand the general picture of the data organization and work structure. The logical database model included a detailed design of the database schema to present the relationships, attributes, and behavior of the data.

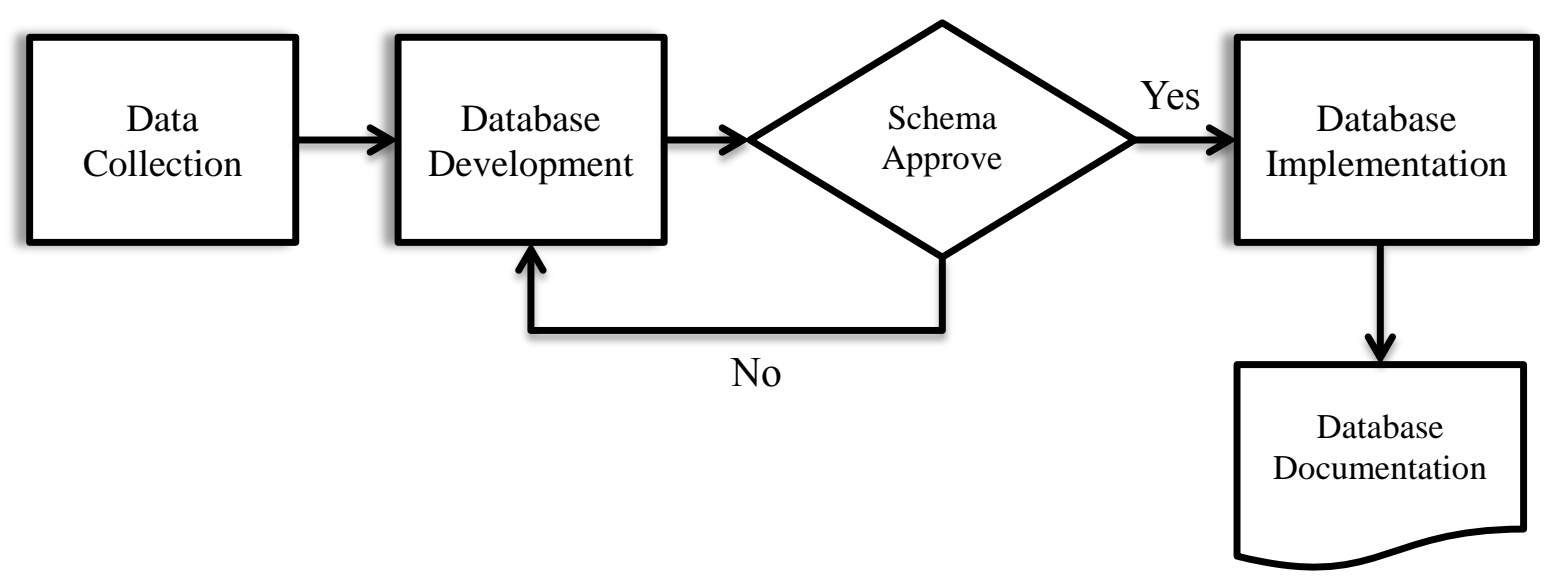

Figure 3.5: Database development workflow

The database development took longer than was originally planned, due to the fact that the data provided by the client were not in a logical, clear, or comprehendible format. These resulted in additional time being spent to sort and recode the data; this however did not cause a delay in the project.

\subsubsection{Application Development}

The application development included a group of tasks. First, the necessary software was selected, including the suite of software from the Esri and Adobe. As previously indicated, ArcGIS 10.1 for Server was used as a platform for hosting the web services. The successful configuration of the server led to a comprehensive testing of the features for data visualization, query, printing, and visual experience of the published services. The inconsistencies identified were addressed; the services were retested, and then published for consumption. Figure 3.6 illustrates the application development workflow. 


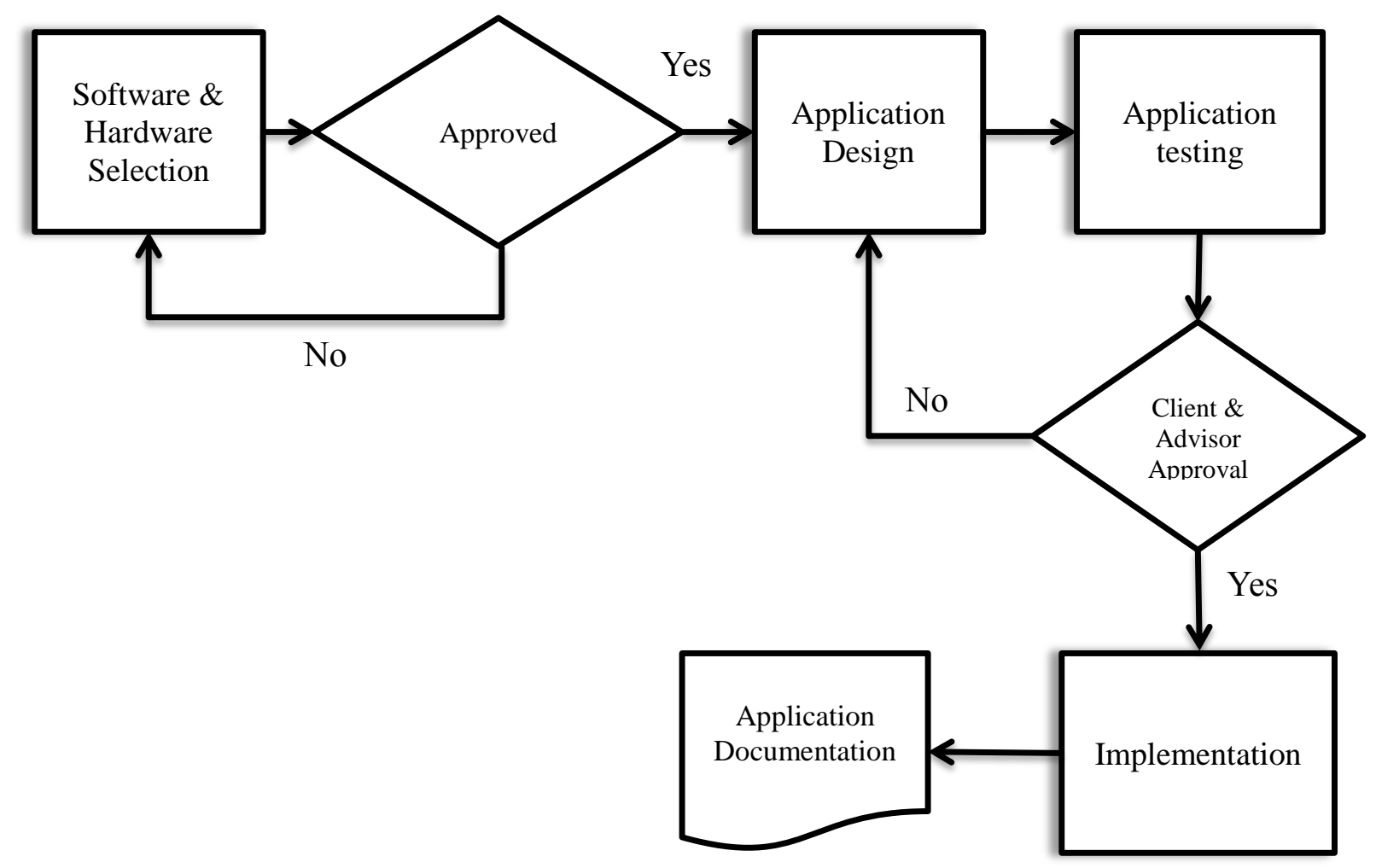

Figure 3.6: Application development workflow

The application development phase was completed within the time allocated. The improvements in the publishing and consuming of services with ArcGIS 10.1 for Server, along with the Flex samples provided by Esri, aided in completing the application on time.

\subsubsection{Documentation and Delivery}

The documentation process was done after each task was completed. Metadata and a report of each task were completed in order to provide a detailed breakdown of each aspect of the project. The final product was delivered to the client with all documentation. This task was completed within the allotted timeline.

During the project development lifecycle, there were some minor changes to the project plan. The timeline was extended for some components, such as database development. However, the project scope remained the same and the project completed on schedule. Figure 3.7 shows the overall breakdown of the project timeline. 


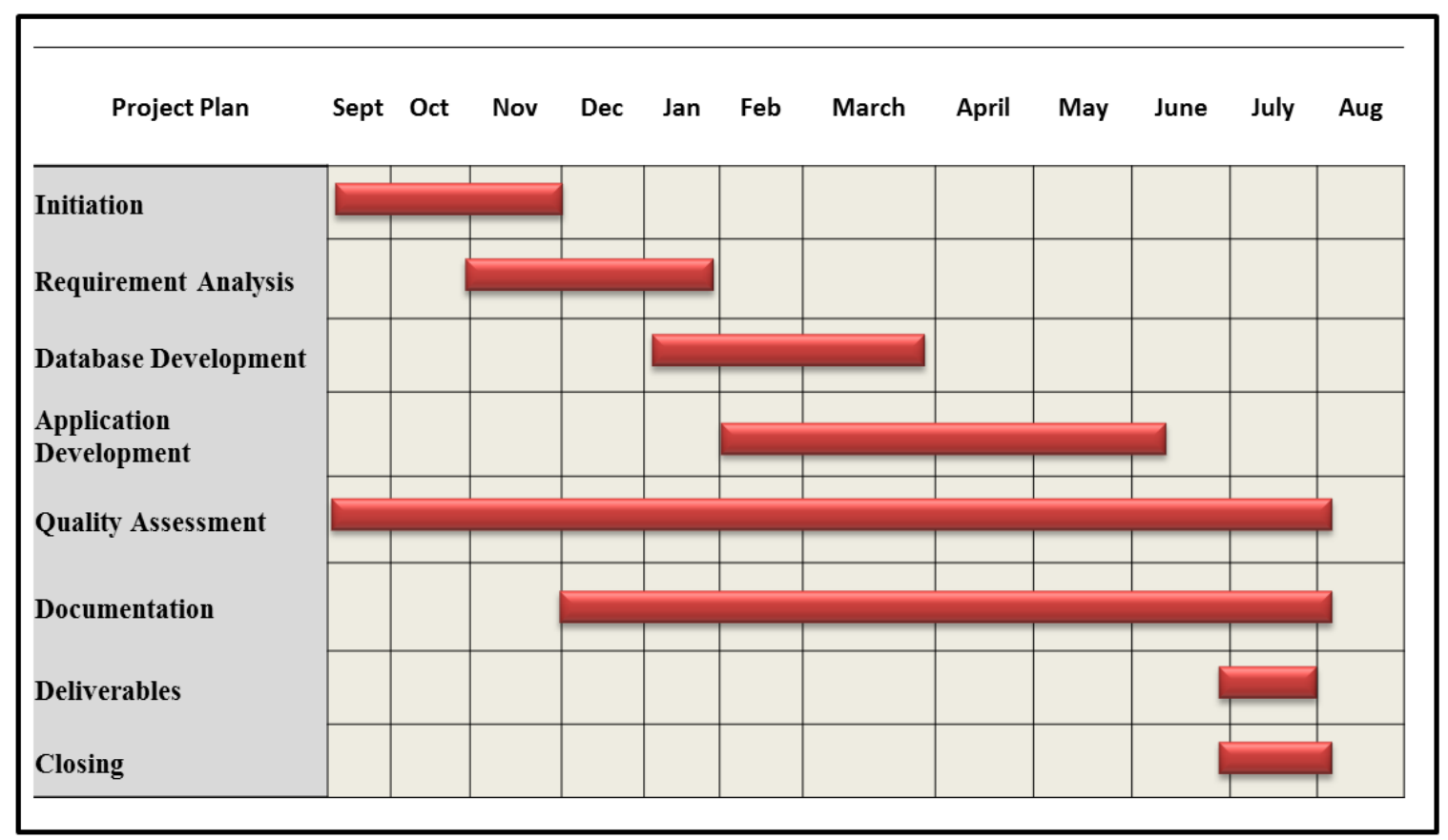

Figure 3.7: Project timeline

\subsection{Summary}

The system requirement analysis and design resulted in a blueprint of a system design to meet the client's needs. This avoided potential problems that could have influenced the project development and kept the project within the allotted timeframe. This chapter revisited the problem statement, presented an overview of the functional and nonfunctional requirements, the system design and the application interface design. The chapter concluded with the discussion of the project plan. The plan covered the five phases of the project implementation with the understanding of the required functionality and system design. 


\section{Chapter 4 - Database Design}

Databases are the foundation of a GIS, as the organizing, structuring, and storage of data for the implementation of GIS related projects are extremely important. The database designed for this project facilitated the effective management, maintenance, and retrieval of data.

This chapter discusses the steps followed in the database design and implementation of this project. Section 4.1 describes the conceptual data model which determined the structure and relationships of the data in the system. Section 4.2 discusses how the conceptual model was achieved within the project. Section 4.3 identifies the sources of the data; and Section 4.5 discusses how the data were prepared for loading into the geodatabase. This chapter concludes with a summary in section 4.6.

\subsection{Conceptual Data Model}

The conceptual data model was the main component behind the logical database model; it was determined by interviews with the client and end users of the project. These activities identified the datasets required to provide a solution to the client's problem and the relationship of each entity.

Figure 4.1 shows the elements of the conceptual data model for this project. The classes included are Surveyed_Person, City, Facility, Program, Resource_Center, and Activity Center. The Surveyed_Person class has a one-to-many relationship with the City class with the association of "Lives in", signifying that one or more surveyed person may live in one city. It has attributes of age, residence, and income. The Program class has a one-to-many association with the Facility class highlighting that many health programs could be held at one facility. The Facility class contains two sub-classes, Resource_Center and Activity Center, and has a one-to-many relationship with the City class. 


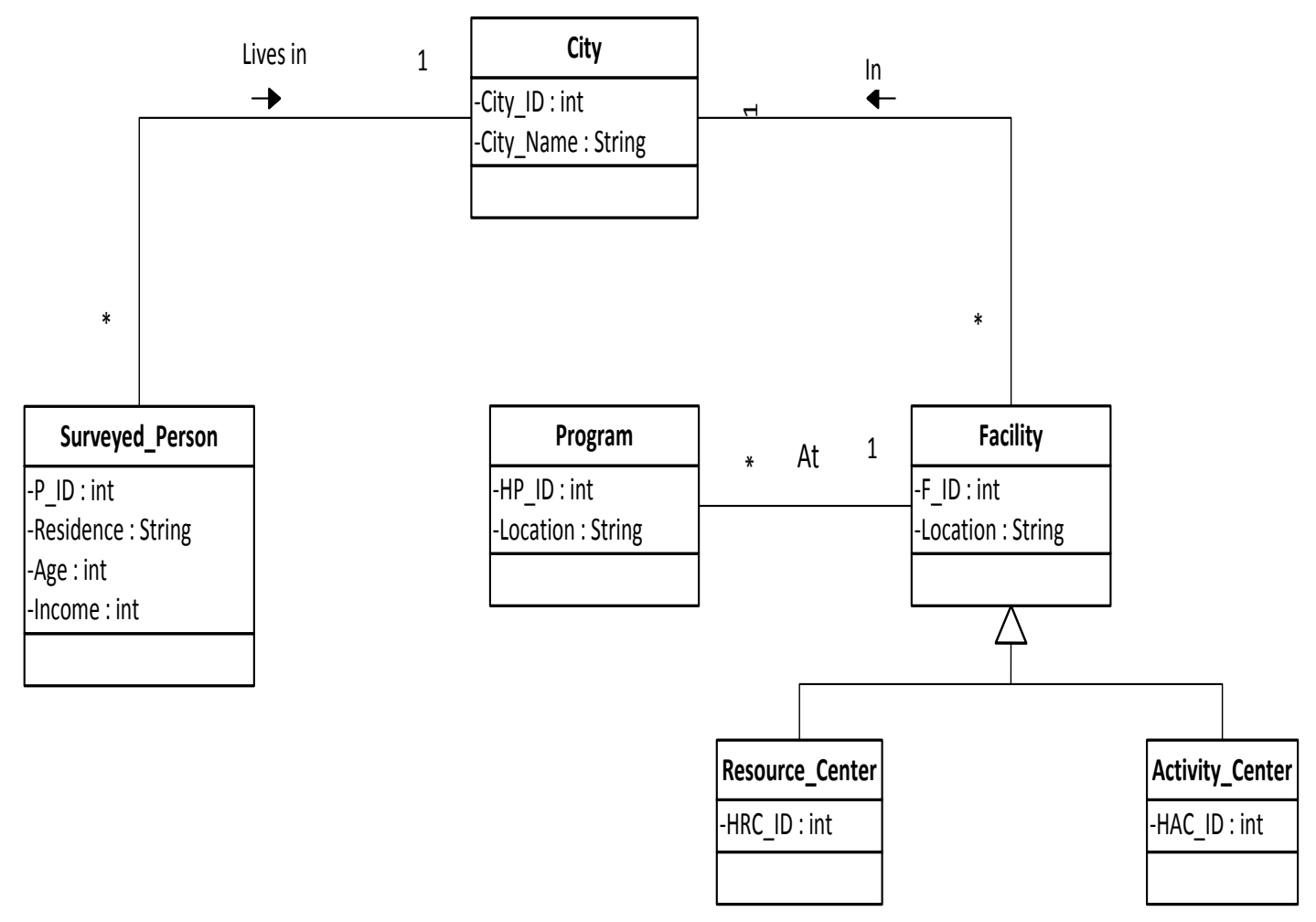

Figure 4.1: Conceptual data model

\subsection{Logical Data Model}

The logical data model structures the physical design and implementation of the database. It contains the representation of the entities, the attributes, the relationships, and the unique identifiers of each feature class represented in the database. The project comprised of 13 feature classes stored in an ArcGIS File Geodatabase; using a flat-file model by not establishing any explicit relationships between the datasets enables faster data retrieval. Table 4.1 and Figure 4.2 illustrate the logical data model and the datasets that comprise each class identified in the conceptual data model. 
Table 4.1: Datasets comprised each class identified in the conceptual data model

\begin{tabular}{|c|c|c|}
\hline Conceptual Entity & Feature Class & Description \\
\hline City & City & $\begin{array}{l}\text { Contains boundaries of the cities within } \\
\text { the Coachella Valley obtained from the } \\
\text { Riverside county GIS Office with the } \\
\text { attributes of Name, Population, Median } \\
\text { Age, and Median Household Income. }\end{array}$ \\
\hline \multirow[t]{2}{*}{ Surveyed_Person } & Adult & $\begin{array}{l}\text { Health indicators, behaviors, and } \\
\text { disparities of surveyed person above the } \\
\text { age of } 18 \text { years. }\end{array}$ \\
\hline & Child & Surveyed Person below 18 years. \\
\hline \multirow{2}{*}{ Activity_Center } & City parks & $\begin{array}{l}\text { The outdoor locations for the hosting of } \\
\text { health related activities such as wellness } \\
\text { walks and health fairs. }\end{array}$ \\
\hline & $\begin{array}{l}\text { Community } \\
\text { centers }\end{array}$ & $\begin{array}{l}\text { Locations where members of the } \\
\text { community gather for indoor group } \\
\text { activities and social support. }\end{array}$ \\
\hline \multirow{3}{*}{ Program } & $\begin{array}{l}\text { Emergency food } \\
\text { distribution } \\
\text { programs }\end{array}$ & $\begin{array}{l}\text { Location of centers that provides food to } \\
\text { help improve the nutritional status of } \\
\text { children and needy adults. }\end{array}$ \\
\hline & $\begin{array}{l}\text { Public school } \\
\text { programs }\end{array}$ & $\begin{array}{l}\text { Location of programs that expands } \\
\text { education options in public elementary } \\
\text { and secondary schools. }\end{array}$ \\
\hline & Youth programs & $\begin{array}{l}\text { Location of programs that train youths } \\
\text { with the skills they need to successfully } \\
\text { make the transition to adulthood and } \\
\text { careers. }\end{array}$ \\
\hline \multirow{4}{*}{ Resource_Center } & $\begin{array}{l}\text { Healthcare } \\
\text { Facilities }\end{array}$ & $\begin{array}{l}\text { Location of medical facilities such as } \\
\text { clinics, doctor's offices, urgent } \\
\text { care centers, and hospitals. }\end{array}$ \\
\hline & Farmers market & $\begin{array}{l}\text { Locations where the farmers sell the } \\
\text { locally grown produces directly to the } \\
\text { residents of the Coachella Valley. }\end{array}$ \\
\hline & Grocery stores & $\begin{array}{l}\text { Locations of retail stores that sells food } \\
\text { and non-food items. }\end{array}$ \\
\hline & Shelters & $\begin{array}{l}\text { Location of homeless shelters and } \\
\text { shelters for women suffering from } \\
\text { domestic abuse. }\end{array}$ \\
\hline
\end{tabular}




\begin{tabular}{|l|l|l|}
\hline Conceptual Entity & Feature Class & \multicolumn{1}{c|}{ Description } \\
\hline & Libraries & $\begin{array}{l}\text { Location of information resources made } \\
\text { available to members the communities. }\end{array}$ \\
\hline
\end{tabular}

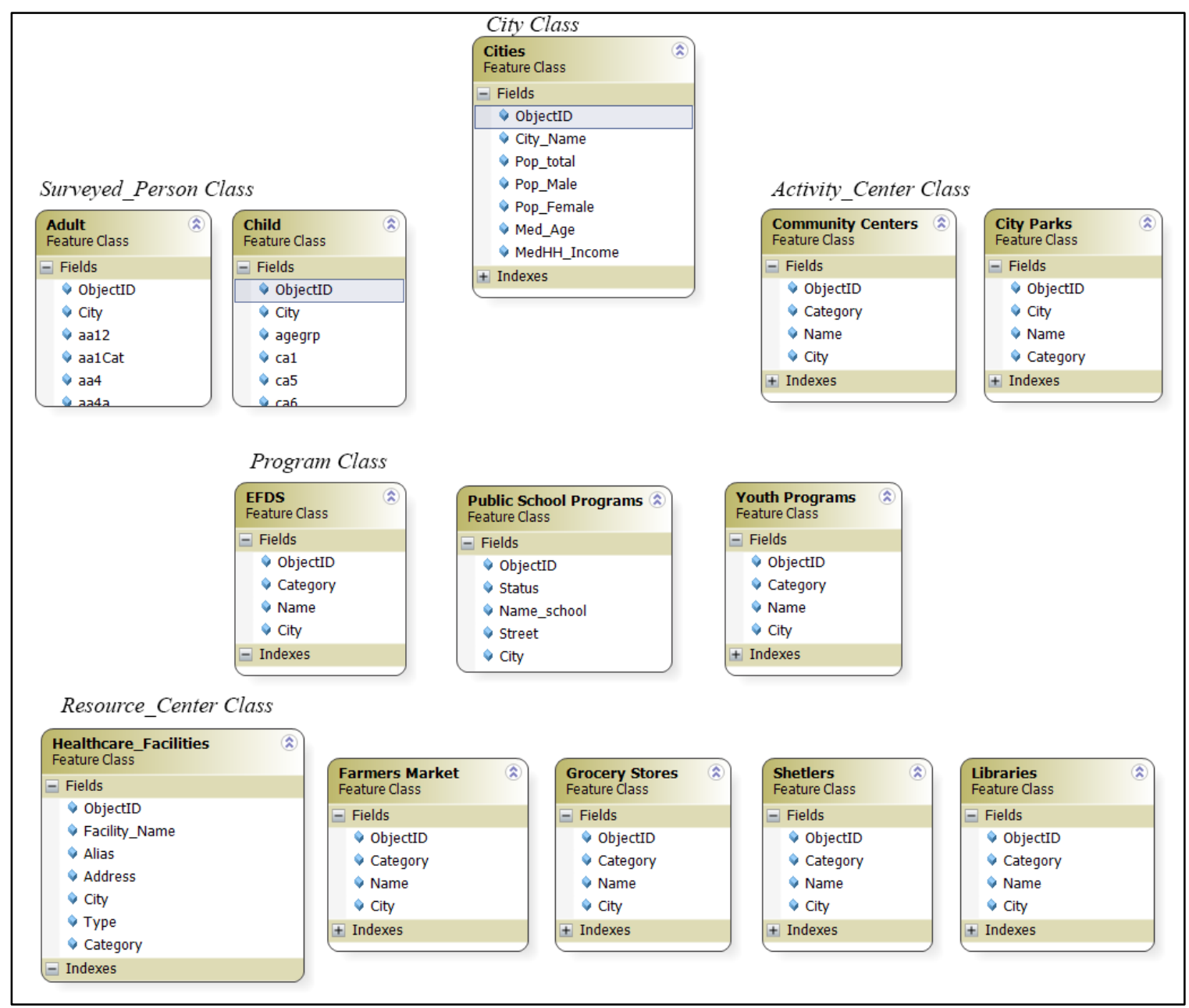

Figure 4.2: Logical data model

The Surveyed_Person class contained the 2007-2010 adult and child health datasets. These two entities were separated within the Surveyed_Person class since they comprised of different health indicators, behaviors, and disparities within the Coachella Valley. The Activities_Center class containes the point feature classes with the locations of city parks and community centers. The Program class includes the feature classes with the locations of the emergency food distribution programs, public school programs, and youth programs. The Resource_Center class comprises of the locations of healthcare facilities, farmers market, grocery stores, shelters, and libraries. The City class contains a polygon feature class of the cities of Coachella Valley received from the Riverside county GIS office with the attributes of name, population, median age, and median household 
income. In addition, the geodatabase contains the cleaned Microsoft Excel spreadsheets containing the client's health data.

\subsection{Data Sources}

Datasets for the project were obtained from different sources. The health datasets were provided by the client in two Microsoft Excel spreadsheets and two SPSS spreadsheets. The Excel spreadsheets contained the adult and child health indicators datasets collected for the period 2007 - 2010 while the SPSS spreadsheets contained the keys for the variables contained in the Excel files.

The Riverside County GIS office provided the datasets for the cities, health facilities, and health programs. The data used in determining the total population, populations of male and female, and median household incomes were obtained from the United States (US) Census Bureau.

\subsection{Data Scrubbing and Loading}

Extensive cleaning and preparation of the data were needed before loading them into the geodatabase. The health datasets provided by the client had a range of values that were very difficult to understand. The client required a new format of representing the surveyed responses and after several meetings, it was decided to re-categorize and generate unique codes for each surveyed response. Those unique codes were used throughout the datasets with approval of the client. The process of generating these codes was done using Microsoft Excel.

The transformation of the datasets provided by the client can be observed in tables 4.2 and 4.3. Table 4.2 shows a sample of the values and their unique codes along with the domain they belong. The original datasets provided by the client, one variable value could have different significances within the same dataset. With the recoding done, these values ranged from one (1) to ninety-nine (99) with each value representing a surveyed response. Table 4.3 shows a sample of the re-organized client's data. The received dataset columns contained names such as ae18, ae6, af19cNew, af19gDich, etc. This nomenclature only made sense to the client. These columns were grouped into classes and aliases were created for public use. 
Table 4.2: Sample of the recoded values (Complete table in Appendix A)

\begin{tabular}{|l|l|r|}
\hline \multirow{2}{*}{ Group Name } & \multicolumn{1}{|c|}{ Domain } & Attribute \\
\hline \multirow{3}{*}{ Boolean } & Yes & 1 \\
\cline { 2 - 3 } & No & 2 \\
\hline \multirow{5}{*}{ Poverty } & $0 \%-100 \%$ & 3 \\
\cline { 2 - 3 } & $101 \%-200 \%$ & 4 \\
\cline { 2 - 3 } & $201 \%-250 \%$ & 5 \\
\cline { 2 - 3 } & $251 \%-300 \%$ & 6 \\
\cline { 2 - 3 } & $>300 \%$ & 7 \\
\hline \multirow{5}{*}{ Age } & $0-5$ yrs. & 8 \\
\cline { 2 - 3 } & $6-11$ yrs. & 10 \\
\cline { 2 - 3 } & $12-17$ yrs. & 11 \\
\hline \multirow{5}{*}{ Rank } & Excellent & 12 \\
\cline { 2 - 3 } & Very Good & 13 \\
\cline { 2 - 3 } & Good & 14 \\
\cline { 2 - 3 } & Fair & 9 \\
\hline
\end{tabular}

Table 4.3: Sample of the recoded column aliases (Complete table in Appendix A)

\begin{tabular}{|c|c|c|}
\hline Group & Field Name & Field Aliases \\
\hline \multirow{5}{*}{ Health Behavior (HB) } & ae18 & HB_HIV/AIDS testing \\
\hline & ae6 & HB_Condom Use \\
\hline & af $19 \mathrm{cNew}$ & HB_Smoking \\
\hline & af19gDich & HB_Binge Drinking \\
\hline & af19hDich & HB_Drunk Driving \\
\hline \multirow{4}{*}{ Healthcare Coverage (HC) } & aa12 & HC_Prescription Coverage \\
\hline & aa4 & HC_Insurance \\
\hline & aa4a & $\begin{array}{l}\mathrm{HC}_{-} \text {No insurance in last } 12 \\
\text { months }\end{array}$ \\
\hline & aa8 & HC_Dental Coverage \\
\hline
\end{tabular}


The recoded datasets, in addition to those received from the Riverside County GIS office, were then loaded into the geodatabase. During the loading process the field types and lengths were set and the fields not required were excluded.

After the successful loading of the data into the geodatabase, the health datasets were then geocoded by cities. Finally, coded value domains were created and assigned to the fields.

\subsection{Summary}

This chapter describes the database design, data model, and data that were required for this project. The chapter began with a presentation of the classes, attributes, and relationship of the data that represent the problem proposed in the form of a conceptual model. The logical model described the physical design and implementation of the database, with the representation of the entities and attributes. The chapter concluded with an explanation of the data sources and the procedures used for cleaning and loading the data into the geodatabase for the implementation of the project. 


\section{Chapter 5 - Implementation}

The implementation phase of this project consisted of the completion of a series of steps to satisfy the project and the client's requirements. A custom web mapping application was developed for HARC which allows the client and their data users to query, view, and print health indicators, behaviors, and disparities for the Coachella Valley.

This chapter explains how the project was implemented and is organized into three sections. Section 5.1 examines the database development. Section 5.2 describes the web application development. It explains the preparation process of the map documents and the publishing of web services. Section 5.3 gives a summary of the chapter.

\subsection{Database Development}

Database development was the first step in the implementation of the project. An Esri File Geodatabase was used to store the spatial and non-spatial data for the project. It was designed and built using the principles of relational database management system, taking its advantages in storing, querying, manipulating, and managing of geospatial data. The database schema was developed using ArcGIS Diagrammer 10.1, a visual and productivity tool to create, edit, and analyze geodatabase schema. Figure 5.1 shows an outline of the geodatabase schema.

\begin{tabular}{|c|}
\hline 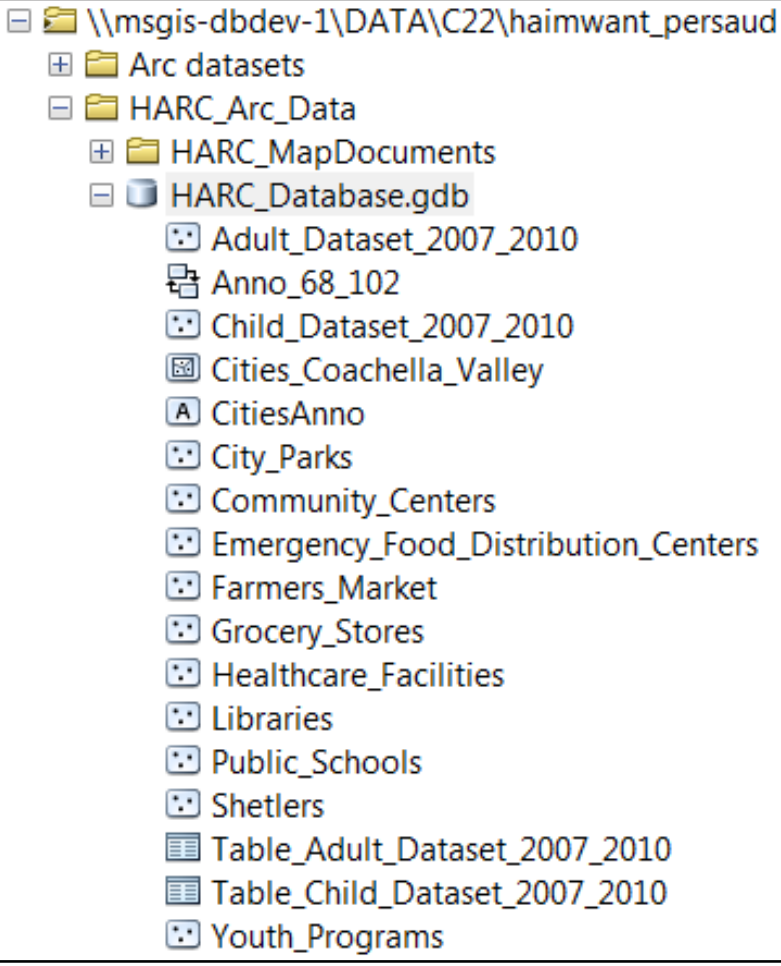 \\
\hline
\end{tabular}

Figure 5.1: Geodatabase schema 


\subsubsection{Data Loading and Geocoding}

The datasets received were recoded and re-ordered using Microsoft Excel; corrections were made to the coded values within the datasets and a grouping structure was created to organize the data. The tables were imported into the geodatabase using the Import Table to Table geoprocessing tool which converted the Microsoft Excel spreadsheets into geodatabase tables. During the import process the data were standardized and field aliases and types were assigned to enable easy understanding of the health variables. Figure 5.2 illustrates the workflow of importing the datasets into a geodatabase. The feature layers were imported using the Feature Class to Feature Class geoprocessing tool. During this process non-required fields were eliminated and the required fields were standardized. Imported layers were then projected into a WGS 1984 Web Mercator (Auxiliary Sphere) coordinate system to align with the basemaps from ArcGIS Online and to reduce the response time of the application.

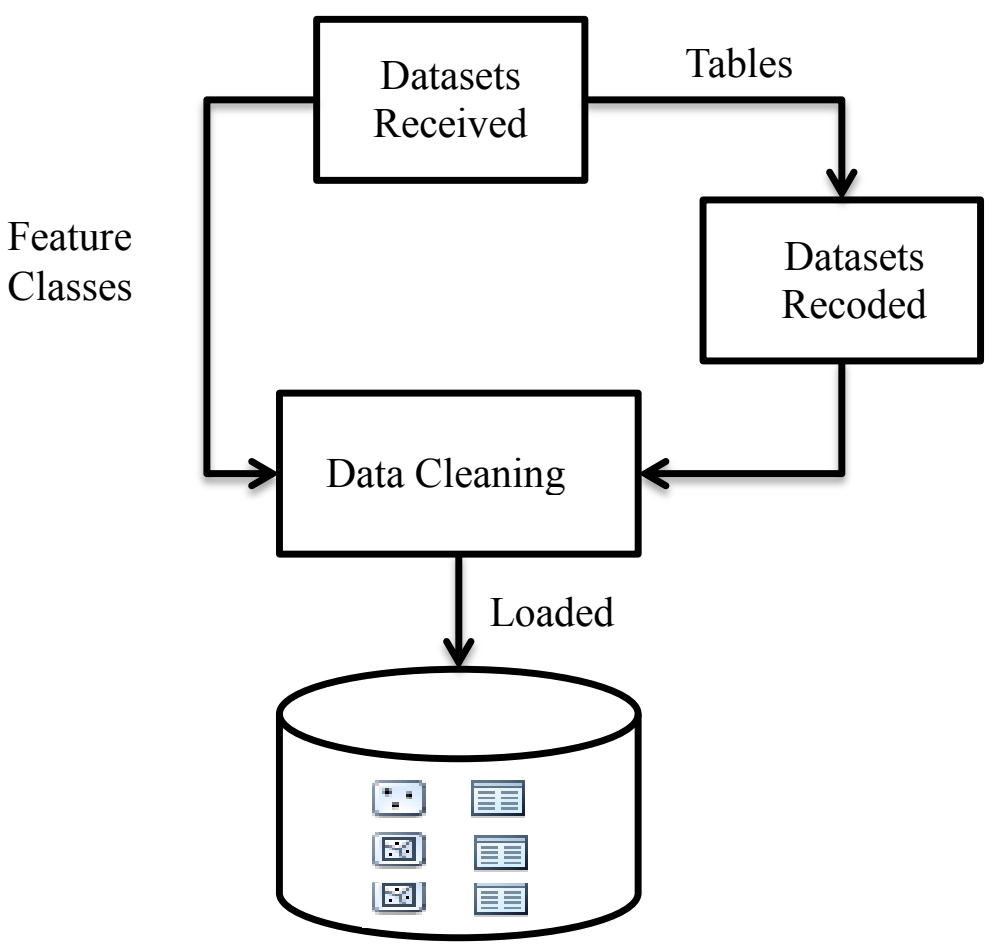

Figure 5.2: Data loading workflow

Once the data were in the geodatabase, the tables containing the health dataset, along with the health programs, facilities, activities, and health resources, were geocoded to generate geographic features with attributes, which were used for mapping and analysis. The geocoding process used an ArcGIS Online, 10.0 North American Address Locator. Figure 5.3 illustrates the workflow and specifications used in geocoding the data. 


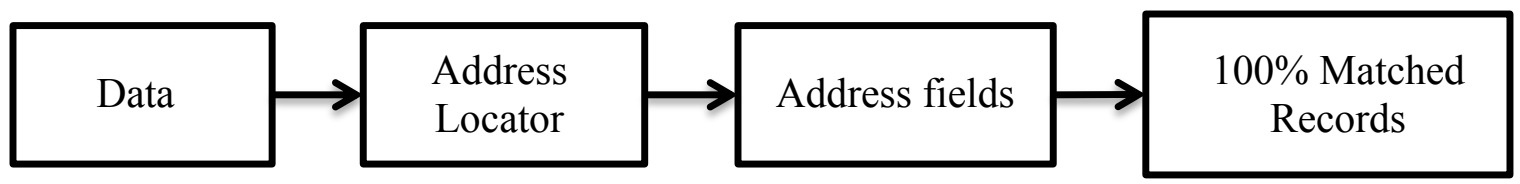

Figure 5.3: Geocoding workflow

\subsubsection{Domain Creation}

To maintain data integrity and reduce data entry errors, 23 coded value domains were created at the geodatabase level and applied to the respective fields of the feature classes and tables within the geodatabase. This enforced that only the values specified for a domain could be entered to the related field. For example, a Boolean domain contains three coded values 1, 2, and 99 with the descriptions of Yes, No, and No-Data respectively; this ensured that only these values can be entered into this type of fields. Figure 5.4 shows the coded value domains using the ArcGIS Diagrammer.

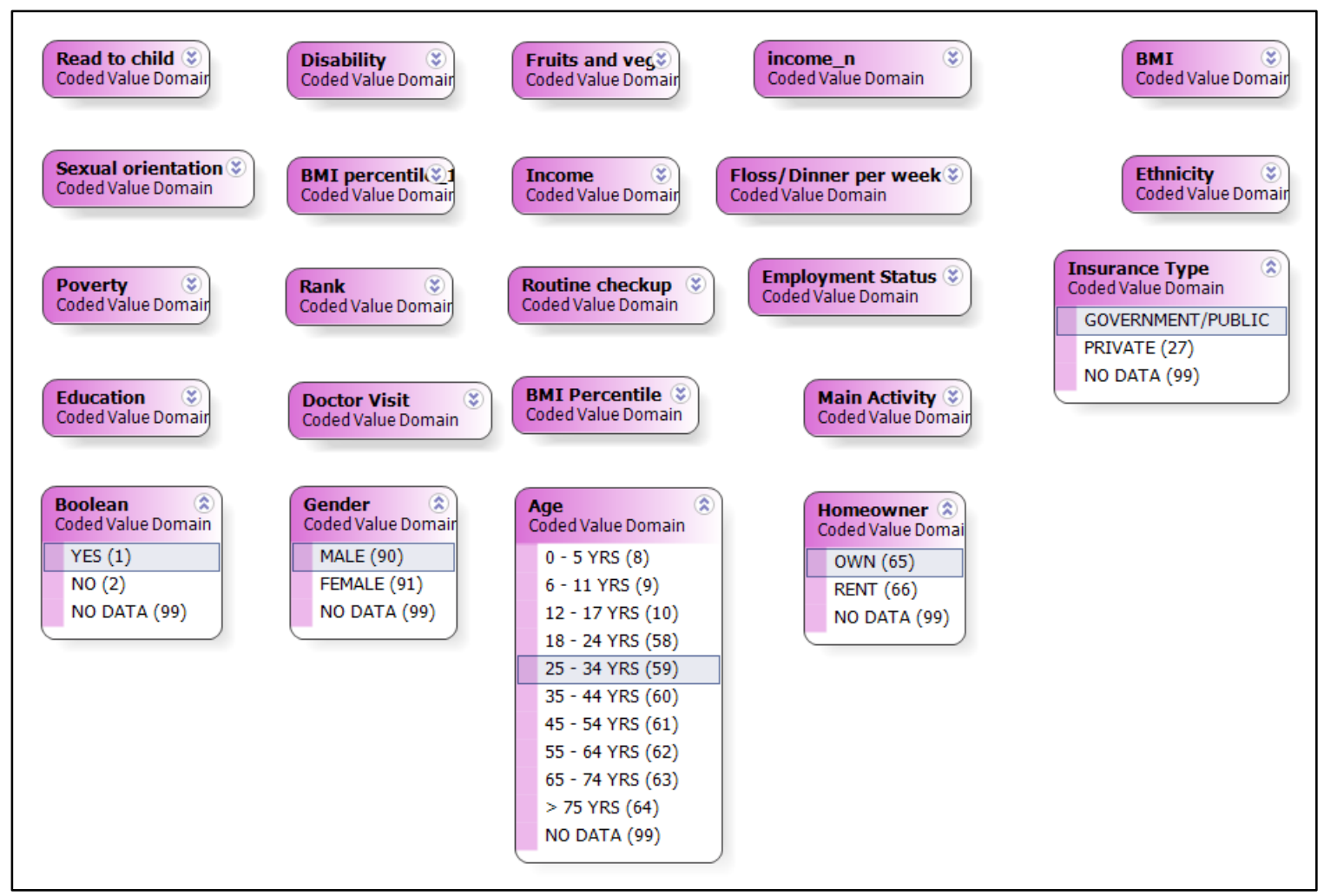

Figure 5.4: Coded value domains

\subsection{Web Application Development}

The main focus of this project was to develop an effective and efficient means of delivering HARC's data to their data users and potential health program donors. A Flex framework was chosen to develop an interactive Rich Internet Application (RIA), with dynamic updates, background data loading, and rich data visualization and controls. This 
section describes on the workflow that were followed in the creation of the web application.

\subsubsection{Preparation of Map Documents}

Once the geodatabase was completed, map documents were prepared and published to a GIS server. ArcGIS Desktop 10.1 was used to create, edit, and manage the map document. It was essential for defining the format, symbology, projection and coordinate system, and the visible scales of feature layers displayed in the map document. Figure 5.5 shows the layers in the map document. Each layer represents different health data categories, such as Health Activities, Programs, Resources, and HARC's Health Datasets. 


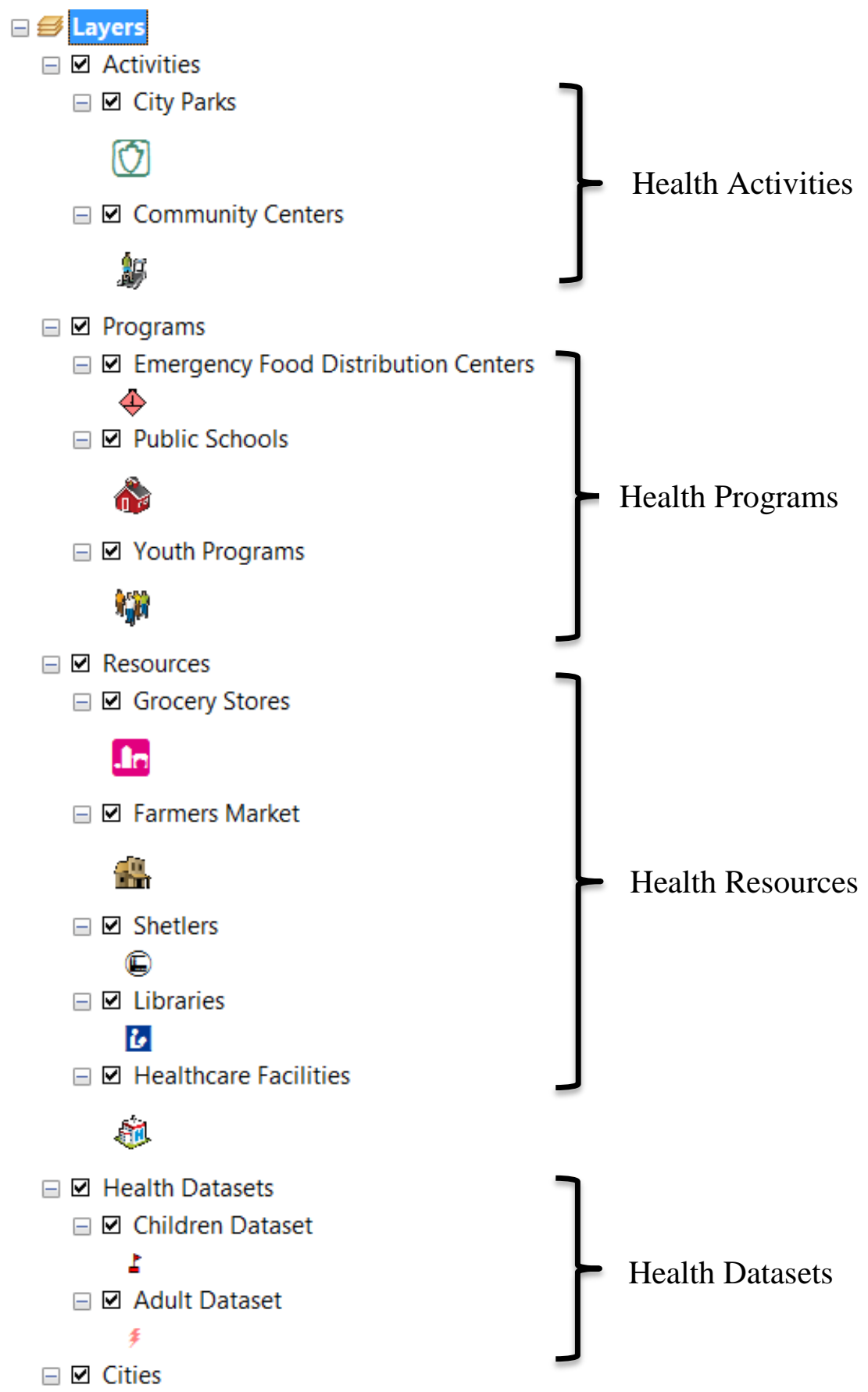

Figure 5.5: Map document layers

Figure 5.6 shows the layers for 10 cities in Coachella Valley. The minimum zooming scales for each layer were set at 1:1,000,000. Basemaps from Esri's ArcGIS Online were used to aid the alignment of the datasets, and to locate and identify features within the study area. Basemaps were then removed from the map document before publishing to the GIS server. 


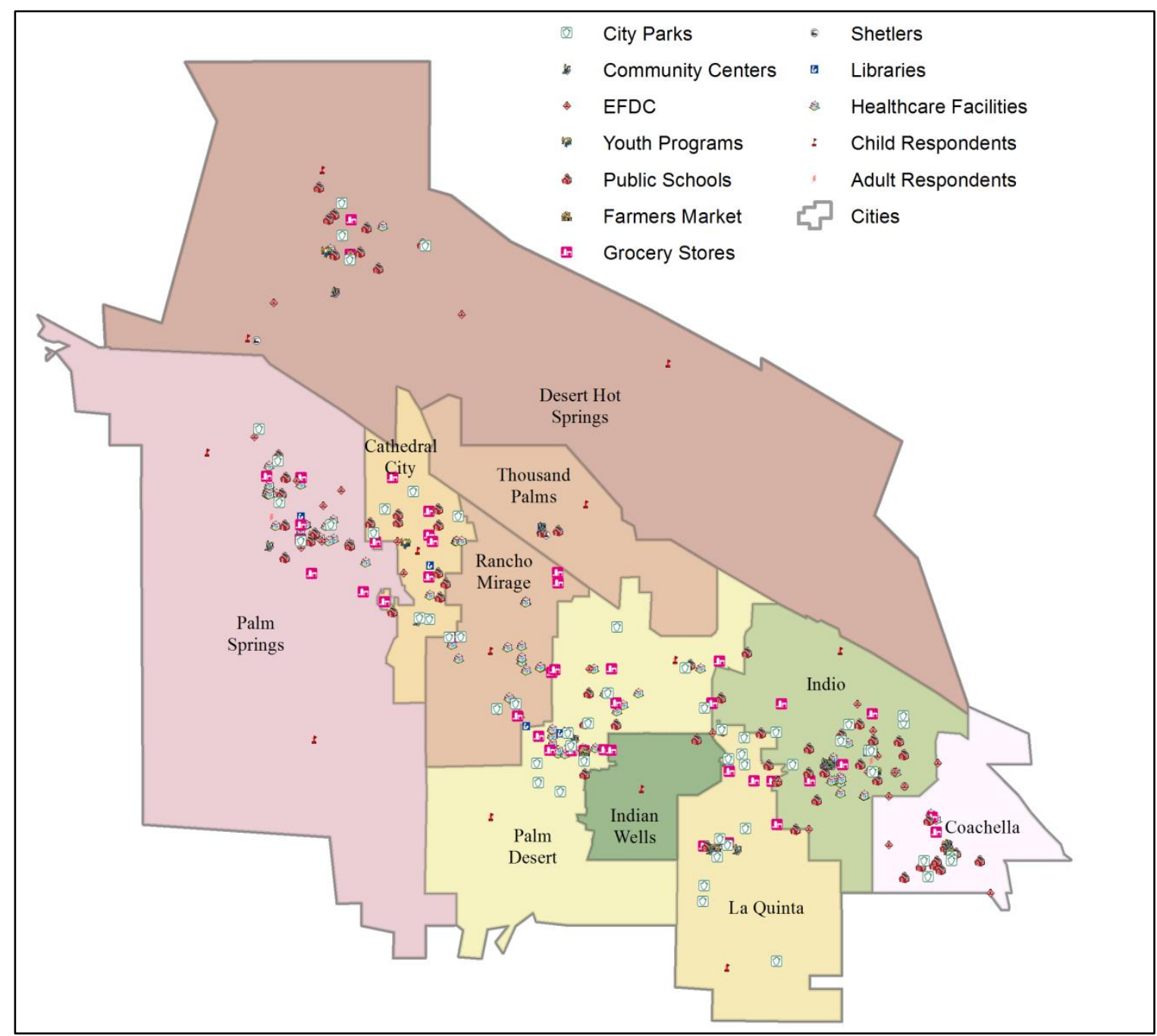

Figure 5.6: Map document with layers

\subsubsection{GIS Server Connection and Data Registration}

Before publishing the ArcGIS Map documents, connections to the GIS server and data registration were established. ArcCatalog 10.1 was used to establish the connection to the ArcGIS Server. This connection method enabled the previewing and error checking of the created map services.

The connection to the ArcGIS 10.1 for Server is simpler than previous versions and is preloaded into the ArcCatalog. When a user double clicks the Add ArcGIS Server tool, the Add ArcGIS Server dialog appears with the options of Use GIS services, Publish GIS services, or Administer GIS services. The option of Publish GIS services was chosen; and this led to the server specification where the Universal Resource Locator (URL), the host name of the ArcGIS Server instance, and publisher authentication, were specified. Once a successful connection was made, the server and the connection type were shown in ArcCatalog to facilitate the publishing of services. Figure 5.7 illustrates the workflow for the server connection. 


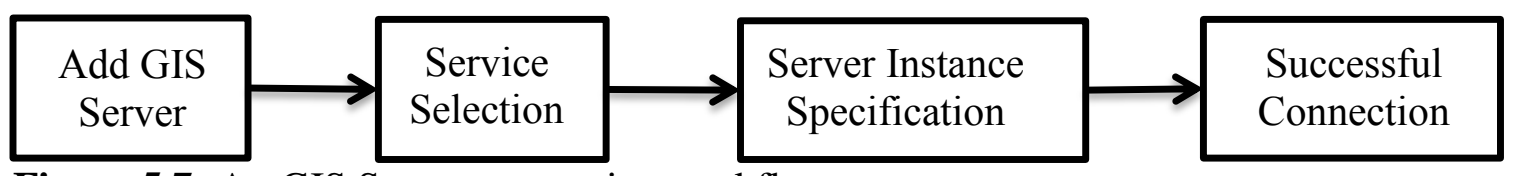

Figure 5.7: ArcGIS Server connection workflow

Data registration provided the ArcGIS Server the location to the data stored in the File geodatabase. This allowed the server to adjust the data paths when publishing, permit the validation of known and approved services by the server administrator, and prevent copying of large amounts of data onto the GIS server. Before registering the data, read permissions were granted to the server to access the data paths.

The registration of the data directories with the server was done via the Data Store, which is accessed through the ArcGIS Server. The File geodatabase was registered as a folder in the Register Folders dialog. Once this was completed, the data registration was validated and the registered File geodatabase appeared in the Registered Folders dialog box. The process used in registering the data is shown in Figure 5.8.

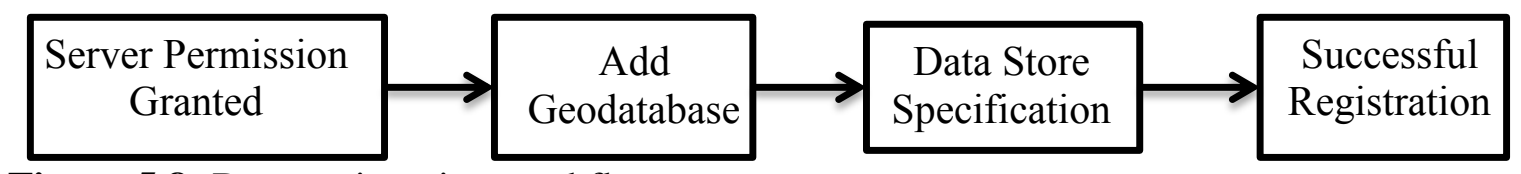

Figure 5.8: Data registration workflow

\subsubsection{Publishing of Services}

With the GIS server connection established and the data registered, the prepared map documents were then published to the server using the ArcMap desktop application. The map services provided the means by which the maps, features, and attributes are available within many types of client applications using ArcGIS. Figure 5.9 presents the workflow of publishing services using ArcGIS.

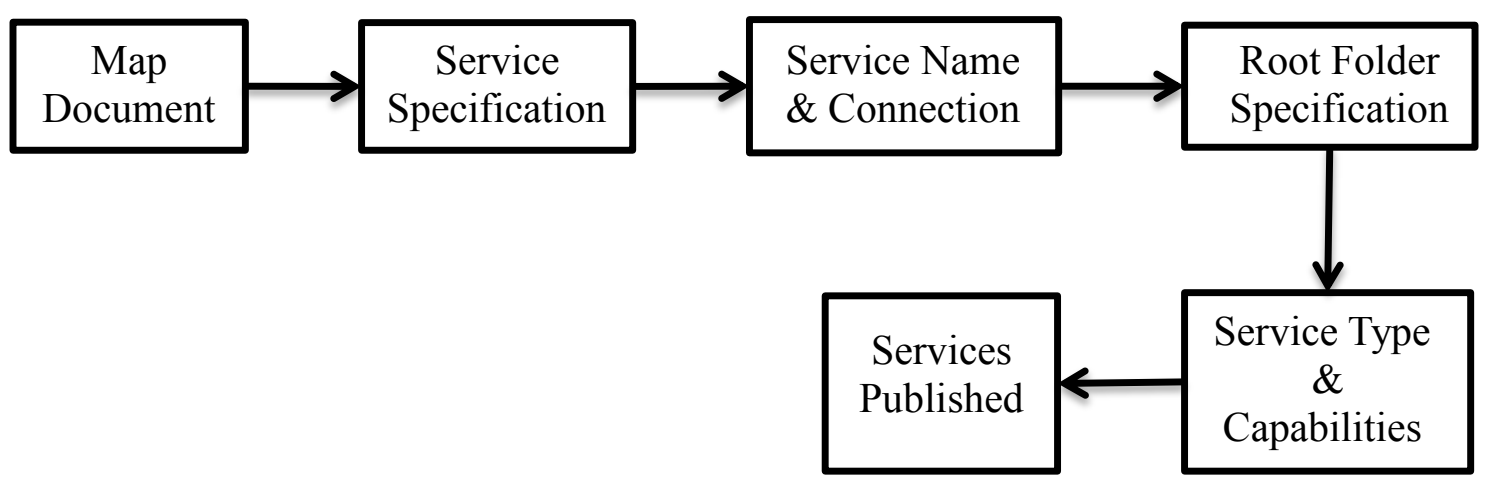

Figure 5.9: Publishing services workflow

Selecting Sharing as a service provided a series of dialogs from which Publish a service was selected and a server root folder was created to store the published services. During this process a service definition file was created and stored temporarily on the local disk. The services capabilities were set to Mapping and Keyhole Markup Language $(K M L)$ with the Mapping properties of URL, Data, Map, and Query. An analysis of the 
services was performed which identified the potential performance impediments and errors that needed to be addressed before the services could be published. Once all the identified issues were addressed, the services were published onto the GIS server and the service definition file was deleted from the local drive.

The ArcGIS REST (Representational State Transfer) Services Directory listed the services hosted by the ArcGIS Server. The hosted GIS resources facilitated the communication between the web application and the geodatabase and were accessed through a unique REST endpoint. Figure 5.10 shows the 16 published map services within the ArcGIS REST Services Directory.

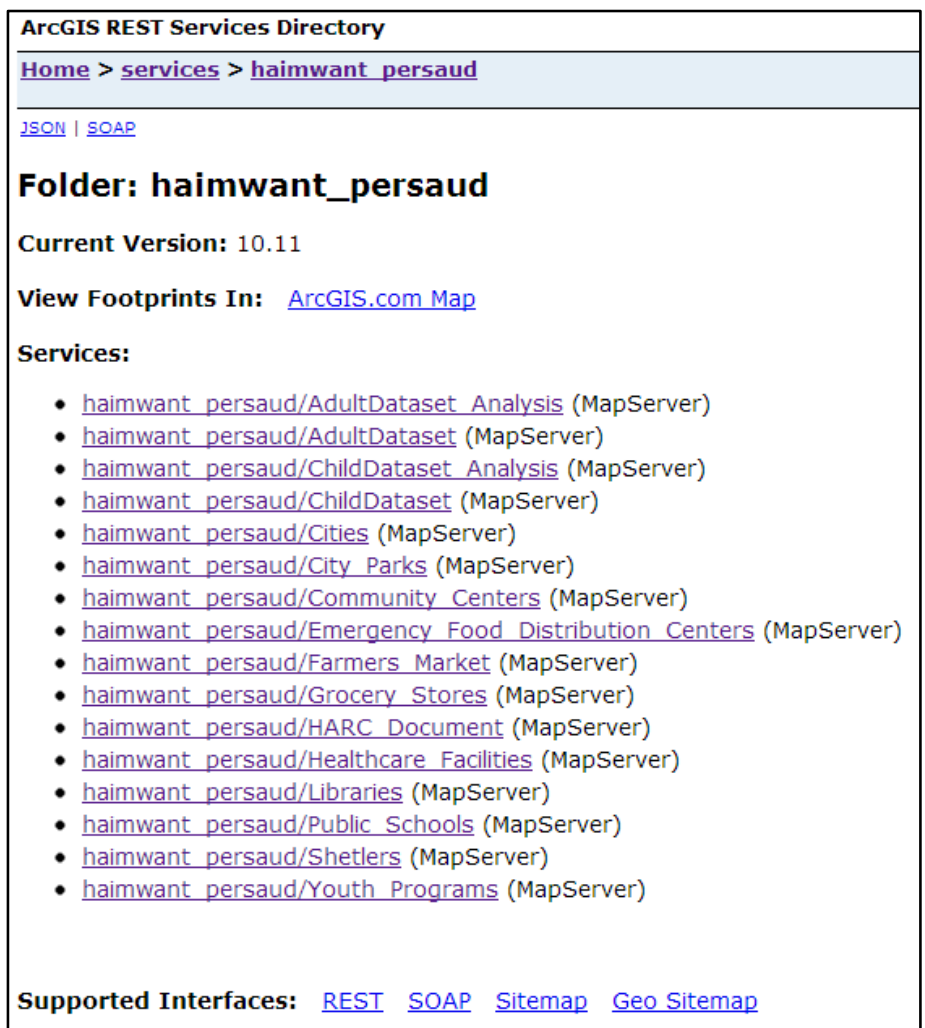

Figure 5.10: ArcGIS REST services directory

\subsubsection{Developing the Web Application}

The application was developed using the Flex framework which includes Adobe Flash Builder as the Integrated Development Environment (IDE), the Flex Software Development Kit (SDK) 4.6, and Esri's ArcGIS API for Flex 3.0. The Flex framework was chosen for its capability to develop interactive Rich Internet Application (RIA), with dynamic updates, background data loading, and rich data visualization and controls (Labriola, Tapper, \& Boles, 2012).

The web application component incorporates the map services that were used to show the map features on the client side. Since the application focused on the Coachella Valley, the initial extent of the map component was set to center at the Coachella Valley when the application is launched (Figure 5.11). 


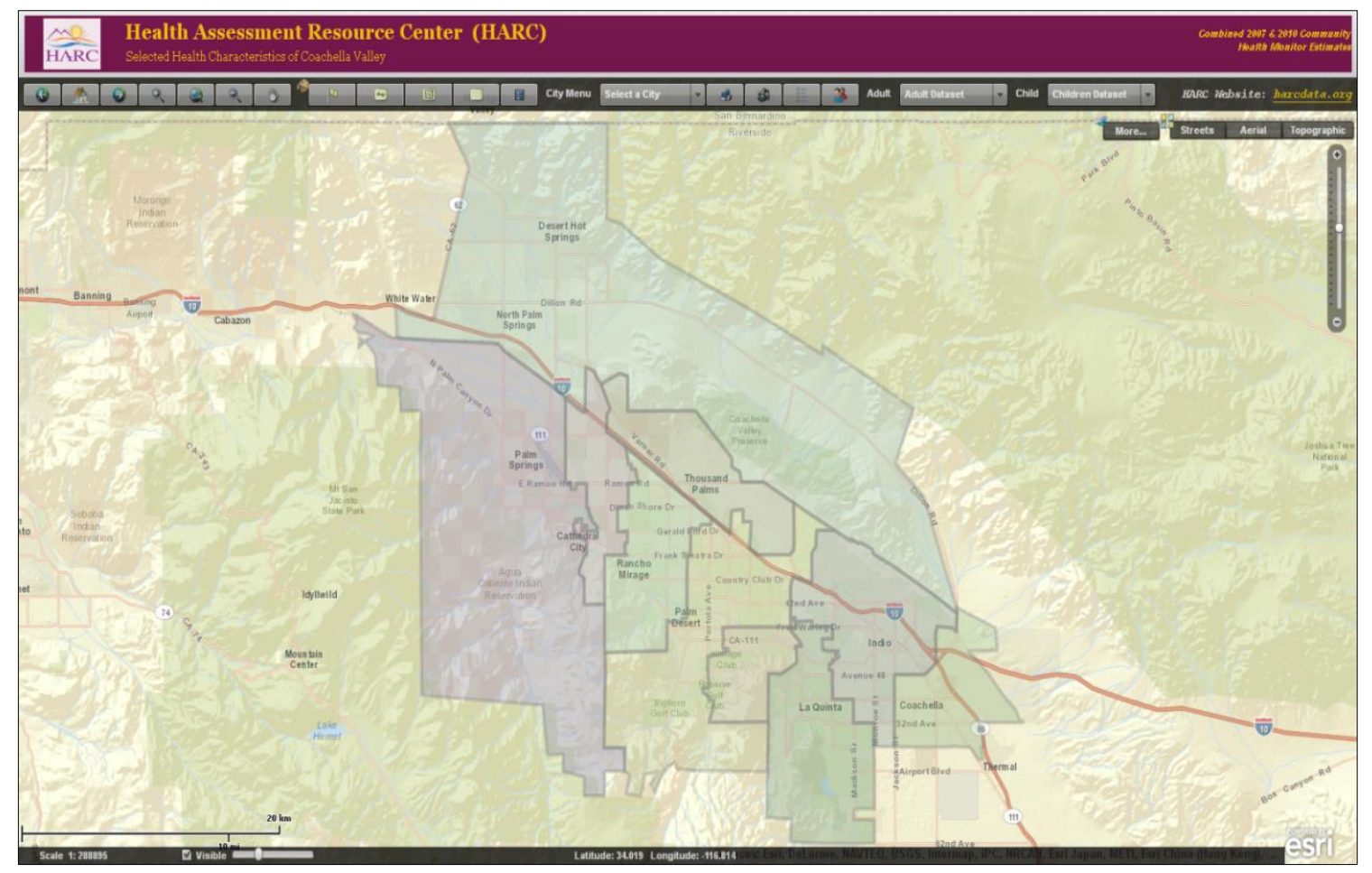

Figure 5.11: Application start-up interface

There were three types of map service layers consumed within the application, namely Graphic Layer, ArcGISTiledMapServiceLayer, and Feature Layer. The Graphic Layer allowed a user to dynamically display graphics on the application in the form of points, lines, and polygons. The graphics drawn are always displayed on top of all other layers in the map application and can be easily cleared. ArcGISTiledMapServiceLayer allowed the incorporation of three cached map services from ArcGIS Online to be used as basemaps within the application. These included the World Streets Map, the World Imagery, and the World Topo Map. The use of the Feature Layer enabled graphical information to be displayed more efficiently on the client's machine. These layers have three propriety modes. The Snapshot mode is used to retrieve all features at once; On demand mode is used to retrieve features that are within the viewing extent; and Selection mode is used to retrieve the selected features. Table 5.1 shows the Feature Layers that were used in the application. The Snapshot mode was used in this application for all feature services. 
Table 5.1 Feature layers used in the application

\begin{tabular}{|l|l|c|}
\hline \multicolumn{1}{|c|}{ Feature Layer } & \multicolumn{1}{c|}{ Usage } & Symbology \\
\hline cityLayer & $\begin{array}{l}\text { Shows the cities within the Coachella } \\
\text { Valley }\end{array}$ & $\begin{array}{l}\text { Shows the locations of farmers markets } \\
\text { within the Coachella Valley }\end{array}$ \\
\hline farmers Market & $\begin{array}{l}\text { Shows the locations of city parks within } \\
\text { the Coachella Valley }\end{array}$ & $\begin{array}{l}\text { Shows the locations of community } \\
\text { centers within the Coachella Valley }\end{array}$ \\
\hline cityParks & $\begin{array}{l}\text { Shows the locations of emergency food } \\
\text { distribution centers within the Coachella } \\
\text { Valley }\end{array}$ & \\
\hline communityCenters \\
emergencyFood
\end{tabular}

Creating and displaying the health data collected by HARC in form of graphs, charts, and maps in an effective and efficient manner was the goal of this project. This was achieved by developing Action Script Classes, XML files, data dictionaries, and array collections. Action Script Classes were created for the Adult and Child health datasets. XML files were created to store the Where Clauses that were used to retrieve data records from database, and data dictionaries and array collections were scripted to sort and store queried data. The sorted array collection then acted as the data provider for the graphs and charts.

To retrieve health data from the published services, Query and QueryTask components were used. The Query component was used to specify the parameters for QueryTask, such as selection statement and returned fields. The QueryTask component was used to execute queries based on the Query components and deliver the returned results. These were implemented using two radio button groups in this application, childDatasetGroup and adultDatasetGroup. The application communicates via an HTTP service to the Where Clauses stored in the XML files. Figure 5.12 presents a snapshot of the application showing the retrieved data presented in graphics. 


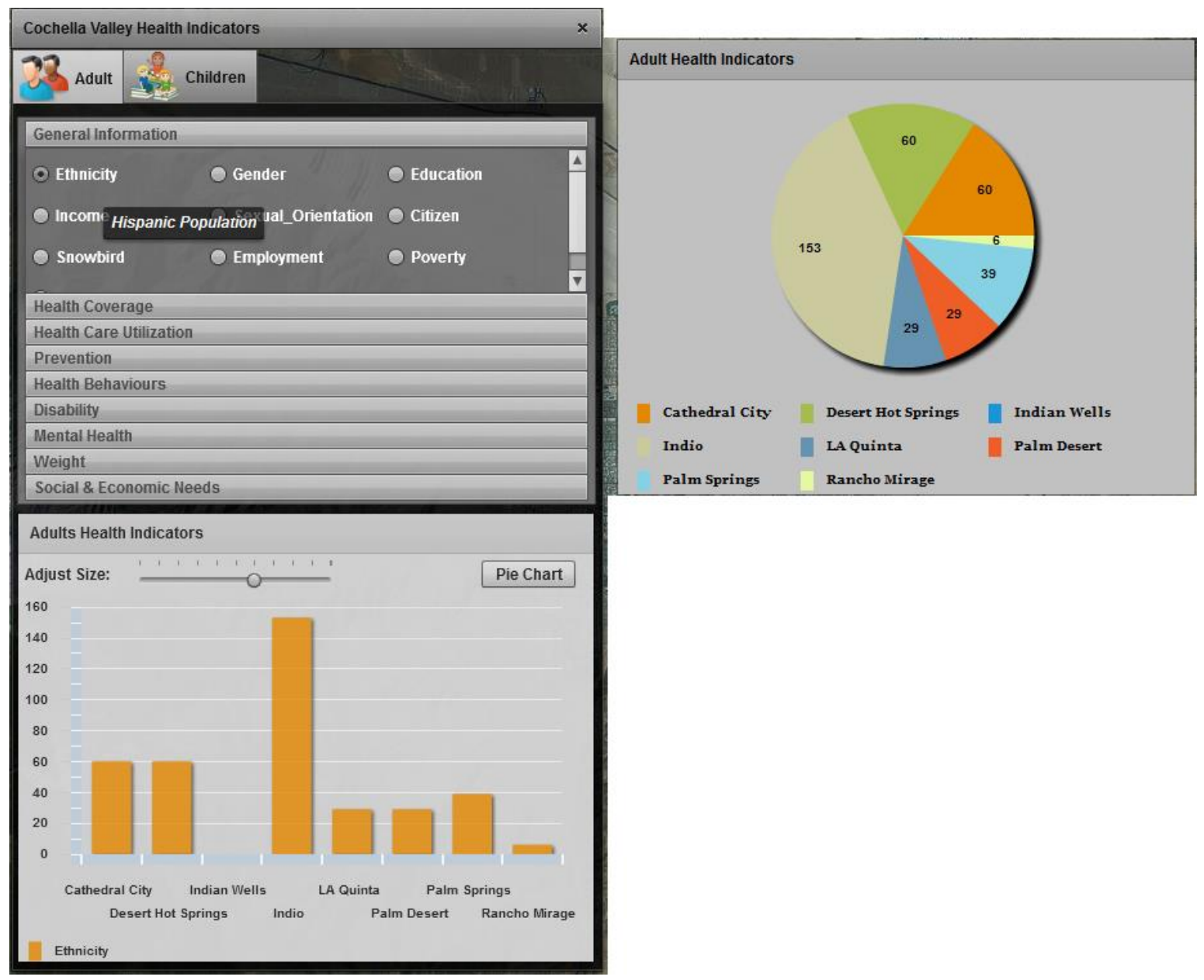

Figure 5.12: Queried data displayed

\subsection{Summary}

This chapter described the implementation of the project. Section 5.1 detailed the steps in the geodatabase development, which includes the processes of data loading, geocoding, and application development. Section 5.2 explained the application development from a general perspective and explained the processes of creating map documents, GIS server connections, data registration, publishing of services, and the application development in Flex. 


\section{Chapter 6 - Use Case}

The primary purpose of this project was to create an application to efficiently and effectively communicate data on health indicators, behaviors, and disparities in the Coachella valley. The application facilitated public health officials and community health organizations to easily visualize and understand the problems faced by the cities in the Coachella Valley, enabling better decision making and attracting potential donors for health programs. This chapter presents the use cases for the application. Section 6.1 describes the application's user interface; Section 6.2 demonstrates how HARC can query, display, and print adult health data for different cities of the Coachella valley; Section 6.3 presents how public health officials could use the children health data to attract potential donors for planed health programs; and Section 6.4 summarizes the chapter.

\subsection{User Interface}

The user interface was designed and organized based on clarity and consistency, by grouping related components together. Its design helped that the common tasks could be done easily. Figure 6.1 shows the application layout.

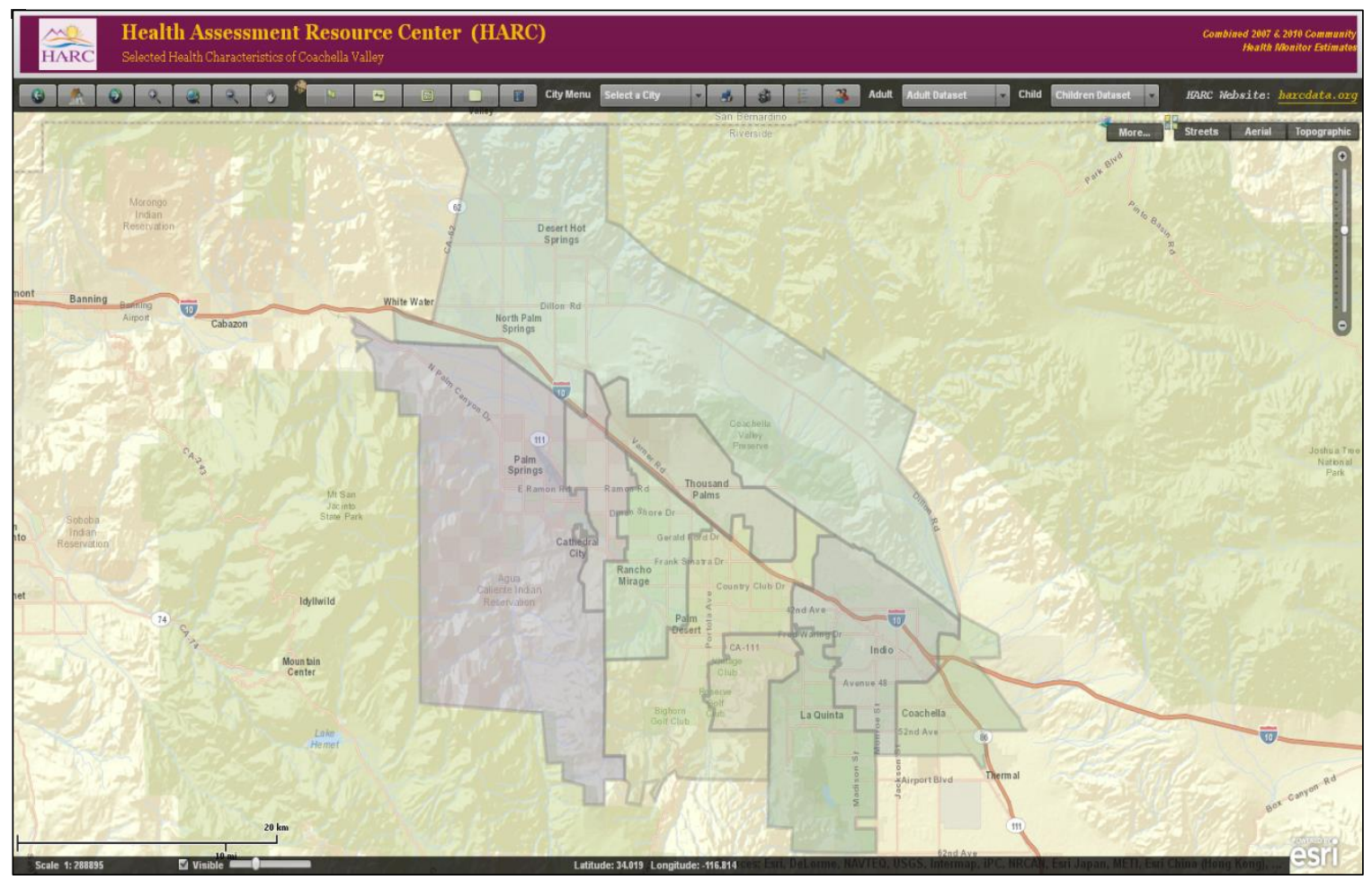

Figure 6.1: User interface

Figure 6.2 and Table 6.1 show the main toolbar and its content respectively. The toolbar provides users with the ability to navigate using basic navigation tools. It includes draw tools for adding and displaying graphics such as points, lines, and polygons of areas 
of interest. The remaining functionalities also includes tools to select and zoom to cities, print the maps created, snapshots of graphs, maps, and charts created (Figure 6.6), and activate the legend and health datasets widgets.

Figure 6.2: Main toolbar

Table 6.1: Contents on the main toolbar

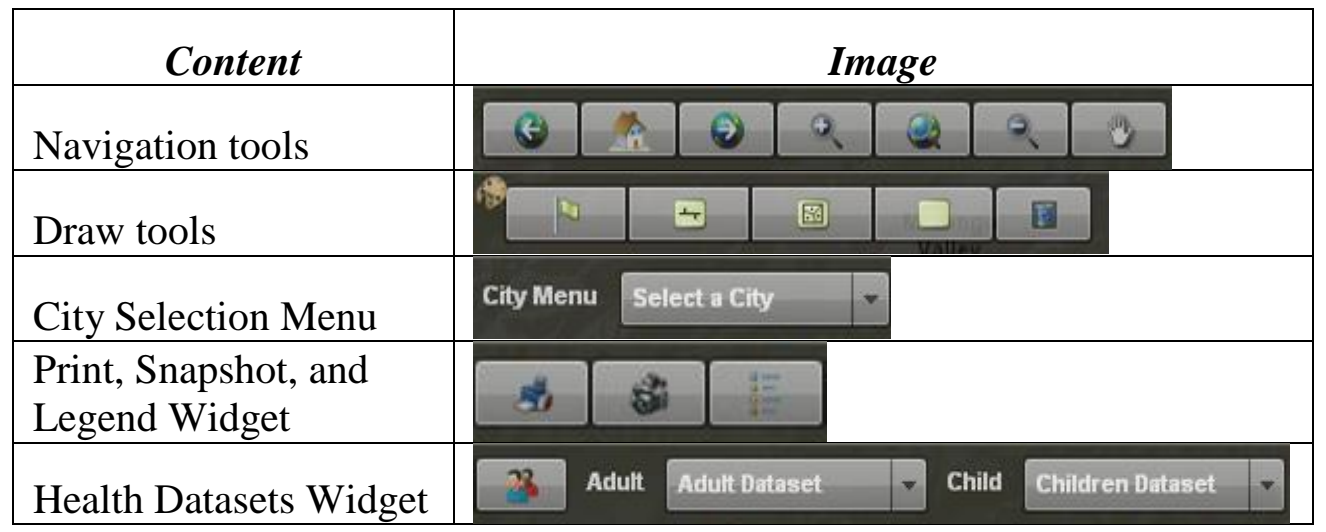

Figure 6.3 shows the base map toolbar used to toggle between base maps. The options are Streets, Imagery, and Topographic. It also includes a More button which activates the widget that contains the health Facilities, Programs, and Activities layers.

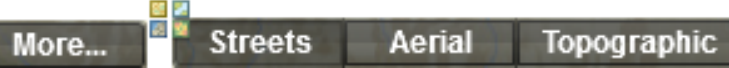

Figure 6.3: Basemaps toolbar

Figure 6.4 presents the tool bar at the bottom of the web page which gives users the ability to make layers visible or invisible, shows position of their cursor on the mapping application in Latitude and Longitude, and the scale at which the map is displayed.

\section{Scale 1: 288895 Q V Visible $\square-2$ Latitude: 34.040 Longitude: -116.916}

Figure 6.4: Bottom toolbar

\subsection{Adult Health Data}

The Coachella Valley Health Assessment Resource Center, is about to receive funding from the Medicare program to raise awareness on the importance and benefits of health insurance within the different cities of the Coachella Valley. They needed to know the distribution of health insurance coverage across the different cities to identify poor health coverage to begin their awareness program. A user would open the application and be presented with the main display showing the 10 cities of the Coachella Valley. Using the main toolbar, the user would then select the dropdown menu of city selection. Display tips guide the user through the operation and tools on the main toolbar. At the city 
dropdown menu, the user selects the city they are interested in and the application automatically zooms to that location, displaying a pop-up window showing the city Name, Population (Male and Female), Median Age and Median Household Income (Figure 6.5).

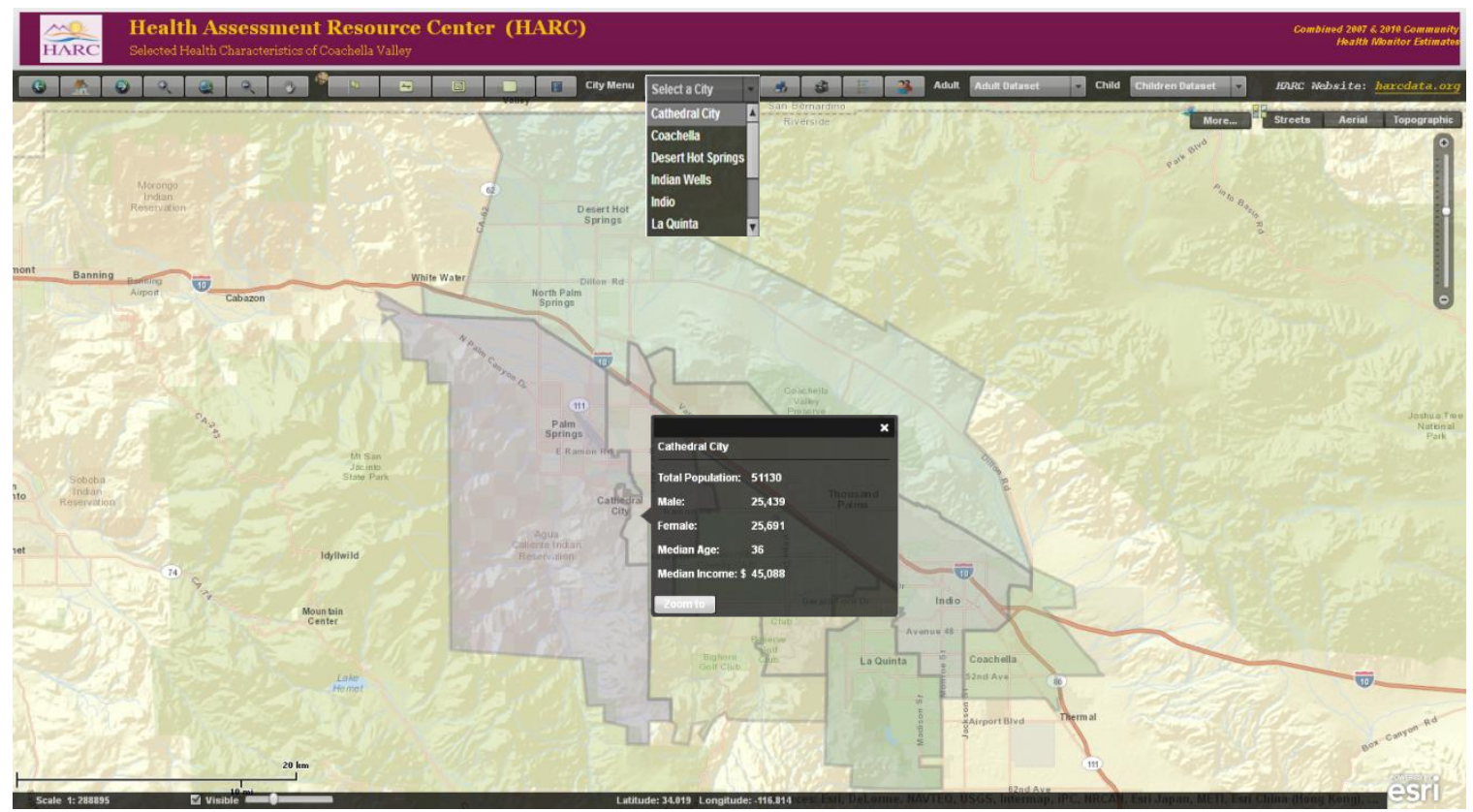

Figure 6.5: City selection

Next, the user would access the adult datasets menu, from the dropdown list selects No Health Insurance where "he or she" would observe the cities with excellent to poor health insurance coverage within the Coachella Valley (Figure 6.6). For additional statistics, the user would activate the Health datasets widget and select the Adult tab, group name Health Coverage. Next the user selects the radio button Health Insurance; this queries the database and retrieves information about individuals with no health insurance. The returned data would be displayed in the form of a histogram as well as in pie chart form. Display tips show the city, the percentage, and the number of individuals (Figure 6.7). 


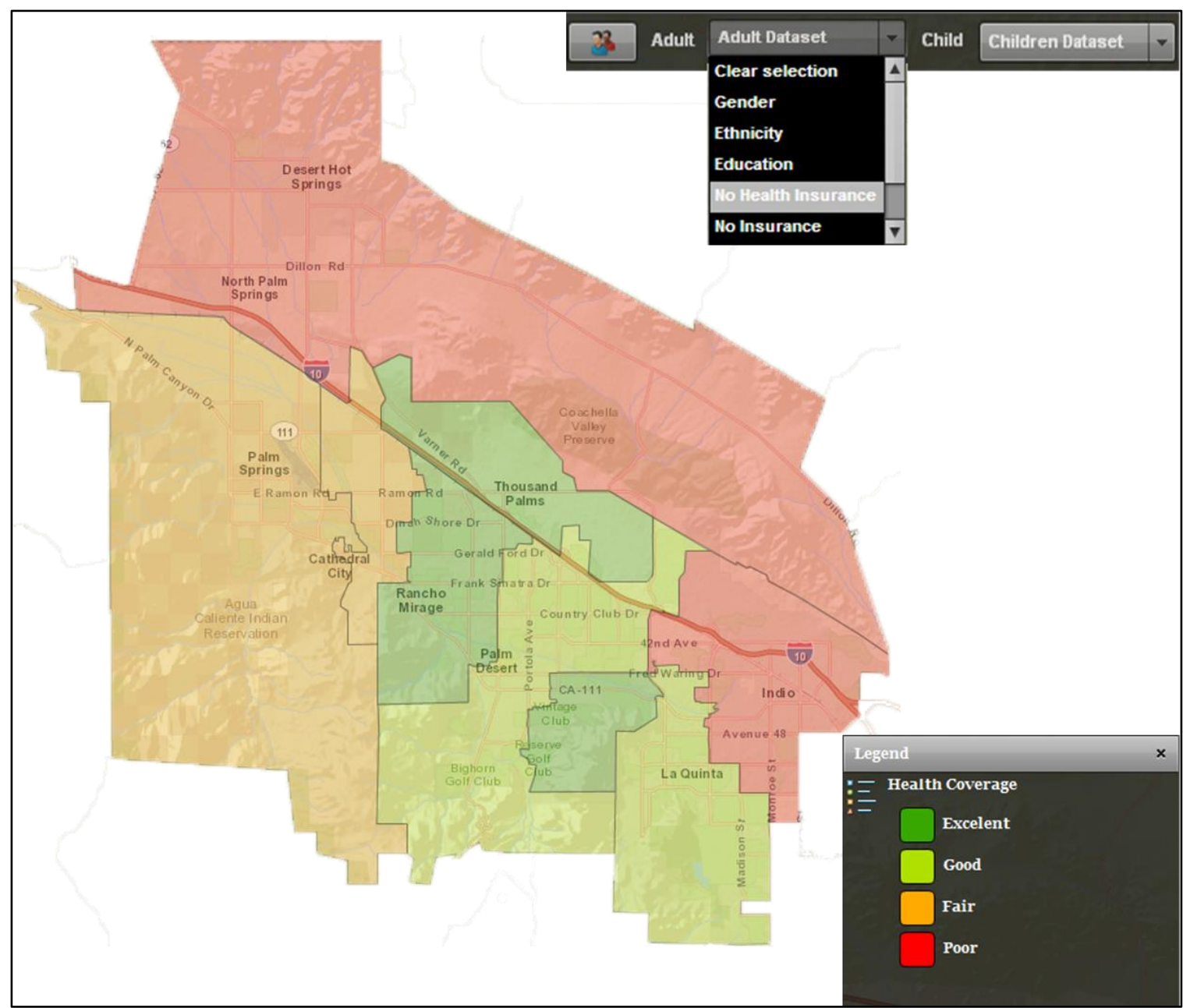

Figure 6.6: Health coverage results displayed 


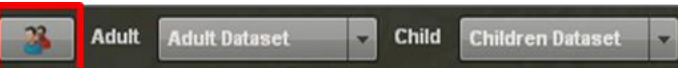

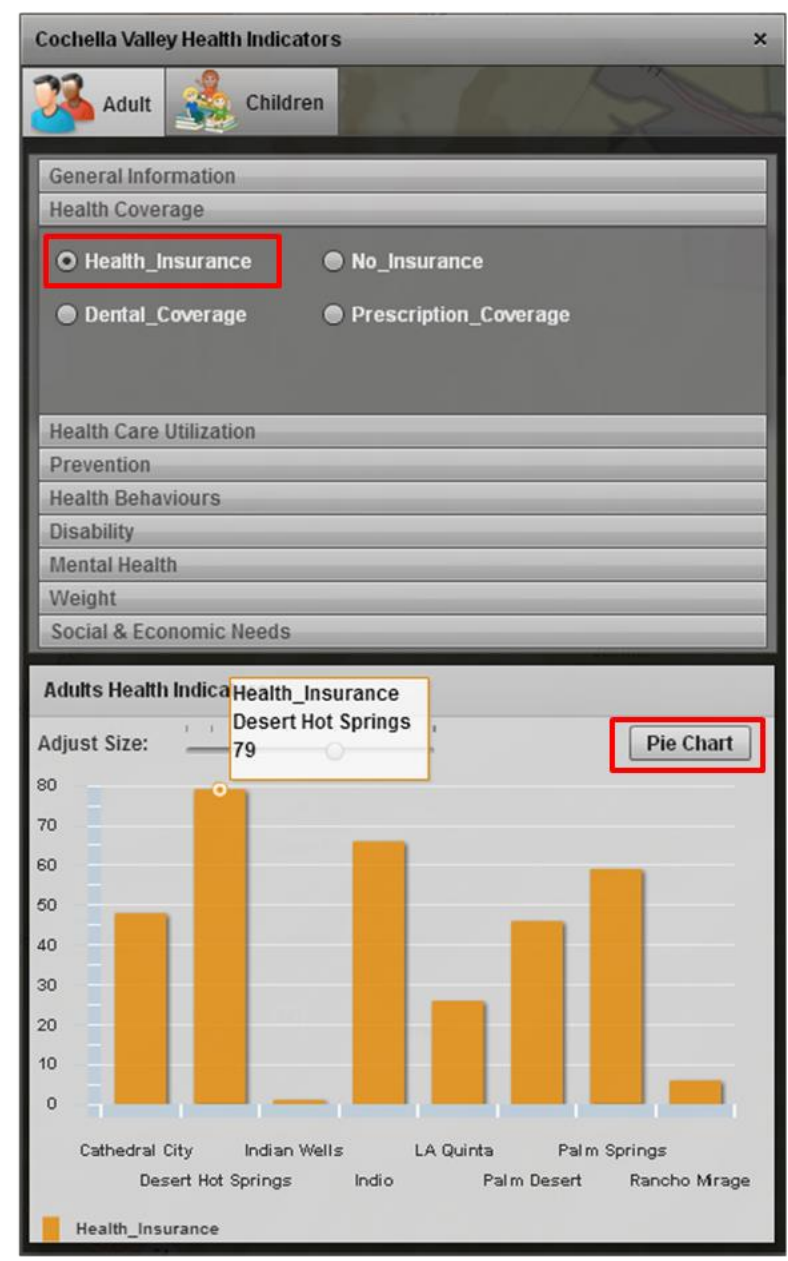

Figure 6.7: Queried data displayed

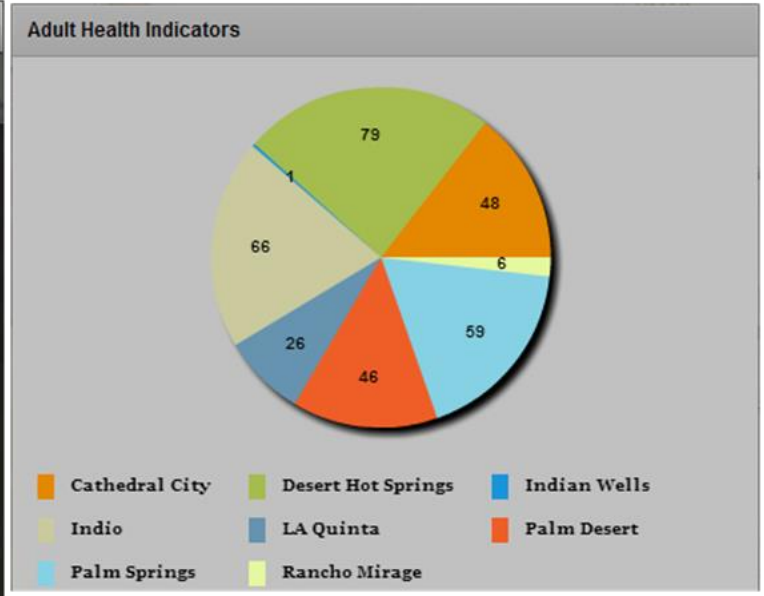
Rancho Mirage

Figure 6.8 illustrates the print widget, giving the user the capability to print the maps generated or export them to formats such as pdf, png, and emf, which could be used in reports and presentations.

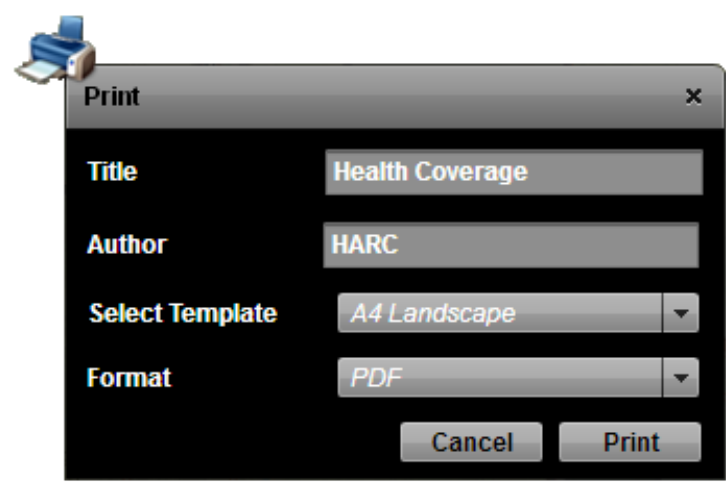

Figure 6.8: Printing and exporting maps generated 


\subsection{Children Health Data}

The public health department of the Coachella Valley needs to create awareness on Sexually Transmitted Infections (STI) and is seeking health information from the cities to present to potential donors for this awareness program. They decide to first target teenage girls within the different cities of the Coachella Valley and want to know the distribution and locations of community centers and public schools that they could use to hold these awareness sessions. A user starts the application and on the main tool bar selects the child dropdown menu and then selects Gender from the list of choices. The application now shows a percentage map of females among the cities of the Coachella Valley (Figure 6.9). The user then activates the health data display by clicking on health datasets widget, and then selects the Children Health data tab so "he or she" can retrieve the different groups of health indicators, behavior, and disparities regarding children (Figure 6.10).

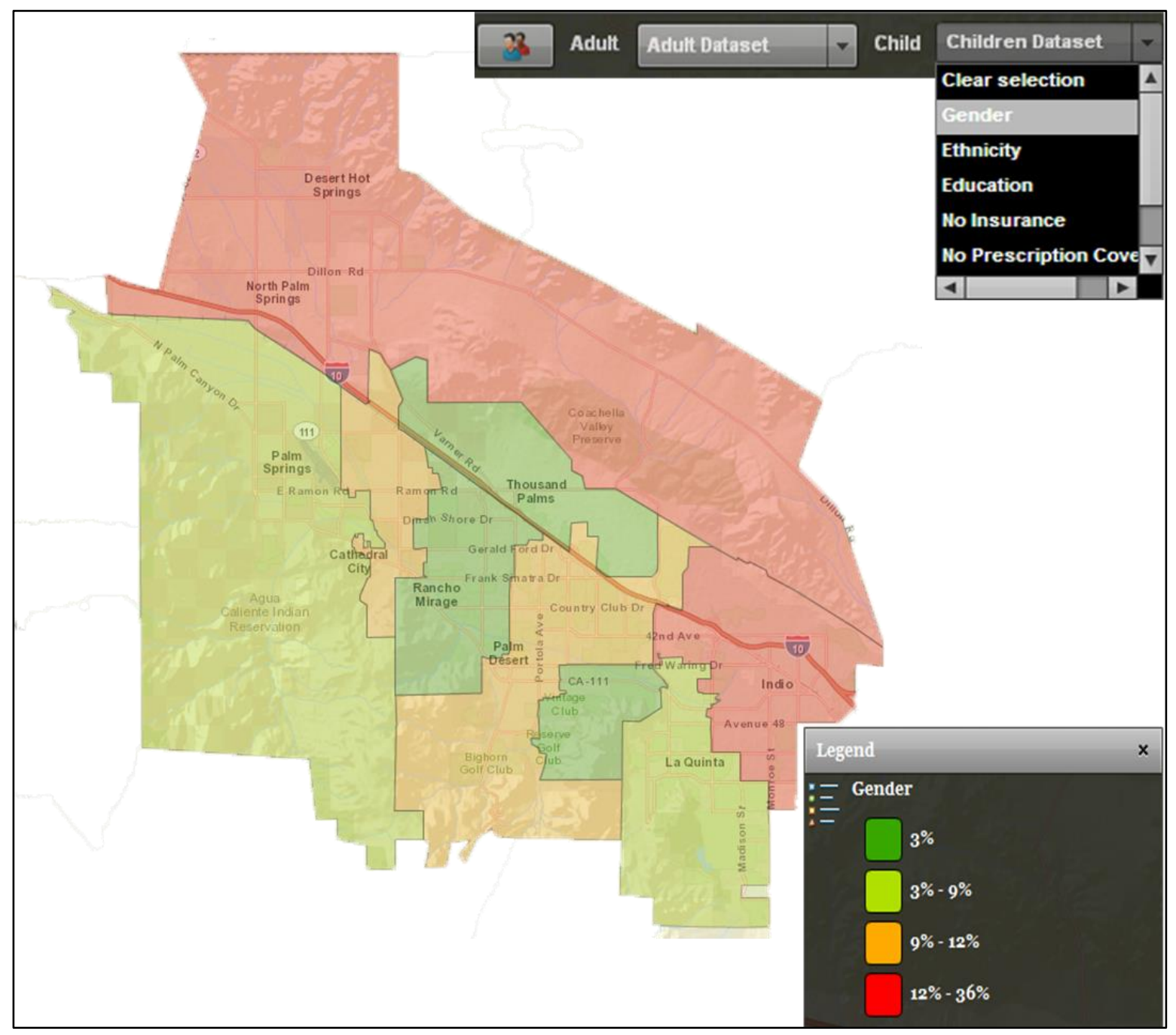

Figure 6.9: Distribution of female population 


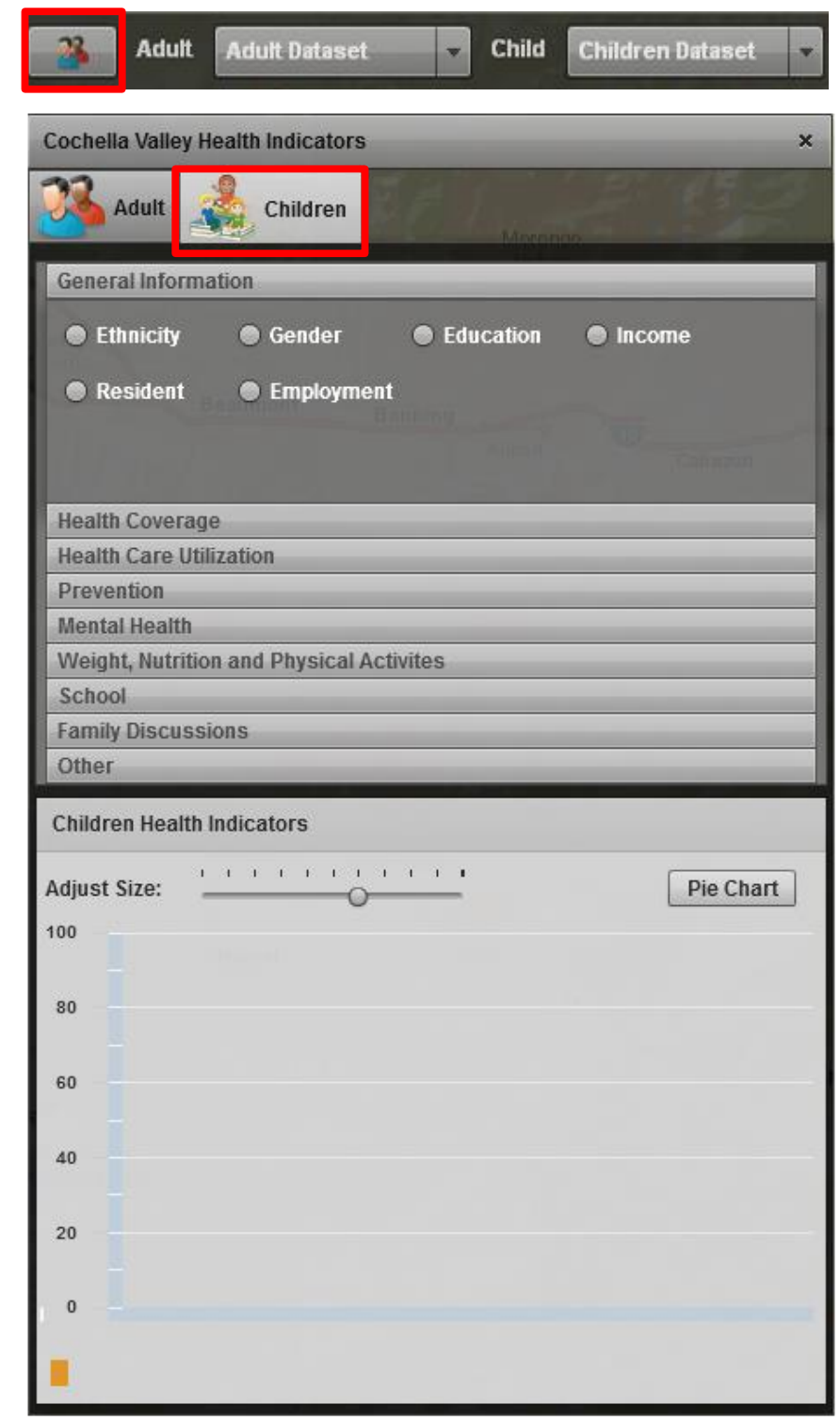

Figure 6.10: Children health data tab

After the user checks the Gender radio button in the General Information group, a query is generated to retrieve related information which is used to generate charts and graphs for visualization (Figure 6.11). 


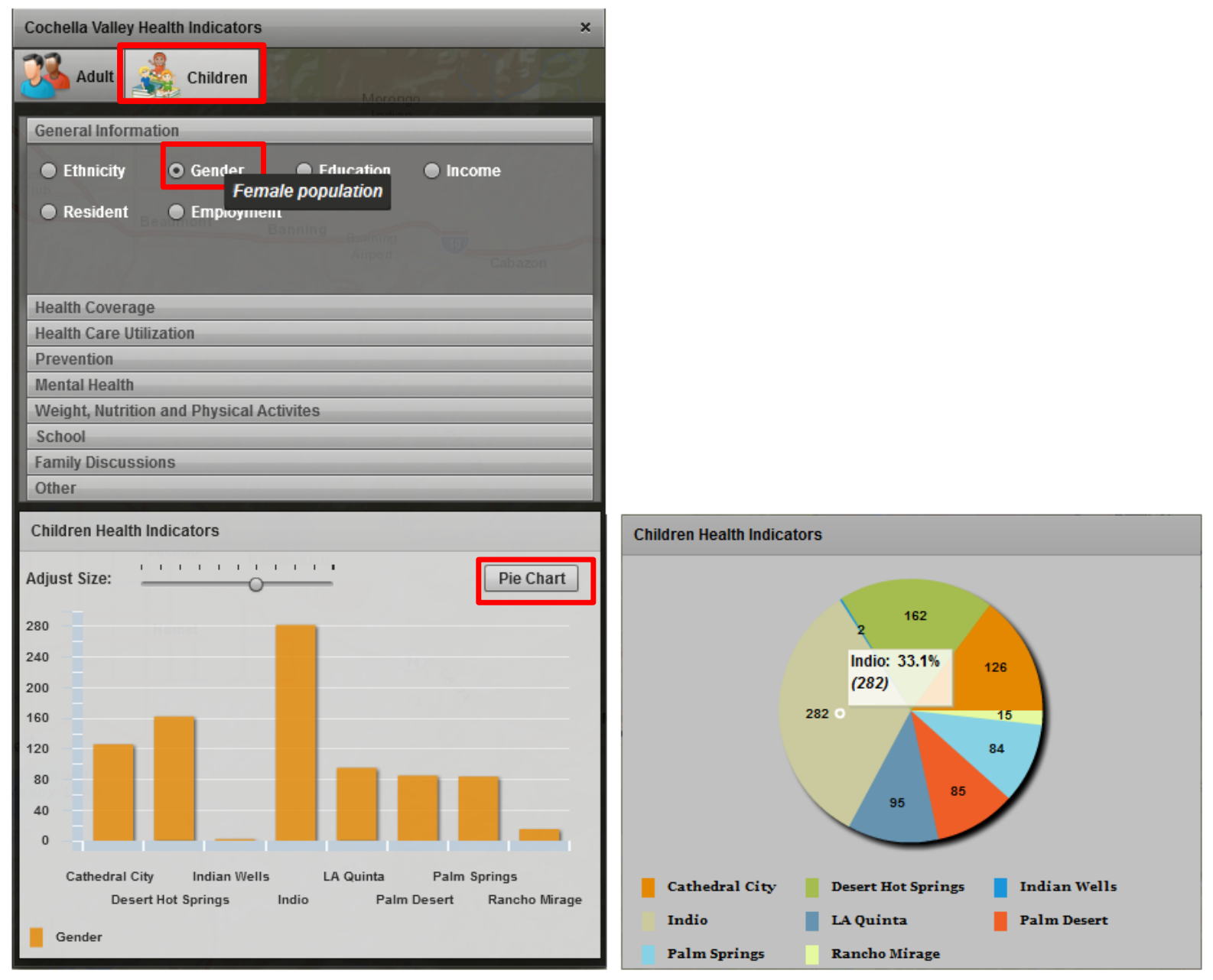

Figure 6.11: Results on gender query

Using the basemaps toolbar, the user selects More to access the health facilities, programs, and activities layers widget (Figure 6.12). The user then checks the boxes next to the Community Centers and the Public Schools, and these layers are displayed on the map. 


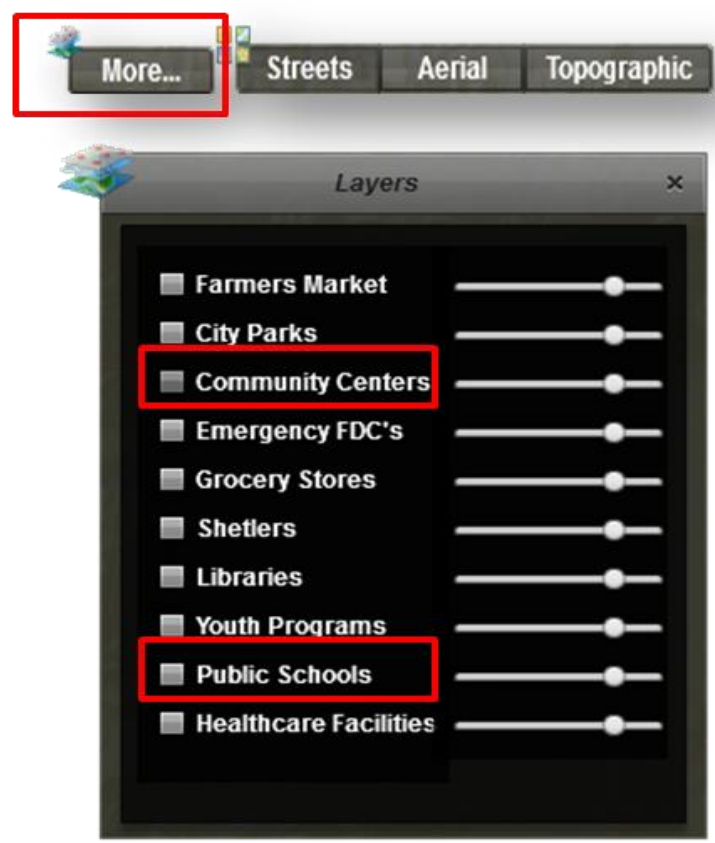

Figure 6.12: Selecting layers

After analyzing the maps, charts, and graphs, the user concludes that the cities of Indio and Desert Hot Springs are ideal places to start the awareness program. Using the draw tools, the user would places a point next to the facility in which these program secessions would be conducted (Figure 6.13). The user then prints and exports the resulted map for presentation to their potential donors of the awareness programs. 


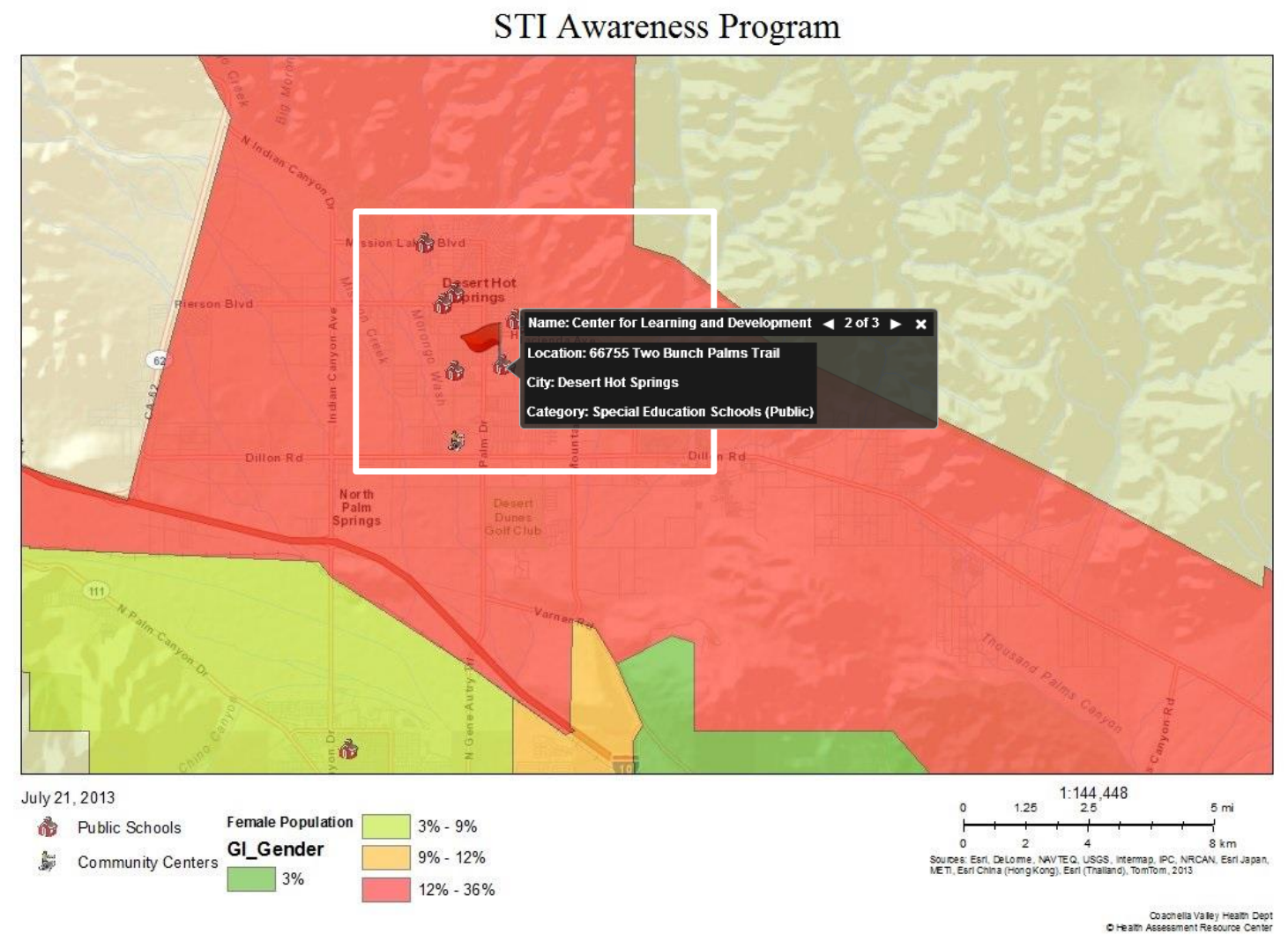

Figure 6.13: Selection of facility

\subsection{Summary}

This chapter described the user interface and demonstrated the use of the application in two different scenarios. The first explained how HARC attempted to query, display, and print adult health data for different cities of the Coachella valley while the second scenario detailed how public health officials could use the results of the children health data to present and attract potential donors for planned health programs. 


\section{Chapter 7 - Conclusions and Future Work}

This project was developed for the Health Assessment Resource Center (HARC) in the Coachella Valley in Southern California. HARC required a means by which they could effectively and efficiently communicate their data on health indicators, behavior, and disparities within the Coachella Valley to public health officials, community health workers, and potential donors of their health programs.

A requirement analysis was conducted in the early stages of the project which determined the functional and non-functional requirements. A review of similar organizations and their methods of disseminating health data were conducted. Combining the information of both analyses, a web-based GIS application was developed to facilitate HARC to communicate their data to their data users. The application enabled users to visualize, query, design, and print maps of health data for the ten cities in the Coachella Valley.

Additional data were gathered from the Riverside County GIS Office and the Federal Census Bureau to complement those provided by HARC. The data were then re-coded and grouped into categories for management and easy interpretation. Aliases were assigned to the fields of the health datasets to make them more understandable; and properly defined data types and field standardization was done. A File geodatabase schema was developed and the data were loaded to the database. The health data, health activities, programs, and facilities were geo-coded at the city level; and coded values domains were created at the database level and applied to the different fields.

Map documents were prepared using the datasets in the database using ArcGIS Desktop 10.1, which allowed the spatial visualization of the health data, health activities, program, and facilities. These documents were published to ArcGIS 10.1 for Server as map services which allowed the data to be visualized across the Internet. Through the web application developed, users can perform queries on different health indicators, behavior, and disparities within the different cities of the Coachella Valley.

The web application was developed using the Adobe Flex framework. Adobe Flash Builder was used as an Integrated Development Environment (IDE) along with the Adobe Flex Software Development Kit (SDK) 4.6, incorporating the Esri's ArcGIS API for Flex 3.0 to create the interactive and expressive web applications. The client and their data users can access the data from various locations by using a web browser with the Flash Player version 11 or higher plugin installed.

The functionalities this application presents enabled the Health Assessment Resource Center to provide easier access and distribution of health indicators, behavior, and disparities to their data users. It also demonstrated how a Web application can be utilized to organize, view, manage, and share data with a wide audience.

The application developed formed the basis for disseminating HARC's health data. Additional components could be developed to better enhance the functionalities and usability of the application. For example data loading and extraction tools could be created to enable HARC to easily update their databases and to allow data users to download data in form of Microsoft Excel tables. The application could also be expanded to a multi editing web environment by creating feature access where community health organizations within the Coachella Valley could upload and update health related data 
separately. This feature would be regulated by enabling features such as Editor Tracking and Ownership Based Editing. The application could also be used for cities within Riverside County; and data could be collected at the census block group level, which would enable a better understanding of the health indicators, behaviors, and disparities in the Coachella Valley. Additionally a flexible spatiotemporal modeling framework could be developed and implemented, providing an approach to study the association of health indicators, behaviors, and disparities within the Coachella Valley across different time periods. 


\section{Works Cited}

Alesheikh, A., Helali, H., \& Behroz, H. (2002). Web GIS: Technologies and Its Applications. Symposium on Geospatial Theory, Processing and Applications. Ottawa.

Beale, L., Abellan, J., Anderson, M., Hambly, P., Hodgson, S., \& Jarup, L. (2007). Environmental public health: A diseases mapping and risk analysis tool. Esri User Conference. San Diego: Esri.

Bedard, Y., Gosselin, P., Rivesta, S., Proulxa, M., Nadeaua, M., Lebelc, G., \& Gagnon, M. (2003). Integrating GIS components with knowledge discovery technology for environmental health. International Journal of Medical Informatics, 70, 79-94. Retrieved from www.elsevier.com/locate/ijmedinf ;http://citeseerx.ist.psu.edu/viewdoc/download?doi=10.1.1.115.9074\&rep=rep1\&t ype $=$ pdf

CDC. (2013, May 15). EPI INFO. Retrieved from Centers for Disease Control and Prevention: http://www.cdc.gov/epiinfo

Chang, Z. (2003). Design and Implementation of distributed Web Services in Mobile GIS Application. Netherlands.

Delmelle, E., Delmelle, E.C., Casas, I., Barto, T. (2010). H.E.L.P: A GIS-based Health Exploratory AnaLysis Tool for Practitioners. Springer Science+Business Media B.V.

ESRI. (2007). Loma Linda University Medical Center Activates Advanced Emergency Geographic Information System. Healthy GIS, 1 \& 4.

ESRI. (2013). ArcGIS Resources: ArcGIS API for Flex. Redlands. Retrieved from http://resources.arcgis.com/en/help/flex-api/concepts/index.html

Fu, P., \& Sun, J. (2011). Web GIS Principles and Application. Redlands: ESRI Press.

Glass, G., Schwartz, B., Morgan, J., Johnson, D., Noy, P., \& Israel, E. (1995). Environmental risk factors for Lyme disease identified with geographic information systems. American Journal of Public Health, 85, 944-948.

Gleick, P. (2013, March 07). 200 Years of Dr. John Snow - A Significant Figure in the World of Water. Circle of Blue. Retrieved from http://www.circleofblue.org/waternews/2013/world/peter-gleick-200-years-of-drjohn-snow-a-significant-figure-in-the-world-of-water/

Kamara, K. (2008). Clustering of mortality among children under five Years due to malaria at the Ifakara Demographic Surveillance Site in Tanzania. Johannesburg, South Africa.

Koch, T. (2005). Cartographies of Disease. Redlands California: Esri Press.

Kurland, K. S., \& Gorr, W. L. (2012). GIS Tutorial For Health Fourth Edition. Redlands California: Esri Press.

Labriola, M., Tapper, J., \& Boles, M. (2012). Adobe Flex 4.5 Fundamentals: Training from the Source. Berkeley: Adobe Press.

Longley, P. A., Goodchild, M. F., Maguire, D. J., \& Rhind, D. W. (2011). Geographic Information Systems and Science. John Wiley and Sons Inc.

Mayunga, J. S. (2002). Handeling Health Data in a GIS Environment: Geo-referencing and Analysis. Tanzania. 
PAHO. (2013, May 15). Application and development of Geographic Information Systems in Public Health and Epidemiology. Retrieved from Pan American Health Organization: http://www.paho.org/English/DD/AIS/sigepi_web2003en.htm

Peng, Z.-R., \& Tsou, M.-H. (2003). Internet GIS:Distributed Geographic Information Services for the Internet and Wireless Network. John Wiley and Sons Inc.

Reissman, D. B., \& et.al. (2001). Use of Geographic Information System Technology to Aid Health Department Decision Making about Childhood Lead Poisoning Prevention Activities. Environmental Health Perspectives, 89-94.

Riner, M. E., Cunningham, C., \& Johnson, A. (2004). Public Health Education and Practice using Geographic Information System Technology. Public Health Nursing, 21(1), 57-65.

Savigny, D., \& Wijeyarante, P. (1994). GIS for Health and the Environment. Ottawa, Canada: International Development Research Center.

Shrestha, J. (2010). Evaluation of Access to Primary Healthcare, A Case Study of Yogyakarta, Indonesia. Retrieved from http://www.itc.nl: http://www.itc.nl/library/papers_2010/msc/upm/shrestha.pdf

WHO. (2013, May 15). Public Health Mapping and GIS. Retrieved from World Health Organization: http://gis.emro.who.int/PublicHealthMappingGIS/HealthMapper.aspx

Wold, C. (2012, October, 03). National Library of Medicine. Retrieved from www.nlm.nih.gov:

http://www.google.com/url?sa=t\&rct=j\&q=\&esrc=s\&source=web\&cd=8\&cad=rj a\&ved=0CF8QFjAH\&url=http\%3A\%2F\%2Fwww.nlm.nih.gov\%2Fnichsr\%2Fhe althindicators\%2FHealth_IndicatorsModule1_FINAL.ppt\&ei=q51sUOHMCYjor AGr7IHABw\&usg=AFQjCNHBh-D5FbW8d9x0UmozQIYFX9wAtA\&sig2=5i 


\section{Appendix A. Recoded Datasets}

Table A.1: Recoded values in the health datasets along with the domain names

\begin{tabular}{|c|c|c|}
\hline Group Name & Domain & Attribute \\
\hline \multirow{2}{*}{ Boolean } & Yes & 1 \\
\hline & No & 2 \\
\hline \multirow{5}{*}{ Poverty } & $0 \%-100 \%$ & 3 \\
\hline & $101 \%-200 \%$ & 4 \\
\hline & $201 \%-250 \%$ & 5 \\
\hline & $251 \%-300 \%$ & 6 \\
\hline & $>300 \%$ & 7 \\
\hline \multirow{10}{*}{ Age } & $0-5$ yrs. & 8 \\
\hline & $6-11$ yrs. & 9 \\
\hline & $12-17$ yrs. & 10 \\
\hline & $18-24$ yrs. & 58 \\
\hline & $25-34$ yrs. & 59 \\
\hline & $35-44$ yrs. & 60 \\
\hline & $45-54$ yrs. & 61 \\
\hline & $55-64$ yrs. & 62 \\
\hline & $65-74$ yrs. & 63 \\
\hline & $>75$ yrs. & 64 \\
\hline \multirow{4}{*}{ Rank } & Excellent & 11 \\
\hline & Very Good & 12 \\
\hline & Good & 13 \\
\hline & Fair & 14 \\
\hline \multirow{6}{*}{ Doctor Visit } & Less than 6 months & 15 \\
\hline & 6 months - 1 yr. & 16 \\
\hline & $1-2$ yrs. & 17 \\
\hline & $2-5$ yrs. & 18 \\
\hline & More than 5 yrs. & 19 \\
\hline & Never & 20 \\
\hline \multirow{6}{*}{ Routine Checkup } & Within the past yr. & 21 \\
\hline & Within the past 2 yrs. & 22 \\
\hline & Within the past 5 yrs. & 23 \\
\hline & More the 5 yrs. & 24 \\
\hline & Never & 25 \\
\hline & Within the past 3 yrs. & 28 \\
\hline
\end{tabular}




\begin{tabular}{|c|c|c|}
\hline Group Name & Domain & Attribute \\
\hline \multirow{2}{*}{ Insurance Type } & Government/Public & 26 \\
\hline & Private & 27 \\
\hline \multirow{2}{*}{ Disability } & No Disability & 29 \\
\hline & At Least 1 Disability & 30 \\
\hline \multirow{2}{*}{ Fruits and Veg } & Child does not eat 5 Servings per day & 33 \\
\hline & Child eats 5 Servings per day & 34 \\
\hline \multirow{5}{*}{ Floss/Dinner per week } & None & 41 \\
\hline & $1-2$ Times per week & 42 \\
\hline & 3 - 4 Times per week & 43 \\
\hline & 5 - 6 Times per week & 44 \\
\hline & Everyday & 45 \\
\hline \multirow{4}{*}{ BMI Percentile_1 } & Less than 5th percentile & 46 \\
\hline & 5-84th Percentile & 47 \\
\hline & 85 - 94th Percentile & 48 \\
\hline & At or above the 95 th percentile & 49 \\
\hline \multirow{5}{*}{ Read to Child } & 5 or more times per week & 51 \\
\hline & $2-4$ times per week & 52 \\
\hline & Once a week & 53 \\
\hline & Less than once a week & 54 \\
\hline & Never & 55 \\
\hline \multirow{4}{*}{ BMI } & Obese & 57 \\
\hline & Overweight & 58 \\
\hline & Underweight & 59 \\
\hline & Normal & 60 \\
\hline \multirow{2}{*}{ Homeowner } & Own & 65 \\
\hline & Rent & 66 \\
\hline \multirow{6}{*}{ Employment Status } & Employed or Self employed & 67 \\
\hline & Out of Work & 68 \\
\hline & Homemaker & 69 \\
\hline & Student & 70 \\
\hline & Retired & 71 \\
\hline & Unable to work & 72 \\
\hline \multirow{2}{*}{ Main Activity } & Active & 73 \\
\hline & Sedimentary & 74 \\
\hline \multirow{2}{*}{ Sexual Orientation } & LGBT & 75 \\
\hline & Heterosexual & 76 \\
\hline
\end{tabular}




\begin{tabular}{|l|l|r|}
\hline Group Name & \multicolumn{1}{|c|}{ Domain } & Attribute \\
\hline & Other & 77 \\
\hline \multirow{5}{*}{ Education } & Less than High School & 80 \\
\cline { 2 - 3 } & High school or GED & 81 \\
\cline { 2 - 3 } & Some College & 82 \\
\cline { 2 - 3 } & College & 83 \\
\cline { 2 - 3 } & Post Graduate & 84 \\
\hline \multirow{5}{*}{ Ethnicity } & White & 85 \\
\cline { 2 - 3 } & Hispanic & 86 \\
\cline { 2 - 3 } & African American & 87 \\
\cline { 2 - 3 } & Other & 88 \\
\hline \multirow{5}{*}{ Incomer } & Male & 90 \\
\cline { 2 - 3 } & Female & 91 \\
\hline & $\$ 0-\$ 24,999$ & 92 \\
\cline { 2 - 3 } & $\$ 2500-\$ 49,999$ & 93 \\
\cline { 2 - 3 } & $\$ 50,000-\$ 74,999$ & 94 \\
\cline { 2 - 3 } & $\$ 75,000$ or More & 95 \\
\cline { 2 - 3 } & Average & 96 \\
\hline & No Data & \\
\hline
\end{tabular}

Table A.2: Recoded Children Dataset with the group names, the original field names, and applied field aliases

\begin{tabular}{|c|l|l|}
\hline \multicolumn{1}{|c|}{ Group } & \multicolumn{1}{|c|}{ Field Name } & \multicolumn{1}{c|}{ Field Aliases } \\
\hline \multirow{5}{*}{ Family Discussion (FD) } & $\mathrm{cm} 1 \mathrm{a}$ & FD_Drugs \\
\cline { 2 - 3 } & $\mathrm{cm} 1 \mathrm{~b}$ & FD_Alcohol \\
\cline { 2 - 3 } & $\mathrm{cm} 1 \mathrm{c}$ & FD_Smoking \\
\cline { 2 - 4 } & $\mathrm{cm} 1 \mathrm{e}$ & FD_Sex \\
\cline { 2 - 4 } & $\mathrm{cm} 1 \mathrm{f}$ & FD_Gangs or Violence \\
\cline { 2 - 4 } & $\mathrm{cm} 1 \mathrm{~g}$ & FD_Anger \\
\cline { 2 - 4 } & $\mathrm{cm} 1 \mathrm{~h}$ & FD_Suicide \\
\hline
\end{tabular}




\begin{tabular}{|c|c|c|}
\hline Group & Field Name & Field Aliases \\
\hline & $\mathrm{cm} 1 \mathrm{i}$ & FD_Interpersonal Violence \\
\hline & $\mathrm{cm} 1 \mathrm{j}$ & FD_Eating Disorder \\
\hline \multirow{8}{*}{$\begin{array}{l}\text { General Information } \\
\text { (GI) }\end{array}$} & agegrp & GI_Age \\
\hline & $\operatorname{cc} 21$ & GI_Gender \\
\hline & ct7New & GI_Employment \\
\hline & educgrp & GI_Education \\
\hline & ethchild & GI_Ethnicity \\
\hline & FPLmid & GI_Poverty \\
\hline & incomegrp & GI_Income \\
\hline & S3 & GI_Fulltime resident \\
\hline \multirow{6}{*}{ Health Coverage $(\mathrm{HC})$} & $\mathrm{ca} 1$ & HC_ Health Insurance Coverage \\
\hline & ca5 & HC_Prescription Coverage \\
\hline & ca6 & HC_ Dental Coverage \\
\hline & ca7 & HC_ Vision Coverage \\
\hline & ca8 & HC__ Mental Health Coverage \\
\hline & $\mathrm{cb} 2 \mathrm{aNew}$ & HC_Public or Private Insurance \\
\hline $\begin{array}{l}\text { Health care Utilization } \\
\text { (HCU) }\end{array}$ & $\mathrm{cc} 1$ & $\mathrm{HCU}_{-}$Recent Doctor Visit \\
\hline \multirow{5}{*}{ Mental Health (MH) } & ci2_a & $\begin{array}{l}\text { MH__Diagnosed Mental } \\
\text { Retardation }\end{array}$ \\
\hline & ci2_b & MH_Diagnosed AADHD \\
\hline & ci2_c & $\begin{array}{l}\text { MH_ Diagnosed Developmental } \\
\text { Delay }\end{array}$ \\
\hline & ci2_d & MH_Diagnosed Eating Disorders \\
\hline & ci2_e & MH_Diagnosed Autism \\
\hline
\end{tabular}




\begin{tabular}{|c|c|c|}
\hline Group & Field Name & Field Aliases \\
\hline & ci2_f & MH_ Diagnosed Mood Disorder \\
\hline & ci2_g & MH_Diagnosed Anxiety Disorder \\
\hline & ci2_h & $\begin{array}{l}\text { MH_Diagnosed Suicidal } \\
\text { Thoughts }\end{array}$ \\
\hline & ci2_i & MH_Other Diagnosed Conditions \\
\hline & ci2b & $\begin{array}{l}\text { MH_Emotional, Behavioral \& } \\
\text { Concentration Difficulties }\end{array}$ \\
\hline \multirow{3}{*}{ Other $(0)$} & $\mathrm{cn} 2$ & $\begin{array}{l}\text { O_ Understanding of } \\
\text { Immunization Schedule }\end{array}$ \\
\hline & $\mathrm{cn} 3$ & $\begin{array}{l}\text { O_Help Using Immunization } \\
\text { Services }\end{array}$ \\
\hline & $\mathrm{CO} 1$ & O_ Read to Child \\
\hline \multirow{3}{*}{ Prevention $(\mathbf{P})$} & cb16cat & $\mathrm{P}_{2}$ Flosses per Week \\
\hline & ck1 & $\mathrm{P}_{-}$Vision Test \\
\hline & $\mathrm{cn} 4$ & $\mathrm{P}_{\text {_ Hearing Test }}$ \\
\hline \multirow{3}{*}{ School (S) } & $\mathrm{cm} 2$ & S_Performance \\
\hline & $\mathrm{cm} 3$ & S_Disciplined by School Officials \\
\hline & $\mathrm{cm} 4$ & S_Absenteeism \\
\hline \multirow{5}{*}{$\begin{array}{l}\text { Weight, Nutrition and } \\
\text { Physical Activity } \\
\text { (WNPA) }\end{array}$} & ck4 & $\begin{array}{l}\text { WNPA_Fruit and Veg } \\
\text { Consumption }\end{array}$ \\
\hline & $\mathrm{cl} 4$ & WNPA_Family Dines Together \\
\hline & celnew & WNPA_Perception of Weight \\
\hline & ci2knew & WNPA_Main Activity \\
\hline & percentileH & WNPA_BMI \\
\hline General Health & cc13New & General Health \\
\hline
\end{tabular}


Table A.3: Recoded Adult Dataset with the group names, the original field names, and applied field aliases

\begin{tabular}{|c|c|c|}
\hline Group & Field Name & Field Aliases \\
\hline \multirow{5}{*}{ Health Behavior (HB) } & ae18 & HB_HIV/AIDS testing \\
\hline & ae6 & HB_Condom Use \\
\hline & af19cNew & HB_Smoking \\
\hline & af19gDich & HB_Binge Drinking \\
\hline & af19hDich & HB_Drunk Driving \\
\hline \multirow{4}{*}{$\begin{array}{c}\text { Healthcare Coverage } \\
\text { (HC) }\end{array}$} & aa12 & HC_Prescription Coverage \\
\hline & aa4 & HC_Insurance \\
\hline & aa4a & $\mathrm{HC}_{-}$No insurance in last 12 month's \\
\hline & aa8 & HC_Dental Coverage \\
\hline \multirow{2}{*}{$\begin{array}{l}\text { Healthcare Utilization } \\
\text { (HCU) }\end{array}$} & ab1 & HCU_ Time since Last doctor Visit \\
\hline & ab7 & HCU_ Time of last routine check-up \\
\hline \multirow{9}{*}{$\begin{array}{c}\text { General Information } \\
\text { (GI) }\end{array}$} & agesgrp & GI_Age \\
\hline & ah1 & GI_Homeownership \\
\hline & ah19 & GI_Citizenship \\
\hline & ah6New & GI_Employment \\
\hline & aj1New & GI_Sexual Orientation \\
\hline & educgrp & GI_Education \\
\hline & ethnicitygrp & GI_Ethnicity \\
\hline & FPLmid & GI_Poverty \\
\hline & gender & GI_Gender \\
\hline
\end{tabular}




\begin{tabular}{|c|c|c|}
\hline Group & Field Name & Field Aliases \\
\hline & s3 & GI_Resident of Coachella Valley \\
\hline \multirow{9}{*}{ Mental Health (MH) } & ac25g & $\begin{array}{l}\text { MH_ Mental Health concerns in the } \\
\text { past } 12 \text { Months }\end{array}$ \\
\hline & ac26a_a & MH_Depressive Disorder \\
\hline & ac26a_b & MH_Bipolar Disorder \\
\hline & ac26a_c & MH_Schizophrenia \\
\hline & ac26a_d & MH_Panic Disorder \\
\hline & ac26a_e & $\begin{array}{l}\text { MH_Obsessive-Compulsive } \\
\text { Disorder }\end{array}$ \\
\hline & ac26a_f & MH_Post-Traumatic Stress Disorder \\
\hline & ac26a_g & MH_Anxiety Disorder \\
\hline & ac26a_h & MH_Phobia \\
\hline \multirow{6}{*}{$\begin{array}{l}\text { Social and Economic } \\
\text { Needs (SEN) }\end{array}$} & ae8h_b & SEN_Housing \\
\hline & ae8h_c & SEN_Rental Assistance \\
\hline & ae8h_d & SEN_Financial Assistance \\
\hline & ae8h_f & SEN_Utility Assistance \\
\hline & ae8h_g & SEN_Transportation \\
\hline & ae8h_h & SEN_Home Health care \\
\hline \multirow{6}{*}{ Prevention $(\mathbf{P})$} & af1 & $\mathrm{P}_{-}$Mammogram Screening \\
\hline & af12 & P_Pap Smear \\
\hline & af12a & $\mathrm{P}_{-}$Time since last pap smear \\
\hline & af14 & $P_{-}$Colorectal Cancer Screening \\
\hline & af17 & $P_{-}$Prostate Screening \\
\hline & af19 & $\begin{array}{l}\text { P_ Time Since Last Prostate } \\
\text { Screening }\end{array}$ \\
\hline
\end{tabular}




\begin{tabular}{|c|l|l|}
\hline \multicolumn{1}{|c|}{ Group } & \multicolumn{1}{|c|}{ Field Name } & \multicolumn{1}{c|}{ Field Aliases } \\
\hline \multirow{4}{*}{ af19a } & P_ Blood Cholesterol Screening \\
\cline { 2 - 3 } & af19b & $\begin{array}{l}\text { P_ Time Since blood Cholesterol } \\
\text { Screening }\end{array}$ \\
\cline { 2 - 3 } & af2 & P_Time since last mammogram \\
\cline { 2 - 3 } & af3 & P_Clinical breast exam \\
\cline { 2 - 3 } & af4 & $\begin{array}{l}\text { P_ Time since last clinical breast } \\
\text { exam }\end{array}$ \\
\hline \multirow{4}{*}{ Weight (W) } & bmi & W_Average BMI \\
\cline { 2 - 3 } & bmicat & W_BMI Category \\
\hline \multirow{2}{*}{ General Health } & aa1Cat & General Health \\
\hline \multirow{2}{*}{ Disability } & ab25Dich & Disability \\
\hline
\end{tabular}




\section{Appendix B. Sample ActionScript Classes}

This ActionScript class was used to handle the Adult health indicators, it was written to define the variables and retrieve the health indicators, behaviors, and disparities in the Coachella Valley.

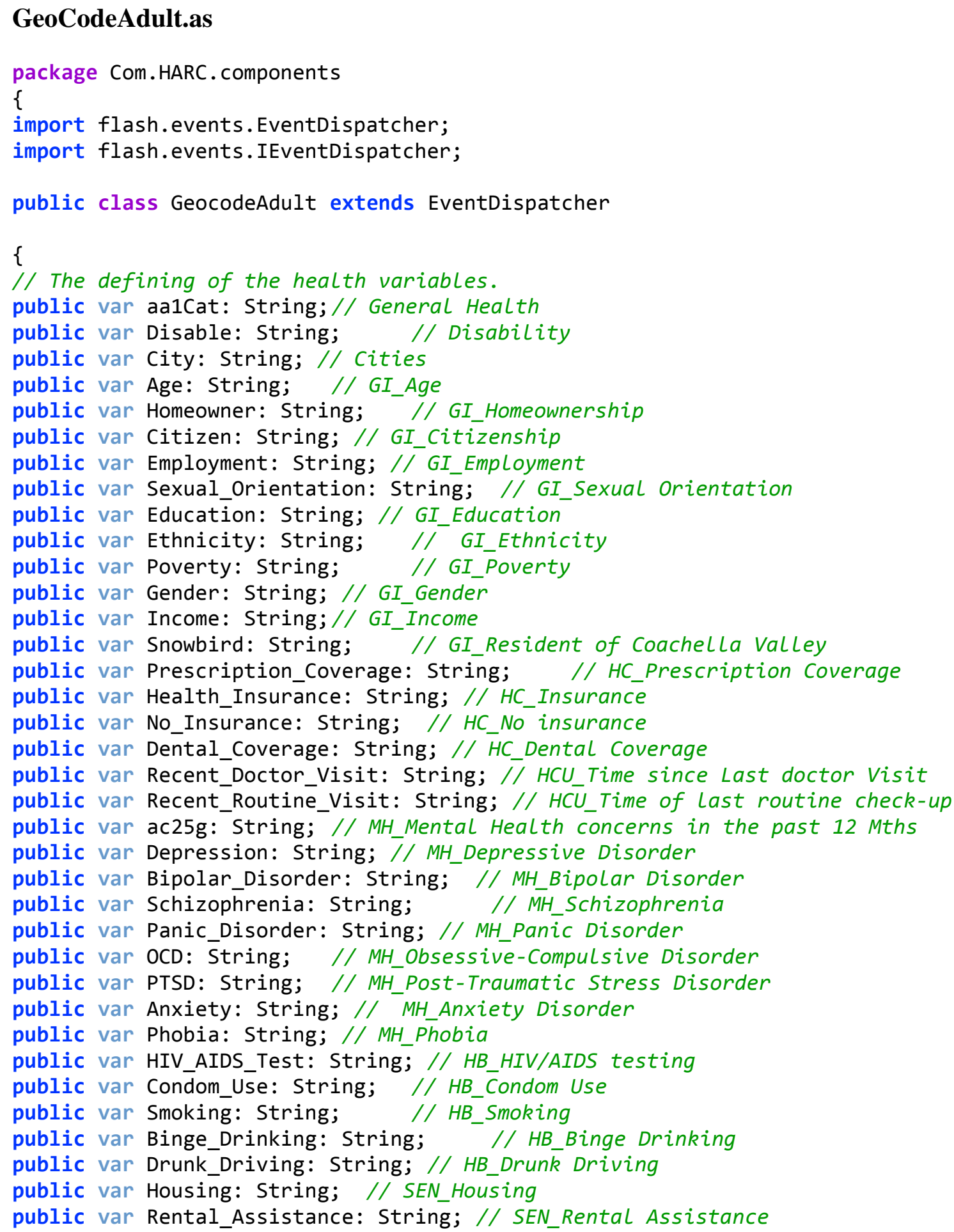




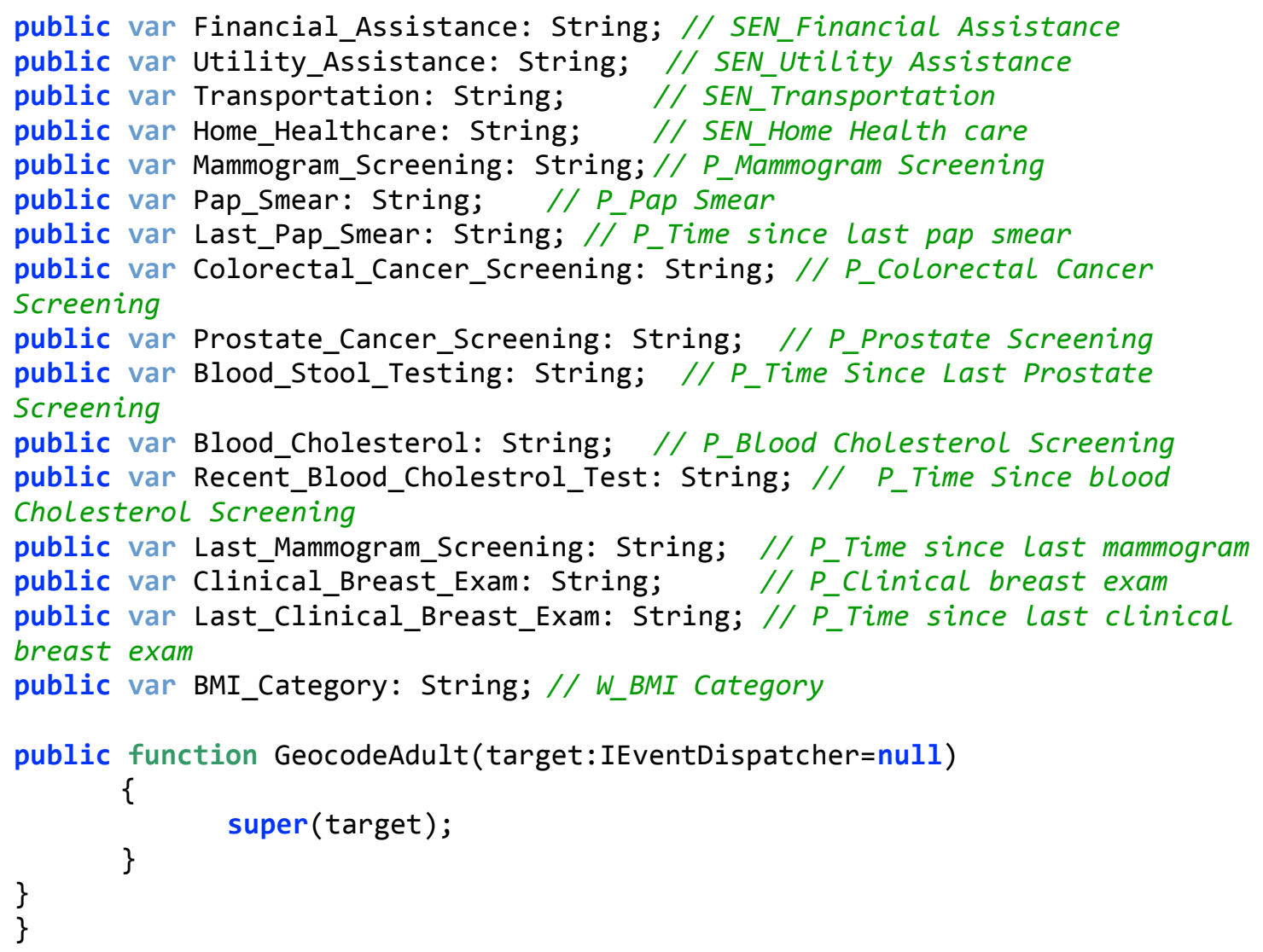




\section{Appendix C. Sample XML Script}

This $\mathrm{xml}$ file was used for the querying of the different indicators in the datasets. These XML files were created to store the Where Clauses that were used to retrieve data records from database.

\section{queryFields.xml}

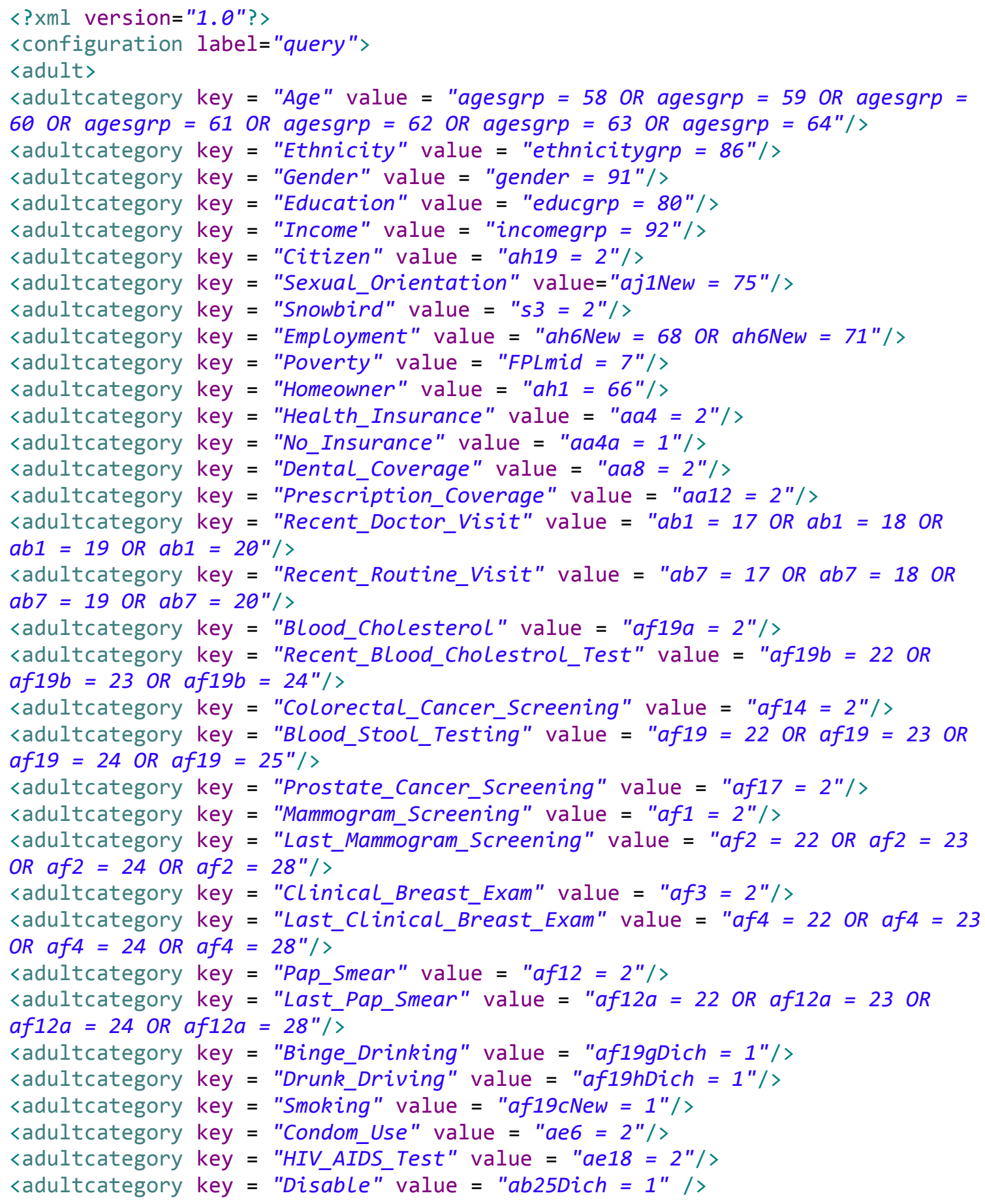




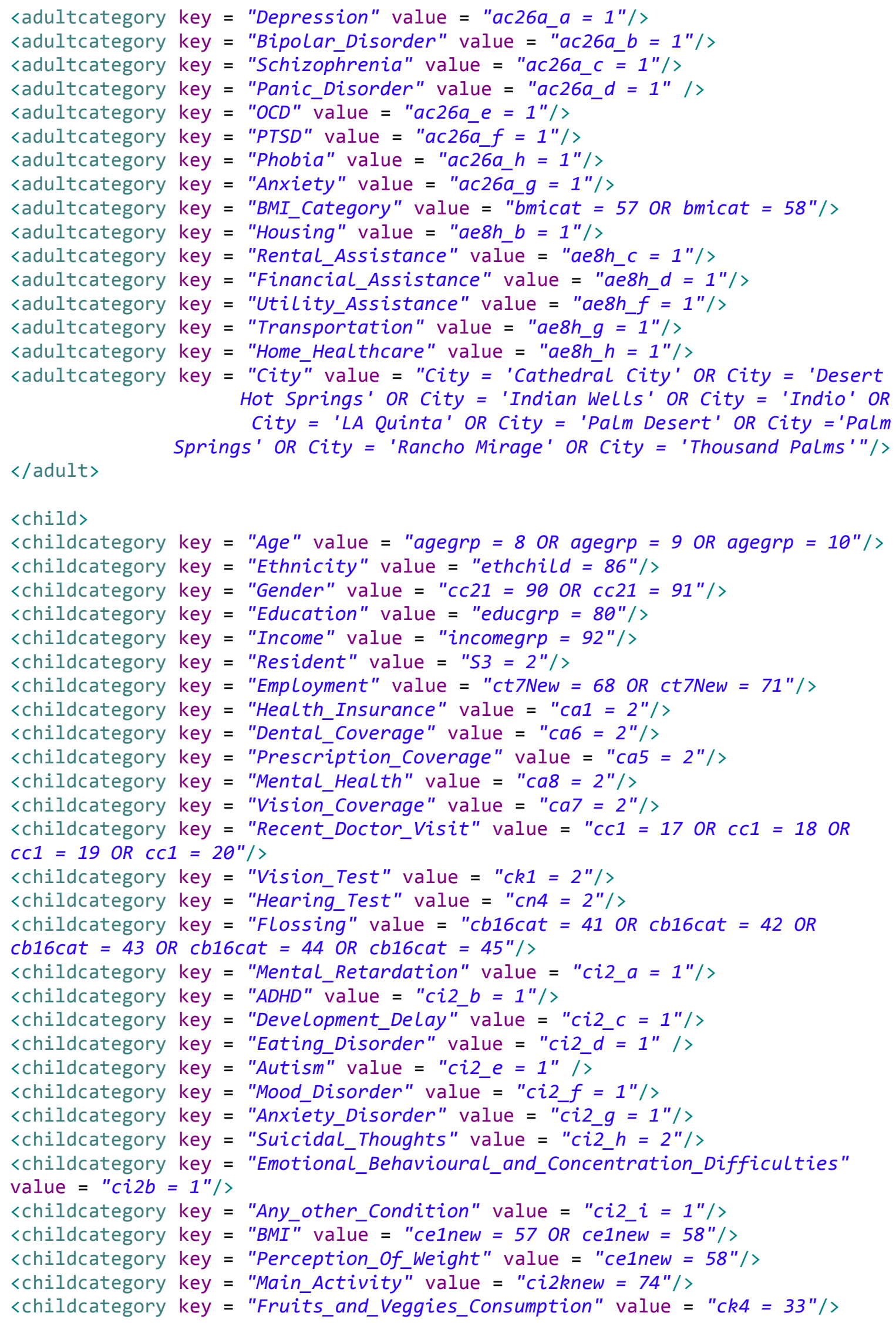




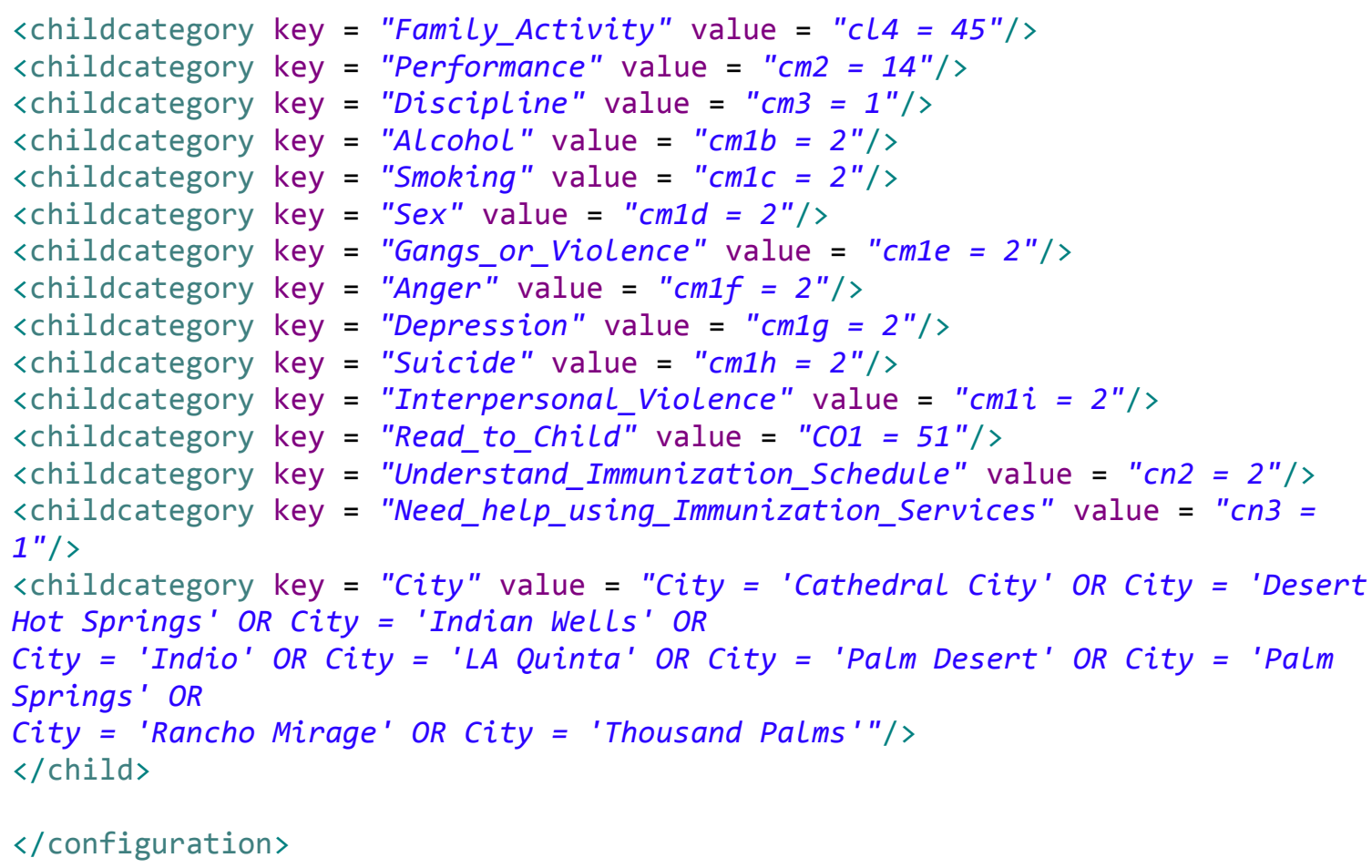




\section{Appendix D. Sample MXML Script}

This sample MXML script was written to specify the Query and QueryTask components. The Query component was used to specify the parameters for QueryTask, such as selection statement and returned fields. The QueryTask component was used to execute queries based on the Query components and deliver the returned results. These were implemented using two radio button groups in this application, childDatasetGroup and adultDatasetGroup. The application communicates via an HTTP service to the Where Clauses stored in the XML files.

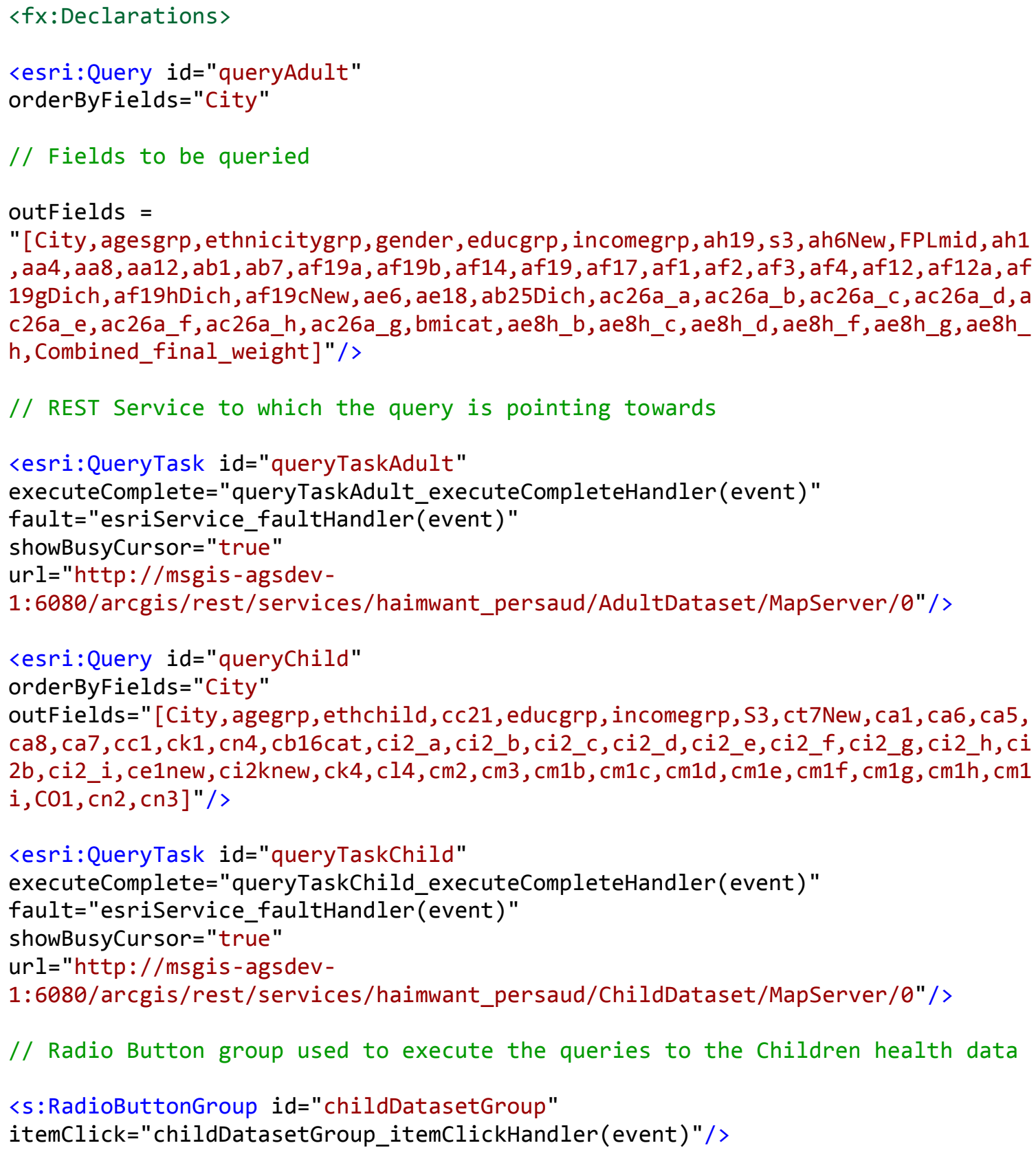


// Radio Button group used to execute the queries to the Adult health data

<s:RadioButtonGroup id="adultDatasetGroup"

itemClick="adultDatasetGroup_itemClickHandler(event)" />

// HTTP Service used to communicate the services

<s:HTTPService id="httpService"

resultFormat="e4x"

url="assets/hashFiles/queryFields.xml"

result="httpService_resultHandler(event)"

fault="httpService_faultHandler(event)"/>

$\langle/ f x$ :Declarations $\rangle$ 


\section{Appendix E. Sample Charts Script}

This Sample code was scripted to display the health datasets in form of charts and graphs.

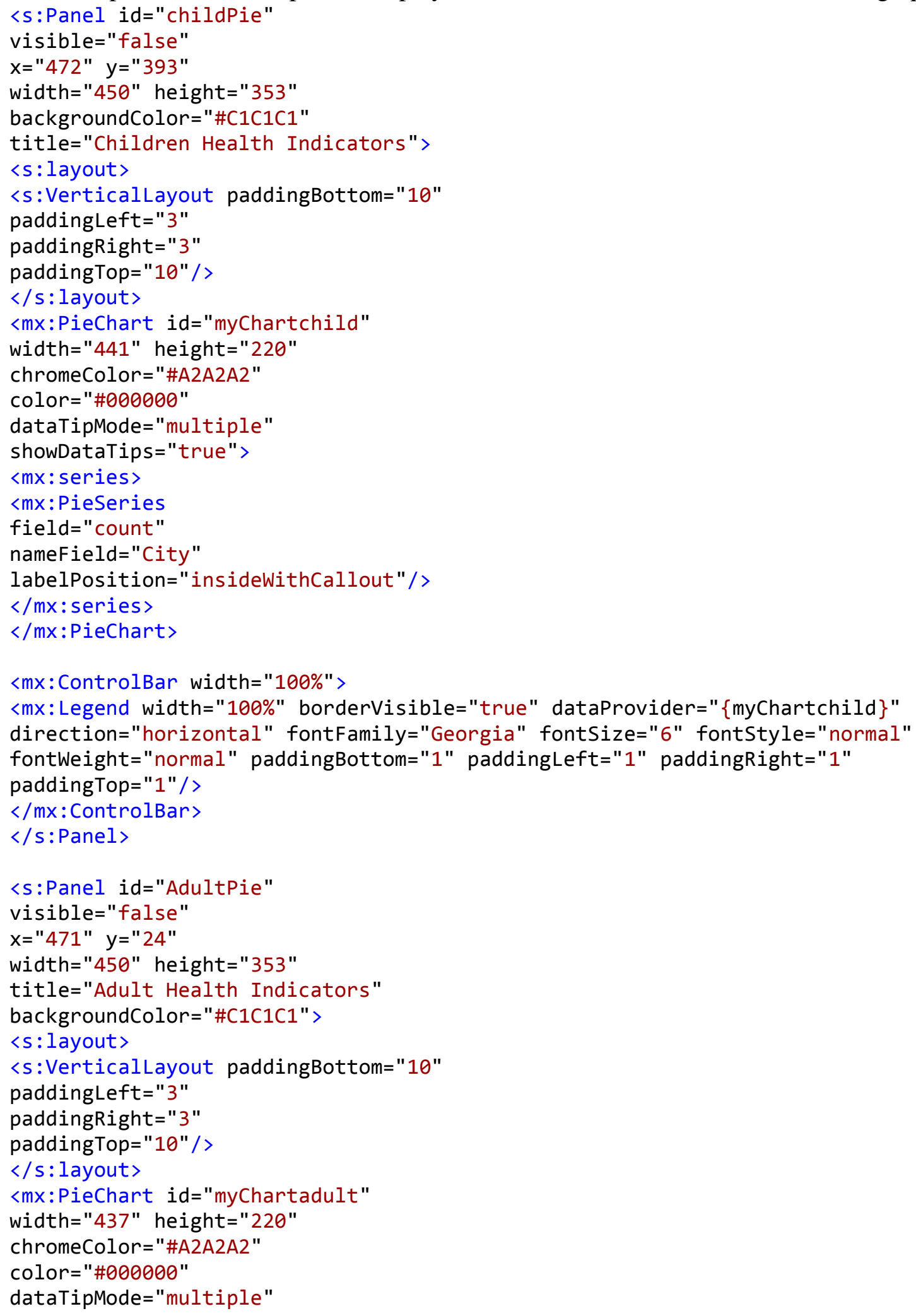




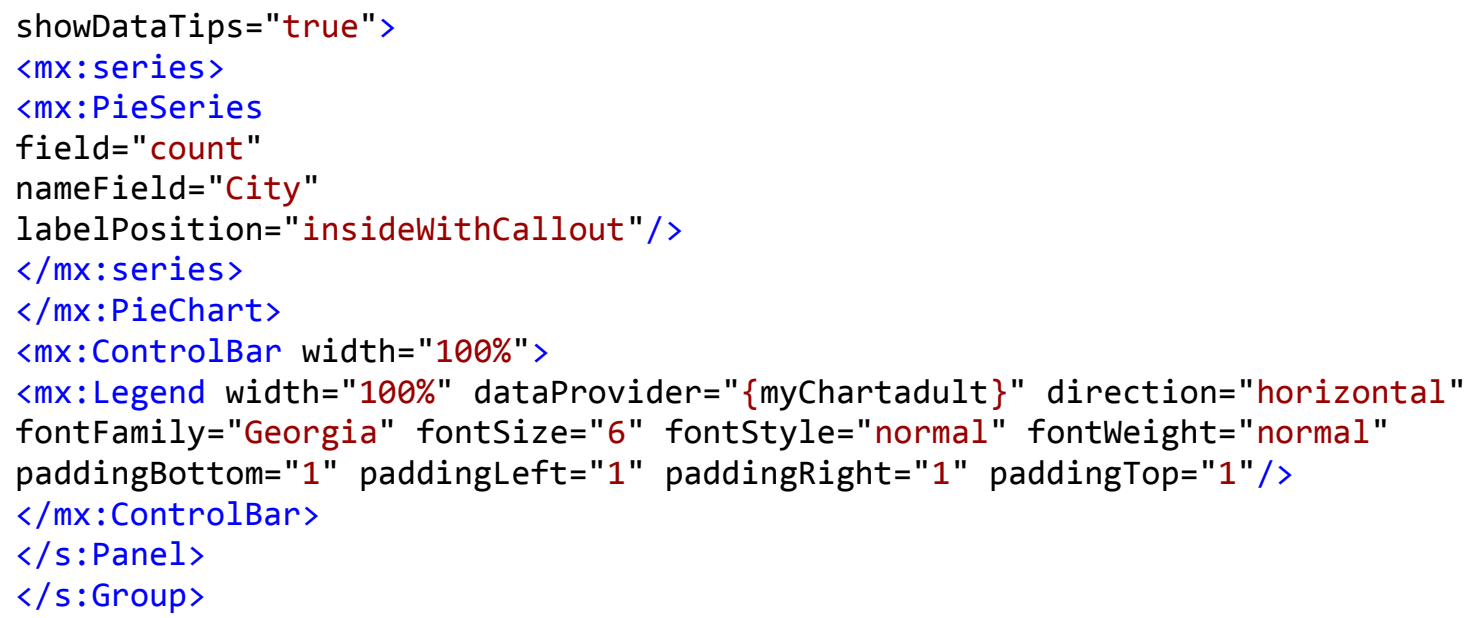




\section{Appendix F. Web-Service Reconfiguration}

This section presents the steps for moving the application from the University of Redlands servers to the clients' servers.

1. Place the File geodatabase containing the datasets for the project in a folder that is accessible to the ArcGIS Server and grant the server read permissions to that folder.

2. Register the folder containing the File geodatabase with the server data store.

3. Republish the services to the ArcGIS Server; this would create a new REST endpoint for each service.

4. Using Adobe Flash Builder, replace the REST endpoints within the application with those published to the clients' ArcGIS Server.

5. The build release of the application should then be exported and placed at the root folder of the IIS server. The application domain name should then be readjusted to that path. 